Review

\title{
A Systemic View on Circular Economy in the Water Industry: Learnings from a Belgian and Dutch Case
}

\author{
Tanaka Mandy Mbavarira * (D) and Christine Grimm
}

check for updates

Citation: Mbavarira, T.M.; Grimm, C. A Systemic View on Circular Economy in the Water Industry: Learnings from a Belgian and Dutch Case. Sustainability 2021, 13, 3313. https://doi.org/10.3390/su13063313

Academic Editor: Mariusz Sojka

Received: 21 December 2020

Accepted: 28 February 2021

Published: 17 March 2021

Publisher's Note: MDPI stays neutral with regard to jurisdictional claims in published maps and institutional affiliations.

Copyright: (c) 2021 by the authors. Licensee MDPI, Basel, Switzerland. This article is an open access article distributed under the terms and conditions of the Creative Commons Attribution (CC BY) license (https:/ / creativecommons.org/licenses/by/ $4.0 /)$.
Institute for Innovation and Technology Management, Lucerne University of Applied Sciences \& Arts, 6048 Horw, Switzerland; christine.grimm@hslu.ch

* Correspondence: tanakamandy.mbavarira@hslu.ch

\begin{abstract}
Water is fundamental to our existence and has increasingly been put under pressure by soaring population growth, urbanization, agricultural farming and climate change; all, of which impact the quantity and quality of our water resources. Water utilities (WUs) are challenged to provide clean, safe drinking water when faced with aging, costly infrastructure, a price of water that is not reflective of its true value and the need for infrastructure to remain resilient in a time when threats of floods and droughts are pervasive. In the linear take-use-discharge approach, wastewater is treated only to be returned to waterways and extracted again for treatment before drinking. This can no longer sustain our water resources as it is costly, energy-intensive and environmentally unsound. Circular economy (CE) has been gaining attention in the water industry to tackle this. It follows the 6 Rs strategy of reduce, reuse, recycle, reclaim, recover and restore to keep water in circulation for longer and reduce the burden on natural systems. The aim of this study is to determine what the economic and operational system effects of CE are on WUs, informing them of CE's potential to change their business operations and business model while highlighting its associated challenges. Based on a review of literature, input from expert interviews (Q4 2019) and case studies, an economic view of the urban water system is qualitatively modeled, on top, of which a circular water economy system is designed using a causal loop-diagramming system mapping tool. Digitalization, water reuse and resource recovery were determined to underpin circularity in water, providing operational benefits through efficiencies and diversification of revenue streams. However, issues of investment and a missing enabling legal framework are slowing the rate of uptake. On this basis, CE represents both a challenge and an opportunity for the water industry.
\end{abstract}

Keywords: circular economy; water; wastewater; causal loop diagram

\section{Introduction}

As a basic human right and public good fundamental to life, the importance of water cannot be overstated. Water underpins all drivers of growth-be it agricultural production, energy generation, industry or manufacturing. Its roots in social, environmental and economic dimensions anchor it at the core of sustainable development. When not well managed, competing interests for water has the potential to cause wars and leave sectors economically vulnerable, especially those that provide basic services. Water scarcity has been detrimental to crop yields and quality; and has threatened thermal power station output due to insufficient water for cooling [1]. The global thirst for water has been exacerbated by the compounding effects of population growth; increased agricultural activity; urbanization, which has seen $75 \%$ of Europe's population living in cities and urban areas; and erratic weather caused by climate change. The greenhouse gas effect of climate change has disrupted the hydrological cycle through elevated moisture, evaporation and temperature, leading to melting snow, rising sea levels and an uneven distribution of rainfall patterns $[2,3]$. The hydrological cycle is evidence that water is circular; however, anthropogenic activities over the last hundred years have disrupted the circulation of the earth's water stock [3]. 


\subsection{Background}

The World Economic Forum (WEF) has consistently highlighted water as a global crisis, ranking it the fourth greatest risk by impact and the ninth greatest risk by likelihood in 2019 [4]. Prior to this, in 2015, the United Nations (UN) drew much attention to water in its sustainable development goals (SDG) with SDG 6: clean water and sanitation. The SDG 6 is concerned with improving water quality and water-use efficiency, as well as integrating water resources management.

Agriculture accounts for roughly three-quarters of global freshwater withdrawals, and agriculture-related nutrients are polluting watersheds. Additional pressure on our renewable freshwater resources (groundwater, rivers, lakes and reservoirs.) stem from energy production and mass tourism, which consume $15 \%$ and $9 \%$ of resources, respectively, while water leakages can contribute up to $60 \%$ of distributed water loss [5]; representing gross operational inefficiencies and potential for savings.

Water demand across Europe is unevenly distributed [6]. The European Environment Agency (EEA) estimates that around one-third of the European Union (EU) territory is exposed to water-stressed (1000-1700 $\mathrm{m}^{3}$ /year per capita of available water resources) conditions, either permanently or temporarily and not only limited to places like Portugal, Spain and Greece but also in more Northern countries, such as Germany, the United Kingdom and Belgium. The decreasing trends in water abstraction observable in Western and Northern Europe can be attributed to improvements in water efficiency and management of water supplies yielding a 19\% decrease between 1990 and 2017 [6].

In order to continue the decrease in water withdrawal levels required to level out pressures on water reserves, circular economy (CE) offers a path in reshaping how water systems operate. The conventional linear take-make-dispose approach for materials is mirrored in the water sector as take-use-discharge. This linear approach, which is prevalent in the majority of water basins today, is short-sighted and inherently unsustainable given today's climate. The concept of CE was first introduced by Pearce and Turner in 1990 [7] and developed further in 2010 in various sectors by the Ellen MacArthur Foundation. The principles of $C E$ are founded on designing out waste and pollution, where today's waste becomes tomorrow's resources that yield economic, social and environmental benefits [8]. It follows the 6Rs strategy: reduce, reuse, recycle, reclaim, recover and restore, which keeps water in circulation for longer to reduce the burden on natural systems and encourage regeneration. The goal of $\mathrm{CE}$ is to decouple economic growth from negative externalities on environmental systems and resource use [9].

The aim of the study is to investigate the economic, environmental and operational effects of a CE on WUs by systematically mapping out cause and effect relations in a qualitative model. The model provides an economic view of an urban water system. The urban water system (UWS) is subsequently augmented with circular economic practices to create a successive model-a circular water economy system (CWES). By drawing on literature, case studies and conducting qualitative research to gain insight into expert views on the water industry and the role that $\mathrm{CE}$ can play in it, the paper sets out to demonstrate the effects of $\mathrm{CE}$ on water quantity, water quality, and operational practices of WUs. This study supports WUs by informing them of CE's potential to change their business operations and business model while highlighting its associated challenges.

\subsection{Context and System Boundary}

The system boundary is set in the context of a European urban water system. Cities are homes to many of the challenges faced by WUs, such as surface water pollution and flooding caused by built-up concrete areas as well as poor drainage, providing great opportunities for cities to meet their sustainable goals.

Figure 1 presents a simplified view of the components of a municipal water system, which are more complex in reality with more connections and interfaces with other systems. However, it sufficiently highlights the interfaces and industries incorporated in the modeling and therewith the system boundary. Combined sewer overflowing (CSO), specified in 
Figure 1, is the legacy infrastructure that is essentially a discharge pipe that releases both stormwater and raw sewage during times of peak flow directly to waterways. Separate sewer systems are alternative systems that decouple stormwater from sanitary sewers. In this study, CSOs are considered. WUs are the focal point of the systemic analysis, with only localized impacts being considered and, therefore, does not go as far as to account for changes to the macroeconomy or broader society. For example, job creation is not considered as a result of the growing demand for third-party water solutions companies.

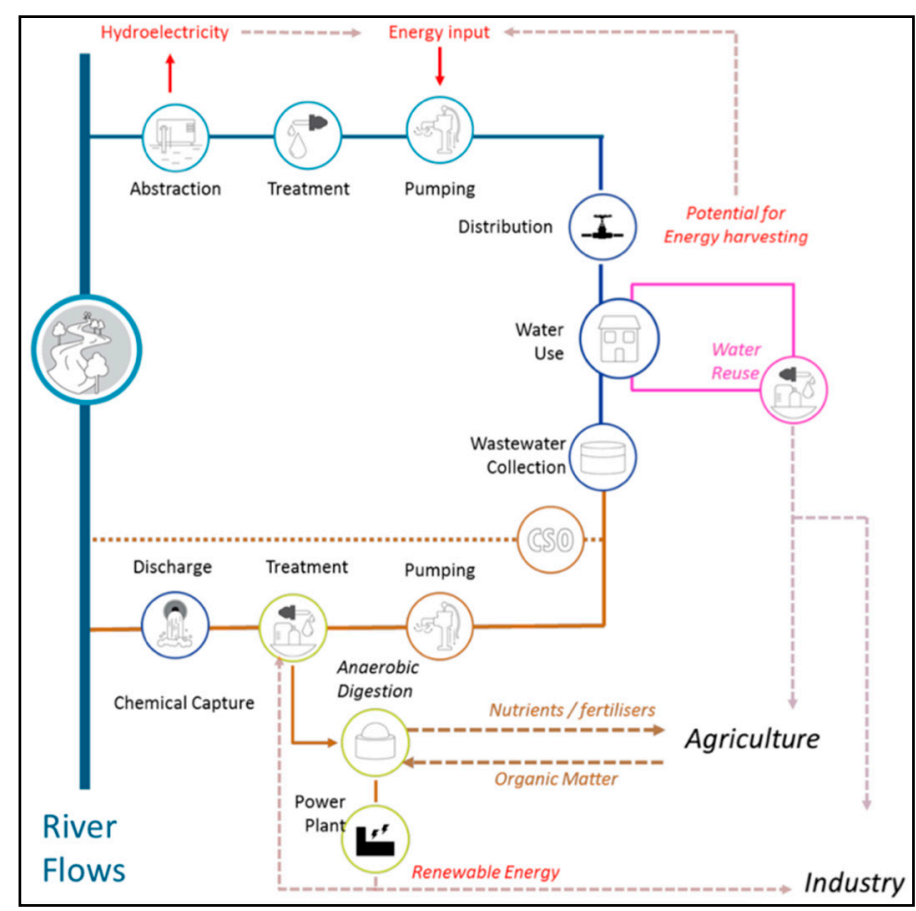

Figure 1. Simplified urban water system with intersectoral interfaces. Sourced from [10]. CSOcombined sewer overflow.

\subsection{Organization of Paper}

The paper is structured as follows: Section 2 provides a review of the literature to establish a knowledge base of prominent themes integral to the models. The methods used in the study are described and reasoned in Section 3. Then, the interview findings and the models are presented in Section 4 . Section 5 critically discusses the results before drawing conclusions in Section 6 and highlighting limitations and suggestions for further research.

\section{State-of-the-Art in Circular Economy and Water}

This section highlights CE strategies for the urban water system and addresses the issues surrounding the price of water. CE has a literature base cutting across various topics, from fashion [11] to manufacturing [12], supply chain management [13] and electronics [14]. The scholarly work regarding $\mathrm{CE}$ in water is relatively nascent. This study contributes to that growing body of literature by integrating $\mathrm{CE}$ in the urban water system and qualitatively mapping out its resulting systemic effects from an operational, economic and environmental standpoint.

Much potential is expected from CE, more so in the water industry because it is viewed as being at the heart of $\mathrm{CE}$, a catalyst for transitioning away from the linear model on a global scale [15]. CE solutions are expected to reduce the EU's virgin material requirements in conjunction with boosting gross national product and jobs [16]. The European Commission is financing a new wave of EU Horizon 2020 projects (ULTIMATE and NextGen) whose findings will inform the development of an EU roadmap for broader uptake circular solution in water. 
In a narrow sense, circularity applies to any one or some of the 6Rs defined in Table 1. Whereas full circularity is holistic in that it applies all 6 Rs in order to close the water, energy and nutrient resource flows by integrating the relevant sectors that create mutual benefit along the extended value chain. In the literature, this is often portrayed as the water-energy-food nexus [17-19]. Some authors have argued more emphasis should be placed on the accompanying organizational, social and regulatory evolution needed for the successful implementation of these technical changes $[20,21]$.

Table 1. Definition of 6Rs pertaining to water. Adapted from [22].

\begin{tabular}{cc}
\hline Rs & Definition \\
\hline Reduce & $\begin{array}{c}\text { Freshwater consumption decrease } \\
\text { The use of wastewater in its crude form (i.e., without prior treatment or } \\
\text { processing) for various purposes inside or outside the loop. } \\
\text { Recycle } \\
\text { Reclaim }\end{array}$ \\
$\begin{array}{r}\text { The use of treated wastewater within the same loop or in the same process } \\
\text { Treatment of wastewater and its use outside the loop } \\
\text { Restore }\end{array}$ & $\begin{array}{r}\text { Extraction of valuable resources (e.g. energy, material) present in wastewater } \\
\text { Replenish water resources through artificial interventions (e.g. rainwater } \\
\text { harvesting, managed aquifer recharge, rejuvenation of water bodies) }\end{array}$ \\
\hline
\end{tabular}

\subsection{Decentralized Solutions}

There is some discussion surrounding the benefits of decentralized solutions as a complementary alternative to the current centralized infrastructure for urban areas on smaller scales, such as individual households, neighborhoods or districts. Decentralized water systems are often regarded as more sustainable than centralized systems because they increase the potential for water conservation and reuse, increase the resiliency of the water infrastructure network, and reduce the cost of infrastructure replacement [23]. Decentralized water production and WW treatment for circular redevelopment in a metropolitan area demonstrated that although local treatment of graywater is sufficiently safe, local water production comes with higher risks and costs [24]. Yet the financial burden of maintaining and upgrading water networks increases the appeal of alternative infrastructures.

Green infrastructure (nature-based solutions) tends to be decentralized, and their role in providing water services is well understood, although undervalued. Rainwater harvesting in Mexico's urban sprawl can play a pivotal role in CE, reducing the cost of damages caused by floods, demand for water and water production costs [25]. Investing in the vitality of a watershed through forest management and wetland restoration are highly successful circular solutions [26]. Green infrastructure can unlock the potential of the natural environment in providing:

- Natural water treatment (through filtration);

- $\quad$ Storage (e.g., aquifers);

- Buffering (i.e., flood protection through reduced stormwater run-off);

- $\quad$ Recreation (e.g., green spaces).

They support a cost-effective, resilient approach to managing the increased floods and droughts that come with global warming that gray infrastructure is not designed to handle [27].

Desalination is a niche in circular water practice best suited to coastal communities or islands. It is a way of augmenting the water supply of these communities for greater water security. As a non-conventional water source, next-generation desalination of seawater requires leaps in technological innovation to deliver autonomous, resilient, modular, and electrified systems that reduce costs, improve performance, and enhance the resilience of nontraditional water reuse systems [28].

\subsection{Digitalization}

Digitalization is a springboard for optimizing the gains circularity offers. The term digital water or smart water refers to water that is sensorized for information regarding 
flow, quality, contents and temperature generating large volumes of data in a high variety of formats from different sources. Namely pressure sensors, flow sensors, quality sensors, smart meters, smart pipes and SCADA systems all in real time [29]—This constitutes the starting point of digitalization. Building on this, ICT aids in the connectivity of those assets to create a networked intelligent system-a smart water grid. It is this connectivity that appears to provides a wealth of benefits [30,31]:

- $\quad$ Reducing energy consumption;

- Avoiding unnecessary water losses;

- Minimizing resource consumption;

- Better monitoring and reporting on quality, quantity, reuse of water, extreme events (floods and water-scarcity), and aids informed decision-making;

- Engaging the end consumers in sustainable behaviors making them aware of individual water consumption patterns.

The water sector has been sluggish when it comes to technology adoption for numerous underlying reasons that can be attributed to industry conservatism, as well as intolerance for infrastructure downtime, which extremely limits the prospects of carrying out reliable field trial tests on water networks [29]. Furthermore, water ICT systems remain a significant challenge regarding the total cost of ownership. The increased ICT costs are compounded by the scarce higher skilled personnel required in addition to the lack of standardization. To combat the problem of standardization, the water industry is working towards the development of international standards for hardware and software platforms that allow interoperability through the seamless integration of data generated from sensors of a number of sensor providers [31]. This will serve to break through the fragmented way of doing business in silos and allow for a high degree of connectivity between networks and necessary knowledge exchange. Lastly, it remains yet to be seen how data can tangibly be valorized in a responsible manner without infringing on EU data privacy law and at the same time ensuring consumer data protection given the cybersecurity issues that can ensue as a result. From the citizen's point of view, it needs to be made clear how data sharing can enhance or benefit their day-to-day life [29].

\subsection{The Economics and Value of Water}

The price of water is not reflective of its true value [32]. Although water itself is effectively free as a public good, the provision of water services is not and is of economic interest [33]. (Water services as defined in Article 2 (38) of the Water Framework Directive: "all services, which provide for households, public institutions or any economic activity: (a) abstraction, impoundment, storage, treatment and distribution of surface water or groundwater, (b) wastewater collection and treatment facilities, which subsequently discharge into surface water." [34]). Water pricing refers to assigning a price to water, including elements, such as utility tariffs [35]. In this study, water pricing means monetizing the abstraction, use, and pollution of water. The increase in the price of water is a political hurdle met with resistance from stakeholders and users, suggesting that in some cases, this resistance originates from lack of information, social issues or the fundamental belief that water is a human right and thus any price increase is socially unjust [35].

With a mandate from the EU's Blueprint to Safeguard Europe's Water Resources, the $\mathrm{EU}$ is looking for new policies to help align the prices of resources, such as water that is not appropriately valued on the market [36]. The public is in charge of setting price limits, regulating and approving water tariffs proposed by water operators. Some member states (e.g., Austria, Czech Republic and the United Kingdom) use subsidies to support cost recovery, complement funding for investment, or support vulnerable customers $[33,37]$. In some cases, price controls and subsidies are policy failures that have been known to cause mispricing. Market failure can be traced back to mispricing as the price of goods and services do little to reflect either the full costs or full benefits [35]. Mispricing has an undesirable effect of preventing WUs from achieving their cost recovery objectives. 
Barriers to full cost recovery contribute to the ailing business model of WUs; meanwhile, threats posed by the linear model can act as drivers of CE. Aging water infrastructure; water leakages that worsen as a result of aging; and infrastructure expansion that requires more energy for pumping water; collectively contribute to the growing cost in providing water services. Given that profit margins for water companies are meager, some water companies can cover costs with a profit but have limited extra funds available to handle potential renewals and/or replacements of existing infrastructure [35]. Water infrastructure is underfunded, and according to McKinsey Global Institute, an estimated \$11.7 trillion must be invested globally between 2013 and 2030 for repair, replacement and expansion [38]. The poor condition of the water network in part owes to the fact that water infrastructure is obscured, underground and far from decision-makers. Moreover, the cost of losing water remains cheaper than repairing the pipes causing the leakages. With infrastructure designed to last for between 25 and 60 years, it begs the question: how can change be brought about against a backdrop of an aging infrastructure?

As a human right, the affordability of water is a core issue that cannot be overlooked. Strong proponents of a less heavily regulated, more market-based pricing scheme for water tariffs want the value of water to be more accurately reflected in its price by accounting for the environmental externalities associated with the supply, treatment and disposal of water fundamentally because there exists a direct causal connection between mispricing and unsustainable development [32,35,39].

Under the current linear economic model, WUs have struggled to fully recover their costs with revenue from pricing instruments, such as water tariffs, taxes and charges (i.e., payment related to services, such as WW collection and treatment, but also applied to levies on emissions/discharges and for water supplies) [35]. Even though in 2010 under Article 9 of the Water Framework Directive (WFD), it was established that water prices must allow for the (adequate) cost recovery of water services, including environmental costs (i.e charging water polluters for the purification of their WW, for the untreated pollution discharged in surface waters, and for activities, such as discharges, abstractions, impoundments and engineering that affect the quality of aquatic ecosystems.) and resource costs (forgone opportunities of alternative water use); and water pricing policies must provide adequate incentives for users to use water resources efficiently. The translation of these principles into real water pricing policies applied in the EU Member States remains unclear. The approaches and calculation methods for internalizing external (environmental and resource) costs into pricing are still a debatable subject [35]. The EEA concluded that the WFD has failed to change pricing policy; at best, some EU member states have managed to attain cost recovery, however paying little to no attention to pricing policy incentives and the recovery of environmental or resource costs.

There is still ground to be covered when it comes to an understanding of the economic benefits of water circularity. Reference [37] assessed the economic impact of linking wastewater (WW) treatment, crop production and bioenergy value chains by reusing treated municipal WW and sludge based on a cost/benefit analysis in Braunschweig, Germany. Between 935'000 EUR and $1^{\prime} 831^{\prime} 000$ EUR in costs were avoided from discharge fees, sludge incineration and sludge dewatering. Instead, the plant operator incurred costs for agricultural sludge utilization at 70\% of 935'000 EUR. Reference [39] estimates the opportunity cost inherent in not replacing the current linear economic model in Jordan's water industry with a circular model by means of a cost-benefit analysis and shadow price approach. The latter is used to estimate the market value of the resources recovered from WW, given that they have no real market value by estimating their avoided costs or environmental benefits. The findings show that when the price of WW is increased by $2.3 \%$, the financial and environmental benefits of CE outweigh the costs. The cost incurred from closing the loop amounts to $1 \mathrm{USD} / \mathrm{m}^{3}$, which represents the average shadow price (i.e., avoided cost associated with discharging undesirable products into the environment (i.e., environmental benefits) associated with the environmental externalities. In European 
terms, given that the average residential water price is 3.37 euros $/ \mathrm{m}^{3}$, the "closing the loop charge" in this instance amounts to about one-third of the average price of water [33].

$\mathrm{CE}$ brings to the foreground the issue of water mispricing and with it the need to internalize externalities; without, which will remain a barrier to transitioning because $\mathrm{CE}$ will certainly incur additional costs that will serve to increase the costs that WUs need to recover.

\section{Methodology}

Qualitative methods are employed given that the research question being investigated is theoretical and exploratory, although the study aims to support the practical application. Furthermore, the nature of the data gathered is incongruent with the data required for quantitative methods.

Figure 2 illustrates that primary information gathered from interviews with five water professionals, water conference proceedings, in addition to literature and case studies, serve to inform and, in some cases, justify the causal relationships contained in the economic view of the urban water system (UWS) model. Moreover, those resources extend and update the UWS model with circular practices for the development of the Circular Water Economy (CWE) model. Analysis of the UWS model highlights opportunities for intervention (i.e., levers), and evaluation of the CWE model gives insight into systemic effects.

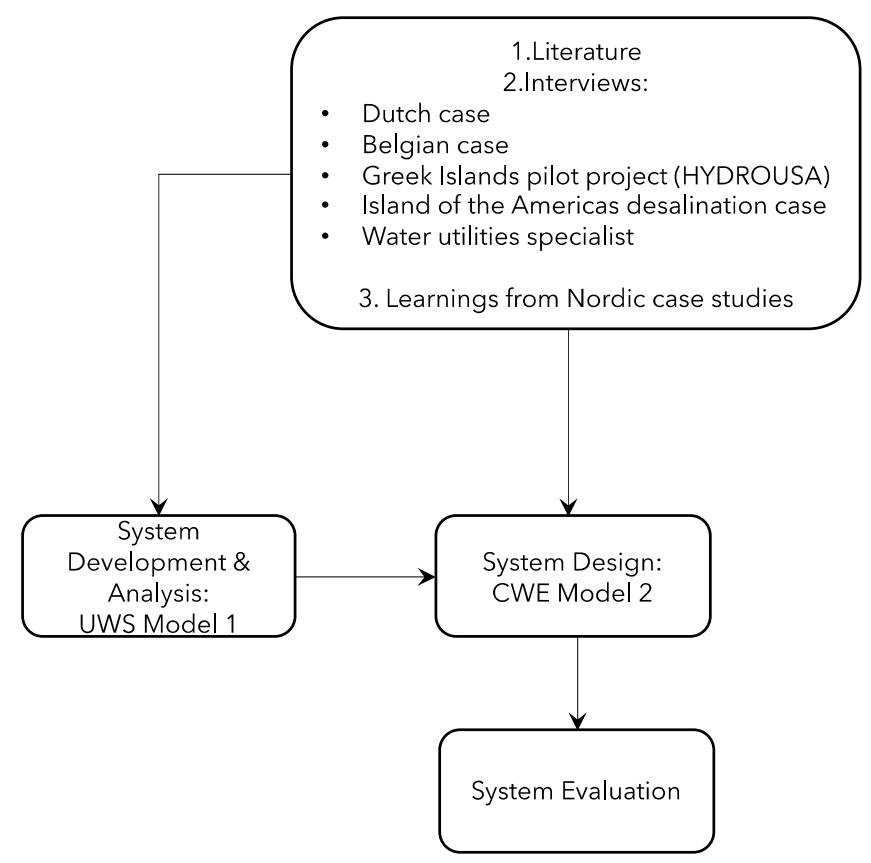

Figure 2. Methodological approach.

Desktop research serves to characterize the system and provide operational insight into WUs and the potential for CE. The interviews are carried out with two WUs (in Belgium and the Netherlands), an HYDROUSA Horizon 2020 EU project coordinator, a water-as-a-service company and a WU solutions expert to describe and contextualize the situation surrounding utilities and explain resulting phenomena. They were conducted in Q4 2019 in a semi-structured manner, with five water industry experts from WUs, academia and companies that service the needs of WUs. They were selected as having responded to emails requesting their participation even though a broader multi-stakeholder view was solicited to take part in the interviews from water managers in water-intensive companies, water solutions companies, nonprofit organizations, researchers and water policy experts. Their participation would have added value to the outcomes of the analysis by challenging the status quo. The interview questions were sent beforehand to allow participants to know ahead of time the kinds of questions that would be asked and to confirm that they 
have knowledge of the subject matter. The interviews conducted were audio or visual online interviews lasting approximately 40 to $60 \mathrm{~min}$ each, consisting of six broad topics. Depending on the expertise of the interviewee, the emphasis was placed on some topics more than others; or in instances where questions of a particular topic were asked, and the interviewee expressed their lack of knowledge in that area, the questions under that topic were not asked further. Transcription is done intelligently- excluding any stuttering, pauses or emotion whilst involving some slight paraphrasing of what was actually said for the clear conveyance of the message- and thematic analysis identified 22 key themes. The cases provided information on the kinds of circular economic practices available to WUs to adopt and their outcomes, confirming some of the cause-and-effect relationships used to build the CWE model.

To explore and understand the complex dynamics currently driving and threatening the urban water system, the study makes use of a system mapping tool called causal loop diagramming. Kumu is the relationship mapping software used to develop the CLDs in this study. Causal loop diagramming is a qualitative approach that can be applied as a precursor to developing quantitative system dynamic models [40]. Causal loop diagrams (CLDs) are very helpful in assisting non-expert stakeholders in developing a better understanding of important interconnections in a complex system, shedding light on feedback loops and connections that may otherwise not be apparent. They can, therefore, lead to a better understanding of the system behavior without a built quantitative model. They thus have a desirable effect of breaking conventional silo-thinking-a well-known problem faced within the water industry.

Table 2 describes the elements and notation used in CLDs and uses examples to illustrate cause-effect relations. Essentially it demonstrates that with node $A$ being the cause and $B$ the effect, they are related in one of two ways: by either a positive (same direction) or a negative (opposite direction) relation. The former meaning that an increase in cause $A$ results in an increase in effect $B$. Or a decrease in cause $A$ results in a decrease in effect $B$. Conversely, the latter means that an increase in cause $A$ results in a decrease in effect $B$. Or decrease in cause $A$ results in an increase in cause $B$. The behavior of a system's dynamics can be in a circular form called Feedback loops. A feedback loop is a closed chain of causal connections that can be reinforcing or balancing [41]. Reinforcing (positive) feedback loops are self-enhancing, leading to exponential growth or to runaway decay over time, whereas balancing (negative) feedback loops are equilibrating or goal-seeking structures in systems, which are both sources of stability and sources of resistance to change [41]. Delays are an essential notation in CLDs, especially for quantitative modeling; they are strong determinants of system behavior because changing delay length may significantly change the behavior of a system.

When viewed from a systems approach, water is a subsystem of "system of systems", which includes, among others, municipal systems (the focal system of this study), the environment, agriculture, industry and energy, as depicted in Figure 1. Systems thinking allows for the identification of CE opportunities that exist within the water system as well as associated systems. A systems approach will enable the assessment of intended and unintended consequences, thereby confirming whether $\mathrm{CE}$ can create added value to the UWS.

A limitation in the methodology lies in the modeling process, given that there is a clear element of subjectivity in how the causal relations and feedback loops are structured and created. For example, if the modeler builds the system by first defining individual causal relations before identifying feedback loops, it can result in a different system than when a modeler first creates feedback loops before creating interlinkages between them. Therefore, reproducibility given the same input data are not guaranteed. It is thus important to note that the UWS and successive CWE models reflect the authors' current thinking about the underlying patterns and interactions that drive tensions and imbalances in the system. The model is viewed as a work in progress that evolves as learnings are incorporated as feedback. 
Table 2. Elements of a causal loop diagram. Adapted from [42].

Description
$\begin{gathered}\text { Change in A, causes change in } \\ \text { increases/decreases, B also } \\ \text { increases/decreases. }\end{gathered}$
$\begin{gathered}\text { Change in A, causes change in } \\ \text { B in the opposite direction. If } \\ \text { A increases/decreases, } \\ \text { conversely B } \\ \text { decreases/increases. }\end{gathered}$
$\begin{gathered}\text { Reinforcing or positive } \\ \text { feedback loop, if it contains an } \\ \text { even number of negative } \\ \text { causal links }\end{gathered}$
$\begin{gathered}\text { Balancing or negative } \\ \text { feedback loop, if it contains an } \\ \text { odd number of negative } \\ \text { causal links }\end{gathered}$
Delay the system when the
system's resonse lags

\section{The Urban Water System Analysis}

The human-managed urban water system model in Figure 3 takes on an economic view of an integrated water utility (a combined water supply and wastewater company). Parts of the model are expounded on in this section. The system's ultimate goal is to maximize freshwater resources and water quality. However, given that it consists of double the number of balancing loops than reinforcing loops, the system is skewed towards change resistance. Refer to Appendix A for the variables (nodes) used in the model and their descriptions. All things being equal, the blue lines represent a direct positive relationship between two nodes and a red line represents an inverse relationship. In the following sections, words in italics indicate a reference to node names that exist in the model.

\subsection{Water Quality}

Water quality is largely affected by heavy agricultural (diffuse pollution) and industrial (point pollution) polluters in addition to the contaminants carried in water during flooding. The risk of flooding and the issue of contaminants in water are amplified in an urban built-up area environment where there is little opportunity for nature to filter and absorb excess water. CSOs add to deteriorating water quality; hence the trend towards green stormwater management (introduced to the CWE model in Section 6.1) which is used to mitigate this and, as a result, drive down treatment costs. During periods of heavy rainfall or snowmelt, the WW volume in a combined sewer system can exceed the capacity of the sewer system or treatment plant. For this reason, combined sewer systems are designed to overflow occasionally and discharge excess WW directly to nearby water bodies. Overall, the poorer the water quality is, the greater the expenses incurred for raw water treatment and thus the greater the O\&M costs become as shown in Figure 4. 


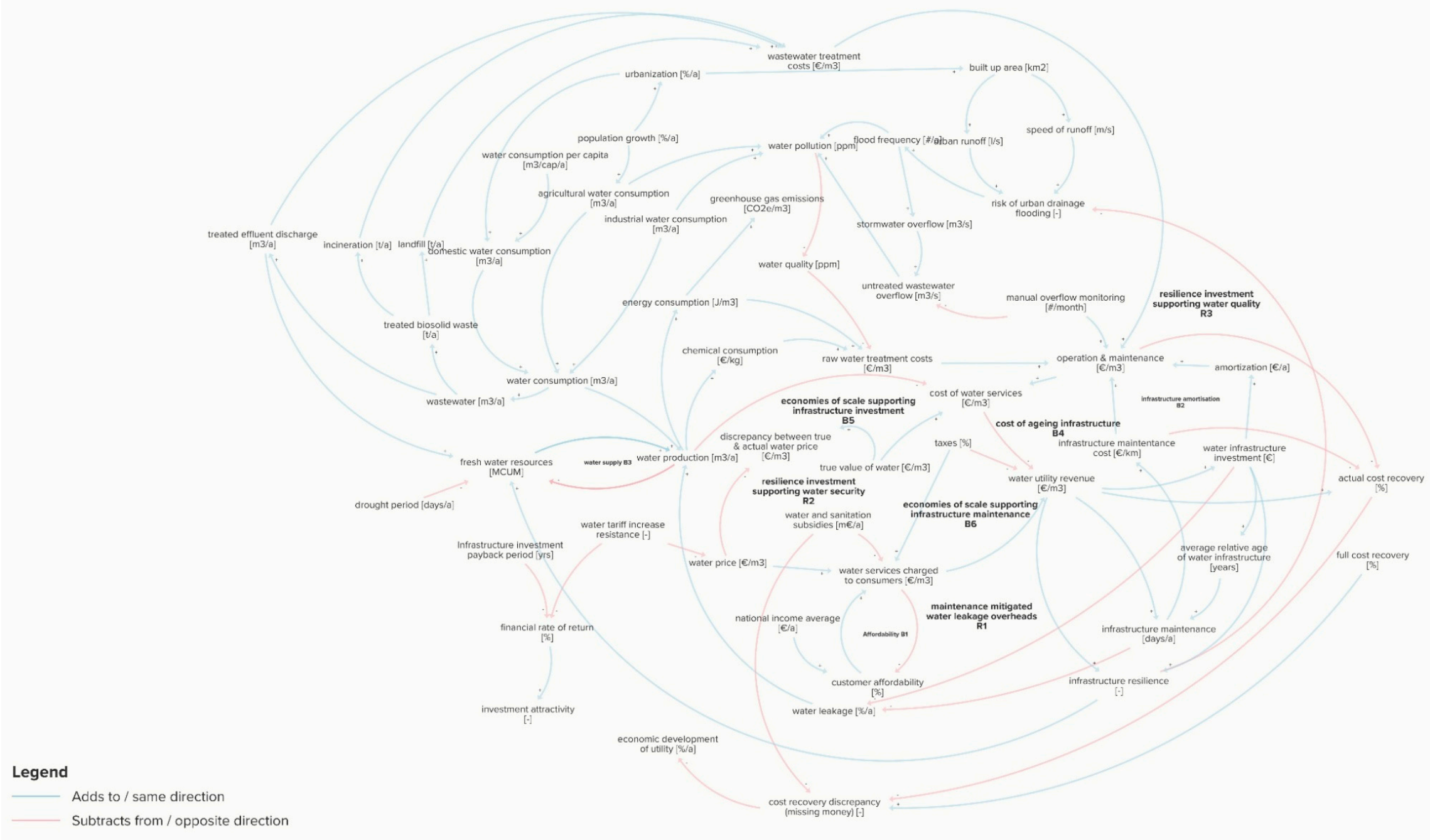

Figure 3. Causal loop diagram (CLD) synthesis describing the economic view of an urban water system. 


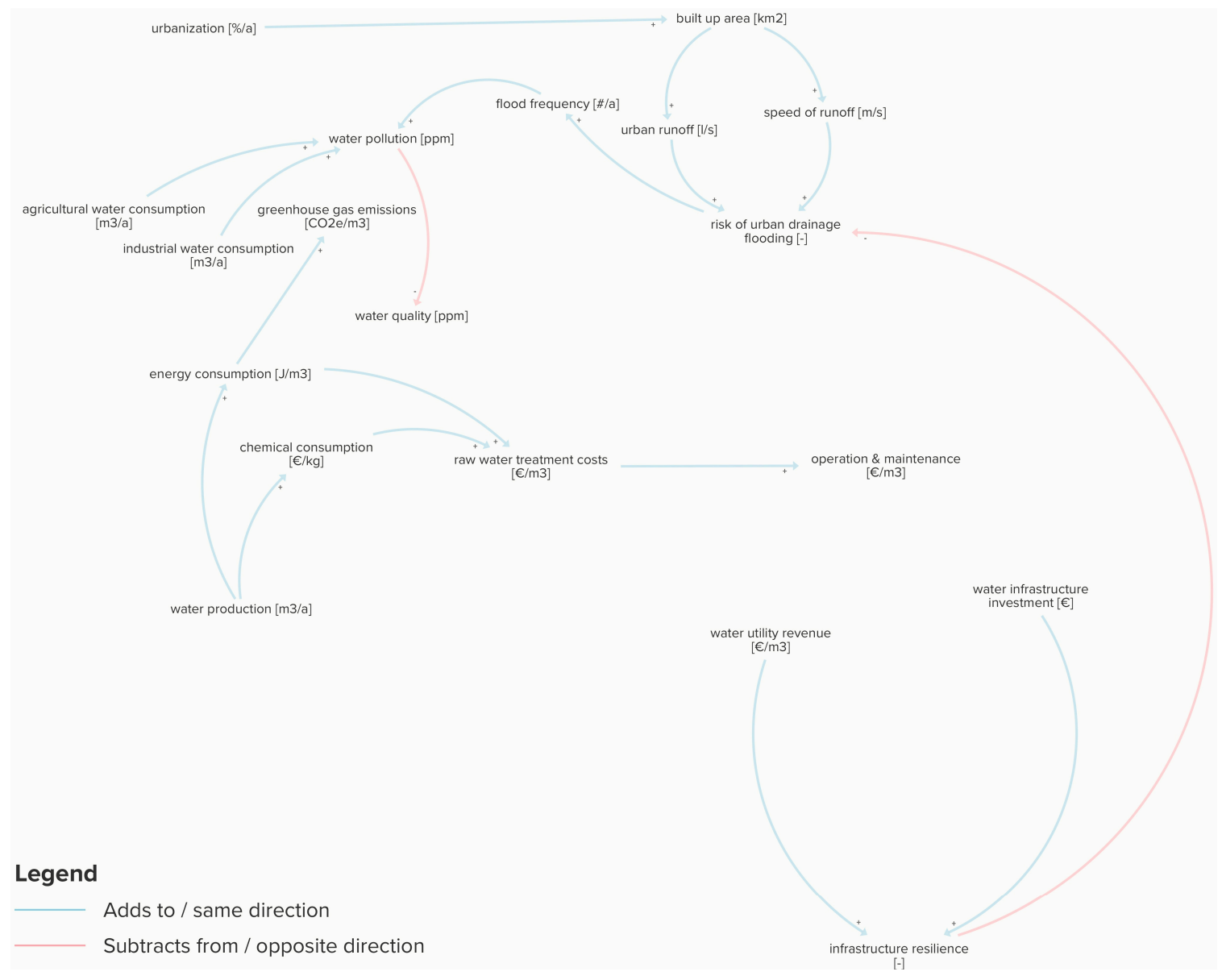

Figure 4. A synthesis of causal relations involving water quality.

\subsection{Cost Recovery}

Water and sanitation subsidies serve to simultaneously decrease the water services charged to consumers and improve the recovery cost of WUs for the sake of affordability. Figure 5 shows the factors affecting what consumers pay for water services that contribute to the WU revenue. The interrelation between water services charged to consumers and customer affordability is one that if a country has a higher national income average, they can afford higher water service charges; however, the higher the service charges are, the fewer customers are able to afford them, creating an Affordability balancing loop that limits the revenue potential of WUs and necessitates subsidies to recover some of the missing money-a tradeoff for affordability.

Cost recovery is referred to as cost recovery discrepancy, i.e., missing money-the difference between full cost recovery and actual cost recovery as depicted in Figure 6. It arises from the true value of water being naturally factored into the cost of providing water services, but not in the regulated water price, which is artificially suppressed by water and sanitation subsidies for more affordable water services charged to consumers. If the water price were to increase matching the true value of water, it follows that water service charges passed on to consumers would be equivalent to the actual cost of water services and thus close the cost recovery discrepancy. How great the cost recovery discrepancy affects the economic development and sustainability of the business. A water tariff increase resistance limits the water price and contributes to an unlucrative, unattractive investment climate. 


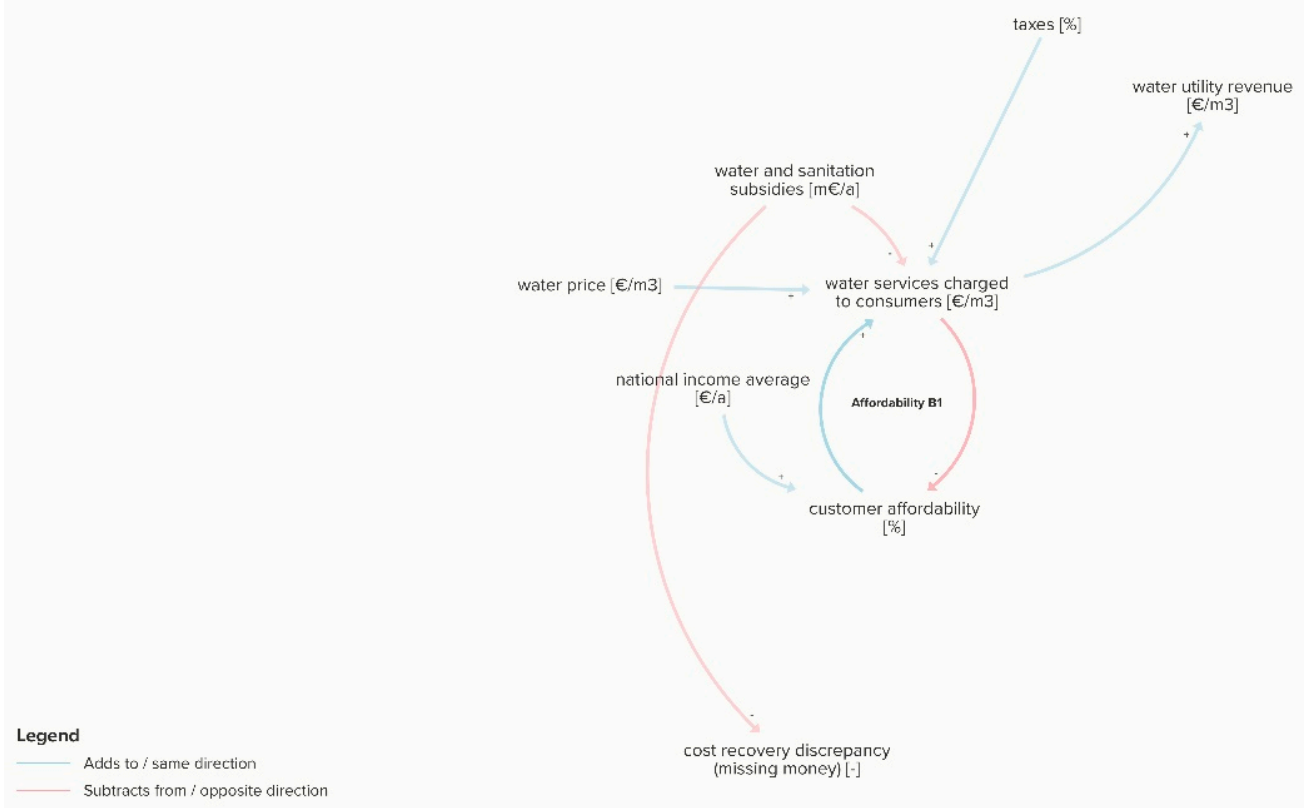

Figure 5. Synthesis of causal relations describing the affordability balancing loop.

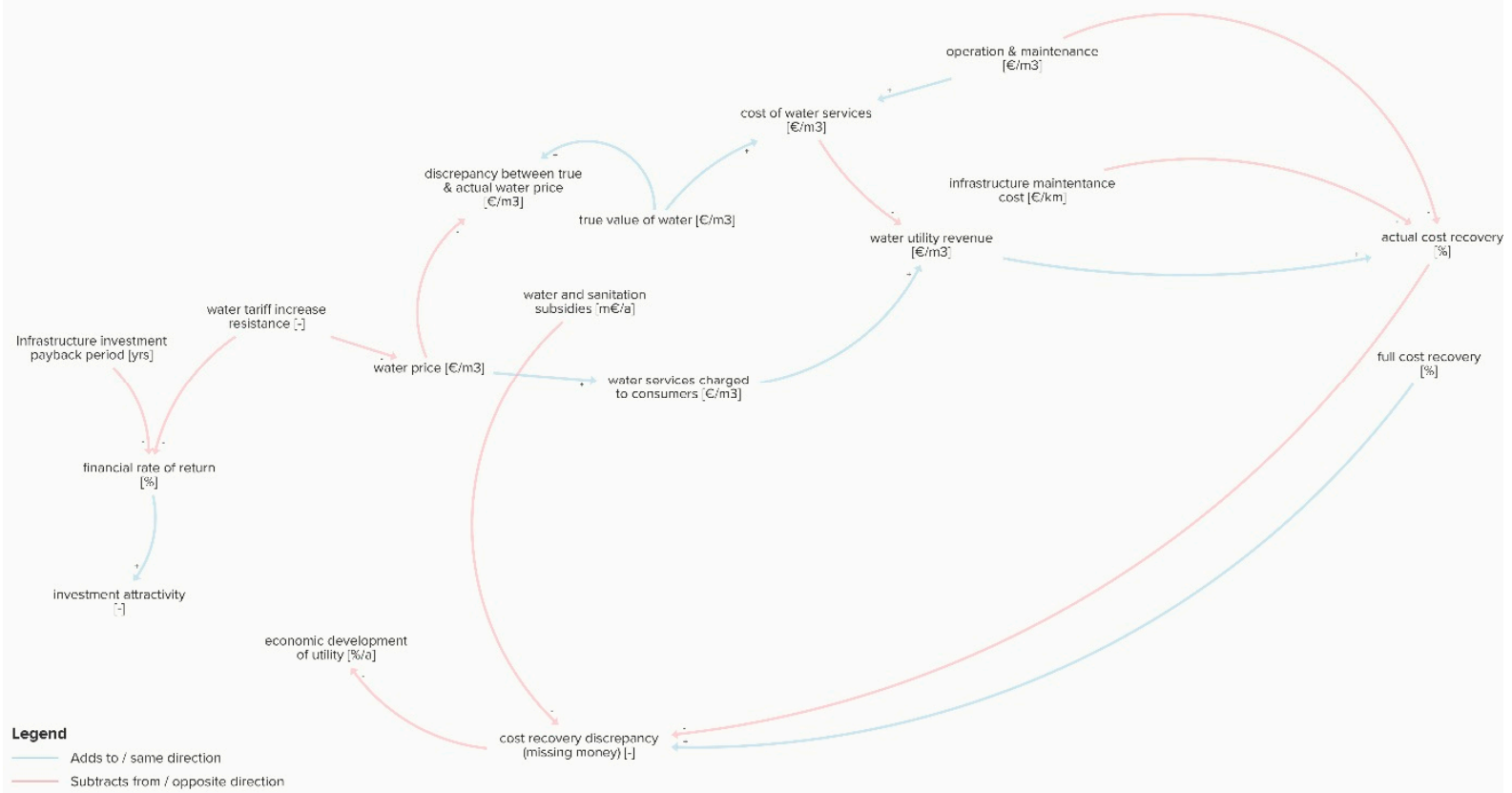

Figure 6. Synthesis of interrelations describing the effect of the gap between water price and value on cost recovery and the effect of the resistance of increasing water tariffs.

\subsection{Economies of Scale Loop}

Economies of Scale (EoS) underpins the business model for water production. It has a stabilizing effect on water production due to its balancing feedback loop. Financially it is in the interest of WUs to supply greater volumes of water at a marginal cost per cubic meter for greater revenue because EoS drives down per capita operation costs and increases revenue that can be used primarily for infrastructure maintenance and water infrastructure investment. Both of which remedy water leakages and thus reduce water production that would have been required to supplement water losses (non-revenue water). The concept of EoS is featured in the balancing loops shown in Figures 7 and 8. 


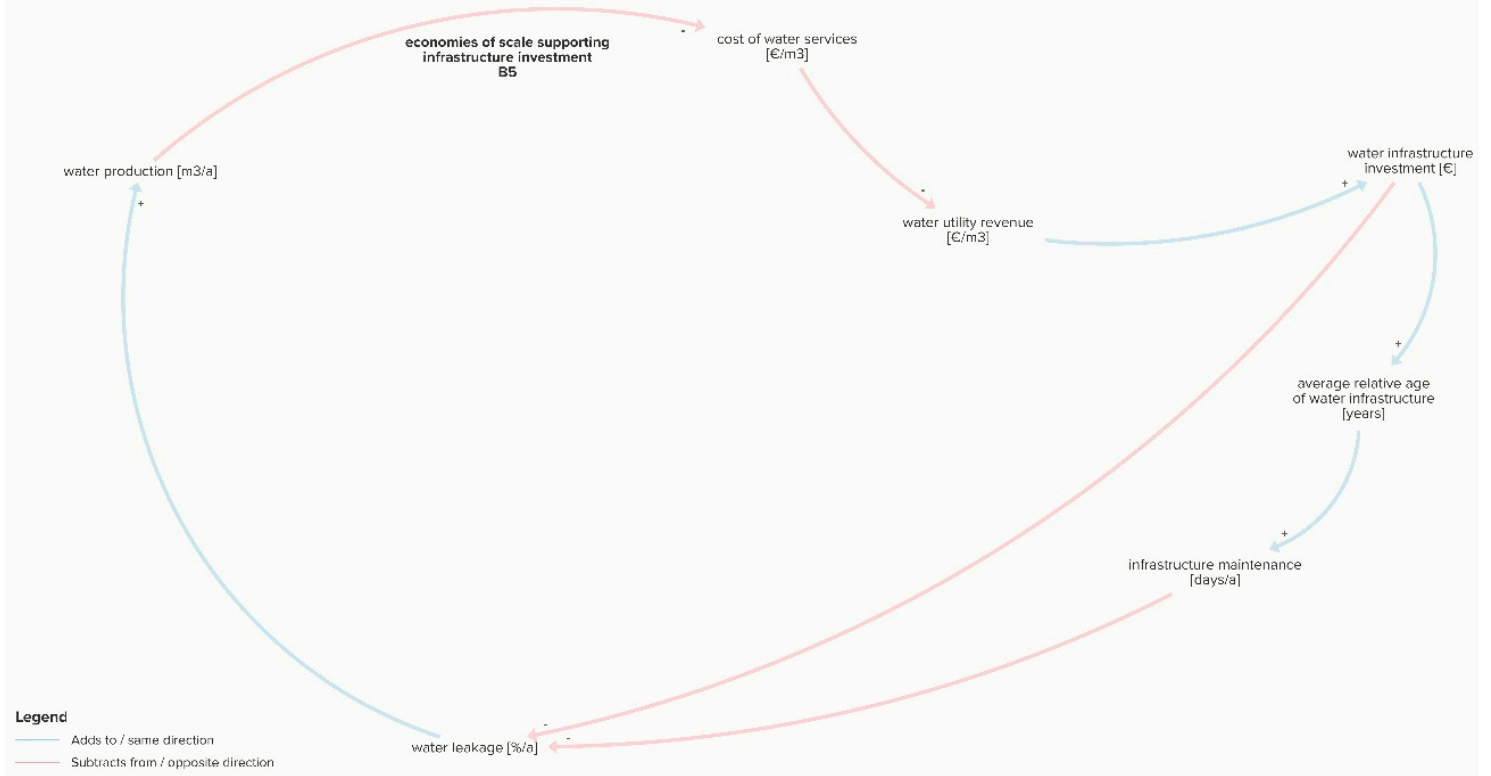

Figure 7. A synthesis of the economies of scale supporting infrastructure investment balancing loop.

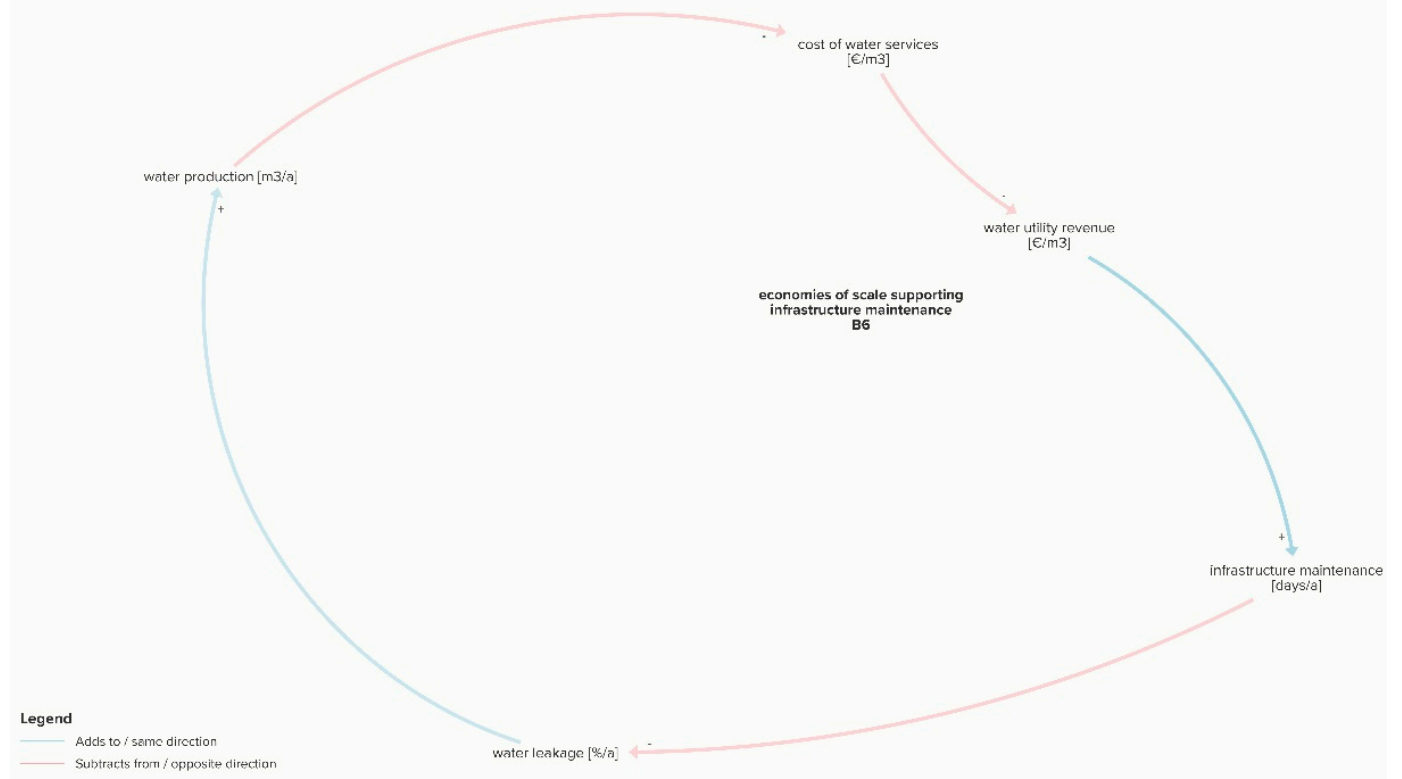

Figure 8. A synthesis of the economies of scale supporting infrastructure maintenance balancing loop.

\subsection{Overheads Loop}

Aging infrastructure makes up a considerable portion of the cost structure, becoming increasingly costly over time as more maintenance is required to mitigate leakages, counteract inefficiencies and improve the longevity of the infrastructure itself. Maintenance, as well as infrastructure investment, can be used to mitigate leakages to reduce non-revenue water, thereby reducing water service costs and boosting revenue. Figure 9 showcases these loops of opposing polarity: the cost of aging infrastructure (R1) dampening revenue and maintenance mitigated water leakages supporting revenue (B4). 


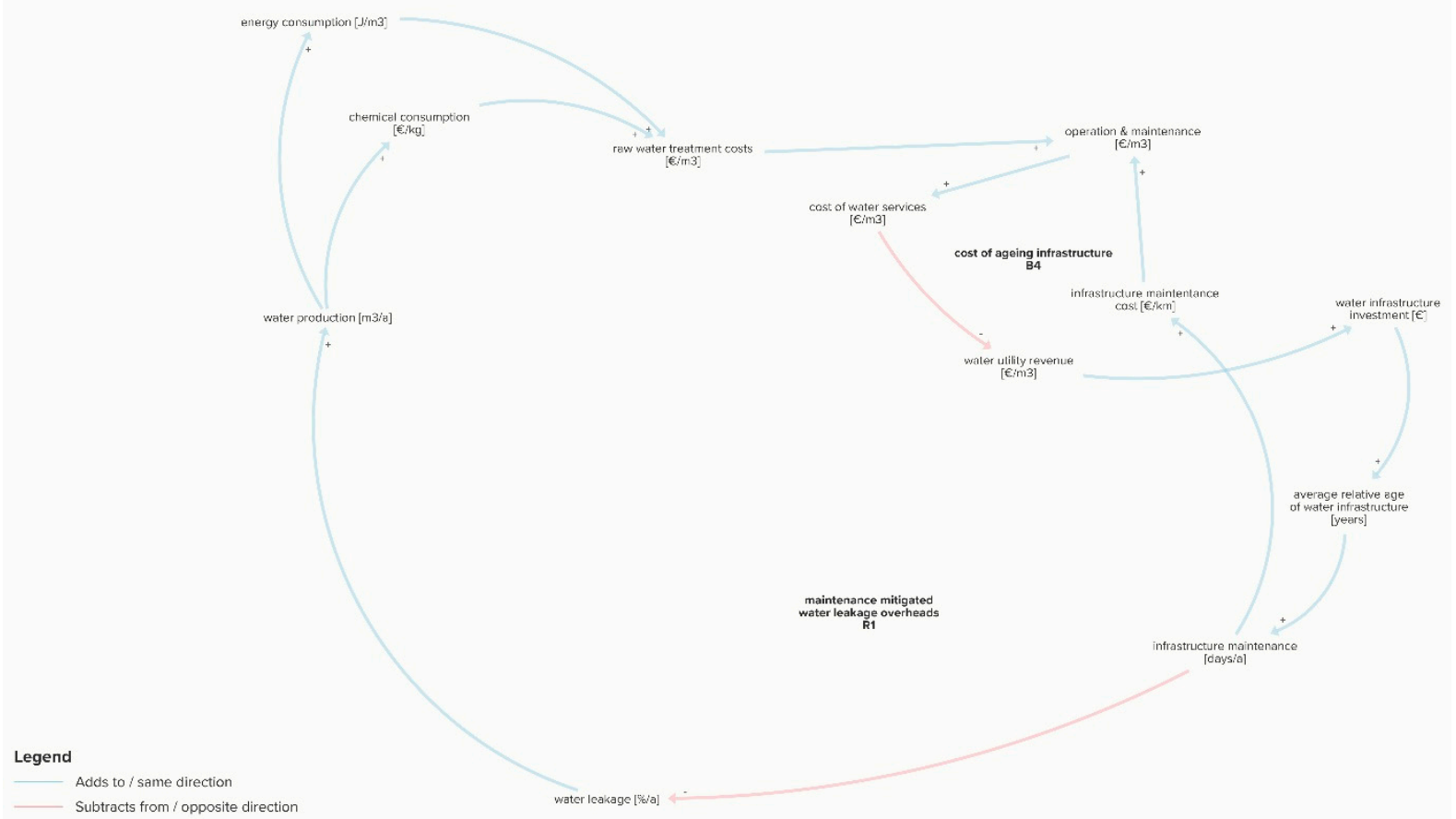

Figure 9. A synthesis of cost of ageing infrastructure balancing loop and maintenance mitigated water leakage overheads reinforcing loop.

Additionally, the depreciation of investments further dampens revenue, as in Figure 10.

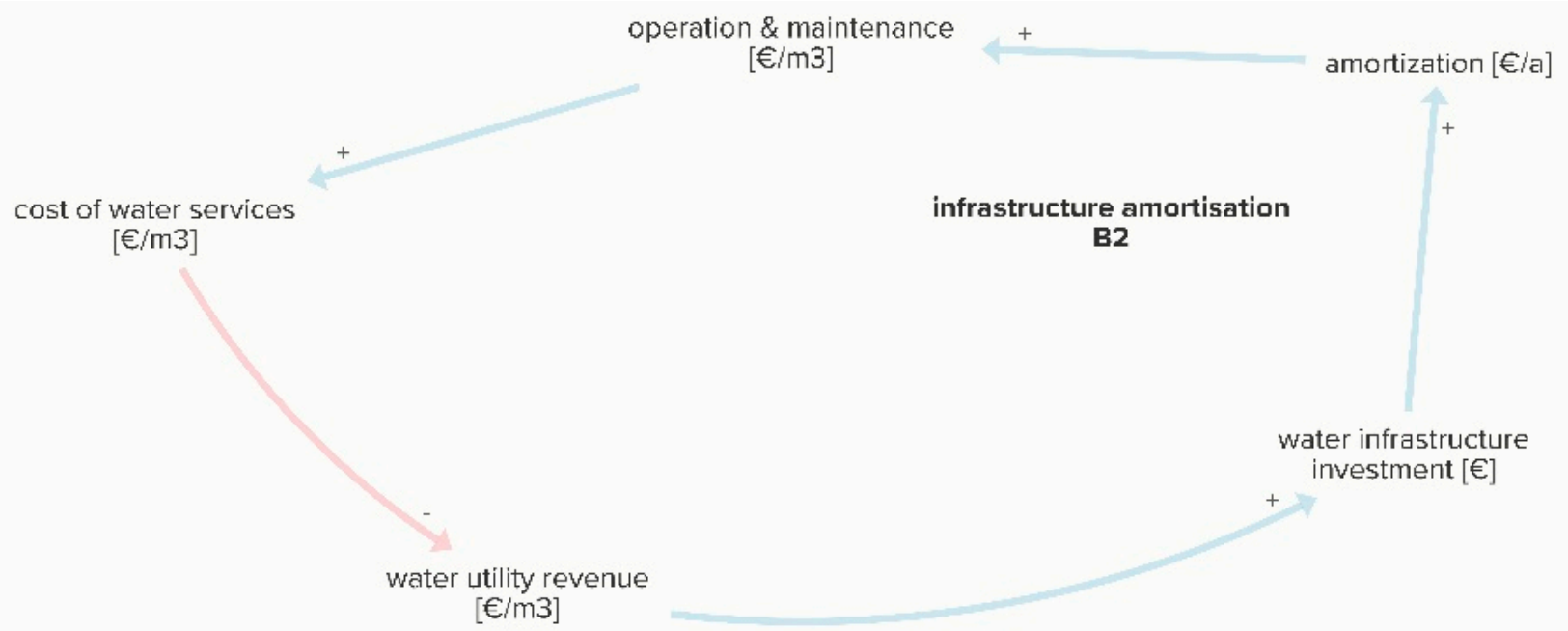

Legend

Figure 10. A synthesis of infrastructure amortization balancing loop.

\subsection{Resilience Investment Loop}

Figure 11 is made up of two reinforcing resilience loops that indicate investing in infrastructure resilience to withstand either extremely wet or dry weather ultimately supports water revenue generation. In periods of flood, infrastructure resilience mitigates urban drainage flooding and its costly impacts of water pollution and thus O\&M costs. In periods of drought, investing in resilience supports water security to meet continuous demand. 


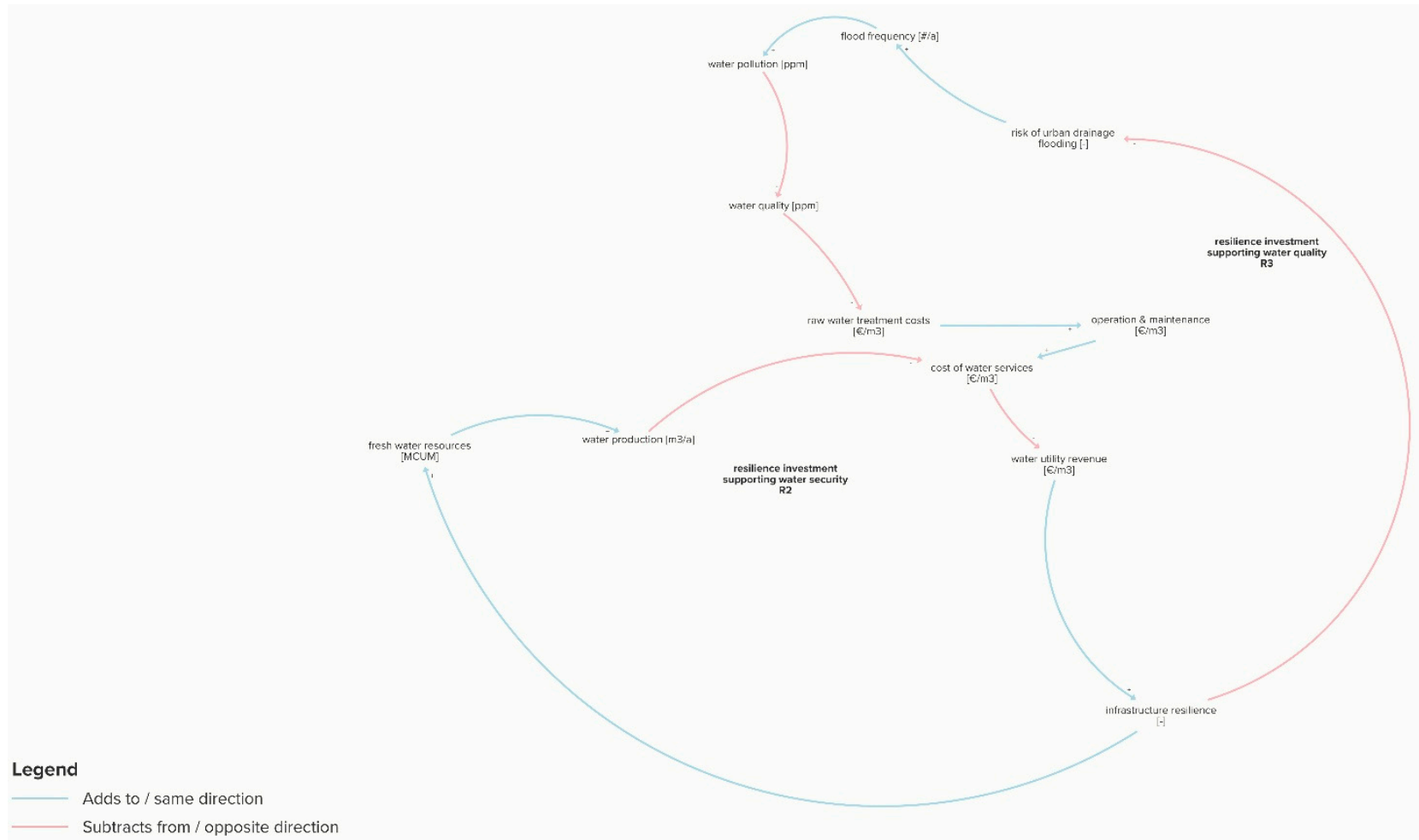

Figure 11. A synthesis of resilience investment supporting water quality and water-scarcity reinforcing loops.

\section{Interview Findings}

Table 3 summarizes the key themes arising from the interviews. Refer to Appendix B for the extended version of the findings and Appendix $C$ for the interview transcripts.

Table 3. Summary of interviews.

\begin{tabular}{|c|c|c|}
\hline & Findings & Description \\
\hline \multirow{8}{*}{ Barriers to $\mathrm{CE}$} & Outdated legislation & $\begin{array}{l}\text { Disincentives CE: } \\
\text { Nutrient recycling is made difficult in those } \\
\text { countries requiring permits } \\
\text { The legal status of waste hinders reclaimed } \\
\text { water or recovered phosphate fertilizers from } \\
\text { entering the food industry }\end{array}$ \\
\hline & Health and safety risks & Hamper social acceptance \\
\hline & $\begin{array}{l}\text { Fluctuating fertilizer quality that cannot always be } \\
\text { guaranteed with varying concentrations in WW }\end{array}$ & Hampers market acceptance \\
\hline & Social acceptance & $\begin{array}{l}\text { Strong psychological effect in society against } \\
\text { direct waste recycling }\end{array}$ \\
\hline & Expensive technology & $\begin{array}{l}\text { Such as online meters (e.g., E. coli, } \mathrm{N} 2 \mathrm{O} \text { probes) } \\
\text { increase overheads for organizations }\end{array}$ \\
\hline & $\begin{array}{c}\text { A high-level of IT readiness and capability for } \\
\text { handling big data }\end{array}$ & Increases overheads for organizations \\
\hline & Prioritization of investments & $\begin{array}{l}\text { Between large-scale infrastructure and } \\
\text { decentralized systems because this ensures that } \\
\text { the massive } 50 \text {-year investment made in } \\
\text { centralized infrastructure does not become } \\
\text { redundant as a result of a complete shift to } \\
\text { decentralized systems. }\end{array}$ \\
\hline & CE remains a concept & $\begin{array}{l}\text { Making it difficult for companies to } \\
\text { adopt practically }\end{array}$ \\
\hline
\end{tabular}


Table 3. Cont.

The price of water is not reflective of the true cost Increasing the price of water is not considered of externalities a viable solution by two respondents.

The cost of closing the loop will need to be socialized

The price of water

There is a need to redesign tariff structures, i.e., alternative billing
Charge for water is to factor in the associated costs into the tariff cost structure using a rising block banded system. Ensures that water remains affordable, but at the same time disincentivizes irresponsible usage An "extreme method" is to not only base charges on the quantity consumed on the supply side but also on the quality discharged on the collection side, similar to a polluter pays principle, but for all consumers. This motivates hospitals and industry to improve the quality of water discharged even if it means they need to include an additional process step locally before discharging. Eventually, the desired effect would be that heavy polluters end up paying less as a result of the additional treatment step prior to discharge because it should cost less than the charge for heavily polluted water. The quality of water discharged to wastewater treatment plants (WWTPs) would improve, making CE easier to implement and the costs of treatment less for WWTPs.

Fluctuating water prices for all sectors based on seasonal availability. In periods of drought, the tariffs would be higher.

Currently, time-based tariffs in the water sector are a "thinking experiment"

Very large investments that depreciate over the next 30 to 50 years are supposed to be funded by water sales revenue

Infrastructure is a financial burden

Large-scale utilities find themselves stuck with the technology and infrastructure they have for decades without the opportunity of rapidly adapting the network or directly investing in and implementing new technologies $\mathrm{CE}$ requires

In Flanders, Belgium, decentralized systems are looking to be deployed; financially, it makes sense to install them in new builds, cities and districts.

A complete shift to decentralization will not occur, but rather decentralized systems will complement centralized treatment to form a hybrid network

They do, however, promise a less capital-intensive outlay of investment; make it easier to shift more rapidly to new technologies because the scale of investment is smaller; and create a demand for water solutions companies to build, operate and maintain decentralized systemsA Flanders WU is carrying out a pilot on decentralized systems and expects a return on investment between $8 \%$ and $12 \%$, with a payback time of 10 to 12 years 
Table 3. Cont.

In the Netherlands, a WU is strategically deploying decentralized systems

An EU Horizon 2020 project, HYDROUSA

(Figure 12), is focused on local decentralized circular solutions in the Greek Islands

Water-as-a-service company practices water reuse for irrigation

Salt recovery from desalination

Circular Practices

Production of biogas and biomethane from anaerobic digestion of dewatered sludge

HYDROUSA is attempting to close the water loop and, in turn, the nutrient and energy loops for full circularity
At specific points, pollution sources, such as hospitals, where a decentralized water solutions company, Pharmafilter ${ }^{\circledR}$, is the owner and monitor of such systems. WW is being treated before being discharged to the WWTP, and the (medicinal) waste is being recovered for reuse by Pharmafilter ${ }^{\circledR}$

Local supply chains that recover water, energy and materials are being developed for valorizing at the local level for the benefit of the local communityHYDROUSA is focusing on providing low-cost, nature-based solutions, which require less operational costs than conventional activated sludge processes for the treatment of WW

Reclaimed water, originally from desalination on island nations in the Americas, is predominantly used for irrigation. The sewage is given to farmers for free due to legal complications hindering nutrient recovery prospects

Alternatively, the WW is treated for potable use

For the water-as-a-service company, the business case for salt recovery is suboptimal, with salt being a cheap commodity and the surface area required for evaporation being substantial

For the HYDROUSA project, nature-based desalination with the help of mangrove tree roots and the recovery of salt sold to the local community is being demonstrated. It is yet to be seen whether this nature-based form of salt recovery is financially viable

In Flanders, the experience has been that unless a sizeable amount of organic matter is available, meager energy yields are sufficient for only heating the reactor for the digestion process. They are thus looking to improve energy yields by integrating the food waste network with the sewage network to increase the organic content for biogas production. Prior to this, the legal obstacle hindering the network merger must be overcome. In the Dutch case, the biomethane cheapens WW treatment by a few cents per cubic meter, where it is injected into the gas grid and is found to be a worthwhile business case. The Dutch WU and HYDROUSA are producing biogas for transportation.

This involves:

digesting and drying sludge for compost and fertigation of agro-forestry and herbs for essential oils production using nature-based infrastructure to purify WW effluent destined for irrigation and households rainwater harvesting and storage 
Table 3. Cont.

The Dutch WUs send their sludge to a third-party company with the aim of producing phosphate fertilizer, bioplastics and treating the sludge for final disposal. Further

Recovery aspirations for circularity include treating and reusing the WW effluent for recreational water bodies designated for swimming instead of discharging into the sea and, in so doing, effectively storing water for drier periods

To evaluate the water quality by measuring $\mathrm{pH}$,

HYDROUSA is deploying many low-cost sensors

HYDROUSA is deploying energy meters

The utility in Flanders is in the development phase when it comes to smart meters

Digitalization temperature and conductivity to determine the salt content of water in case any seawater has seeped into the groundwater

To determine the energy efficiency of the systems

Online data would be shared with the families, informing them of the presence of leaks and providing daily consumption data for comparison with other households in order to create awareness about their water consumption

Consumers are updated regularly on their usage patterns. Due to privacy issues, the consumption data of other consumers cannot be shared. If end-users are exceeding their usual consumption levels, the utility passes on tips for conserving water

To monitor the network efficiency and to detect leaks using district metered areas (DMAs). DMAs can locate and identify leakages with automated online data analysis using statistics to define where the leakage is and for how long it has been there.

Drawing from the experiences in the HYDROUSA project, the critical success factors to circularity have so far demonstrated to be anchored in:

- The bankability of projects to draw in investor interest;

- Knowing the needs of the end consumers of the products recovered to ensure a market demand. (This was accomplished through intentional stakeholder engagement with methods, such as co-creation workshops, hackathons, summer camps, local seminars, and demonstration events where end consumers provided feedback that helped develop the design of the project)

- Legislation being an enabler of circular practices.

Figure 13 shows the holistic approach to smart water, supported by three dimensions: smart design, which pertains to the physical and legal infrastructure used to deliver smart water; smart use is determined by the methods used to minimize and eliminate waste known as the 6Rs (preconditions to CE), and smart control refers to digitally-enabled practices that optimize operational efficiencies as well as convert data into information forming the foundation of innovative solutions. Most cases partially employ some of the 6Rs and some form of digitalization, but hardly any embody this holistic approach. 


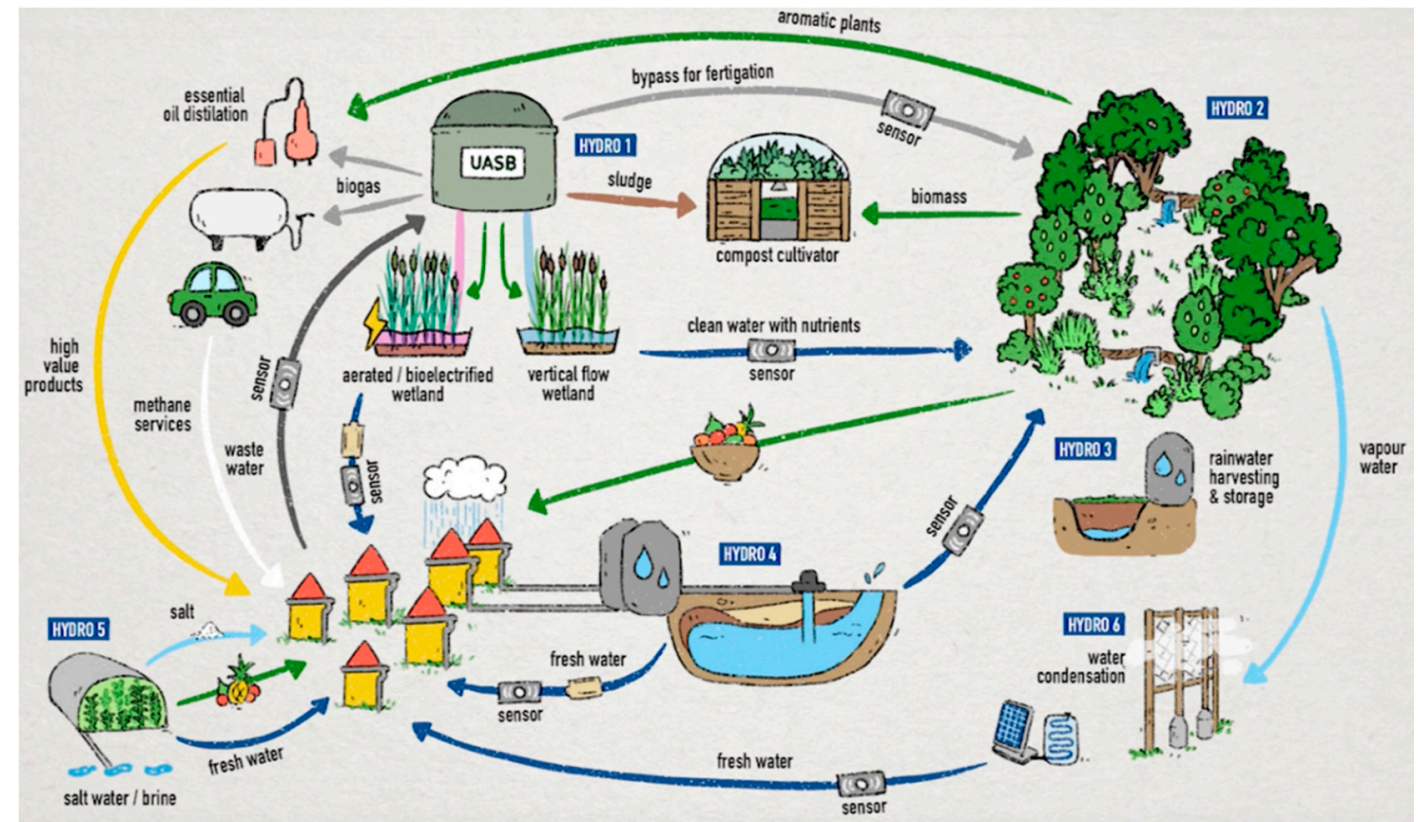

Figure 12. HYDROUSA project.

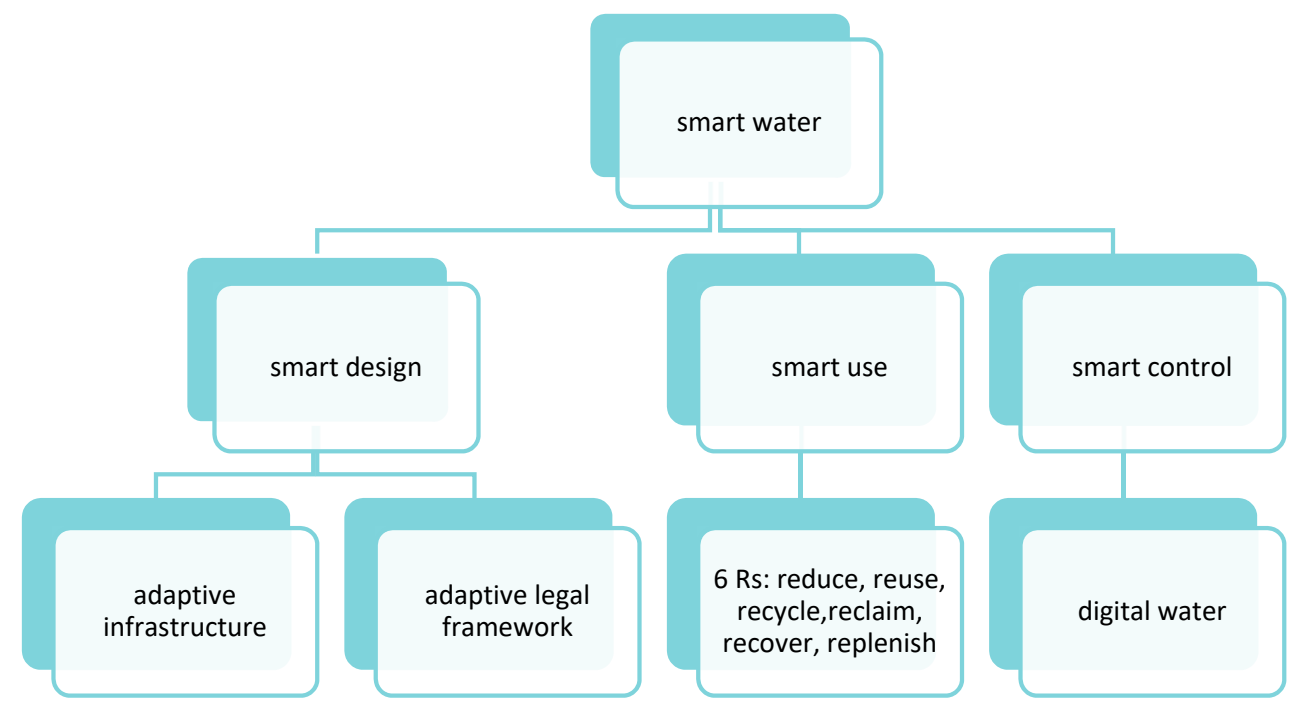

Figure 13. Holistic approach to smart water. Created based on a presentation given at AIWW 2019 by Kalanithy Vairavamoorthy (Executive Director at International Water Association (IWA)). The Nordic countries are at the forefront of digital water, creating smart water solutions born out of strong collaboration and learning efforts between utilities, municipalities and technology partners. The four Nordic WW associations have managed to leverage digitalization in various forms to tackle the individual problems specific to their water networks. Appendix D contains the cases supporting the circular water economy (CWE) model.

\section{The Circular Water System}

The CWE system depicted in Figure 14 builds on top of and modifies the economic view of the UWS found in Figure 3. It focuses on areas of intervention that leverage circularity, their expected consequences and improvements that can support the business model. It consists of an equal balance of reinforcing loops to balancing loops suggesting less resistance to change when compared to the UWS. 
Legend

Adds to / same direction

Subtracts from / opposite direction

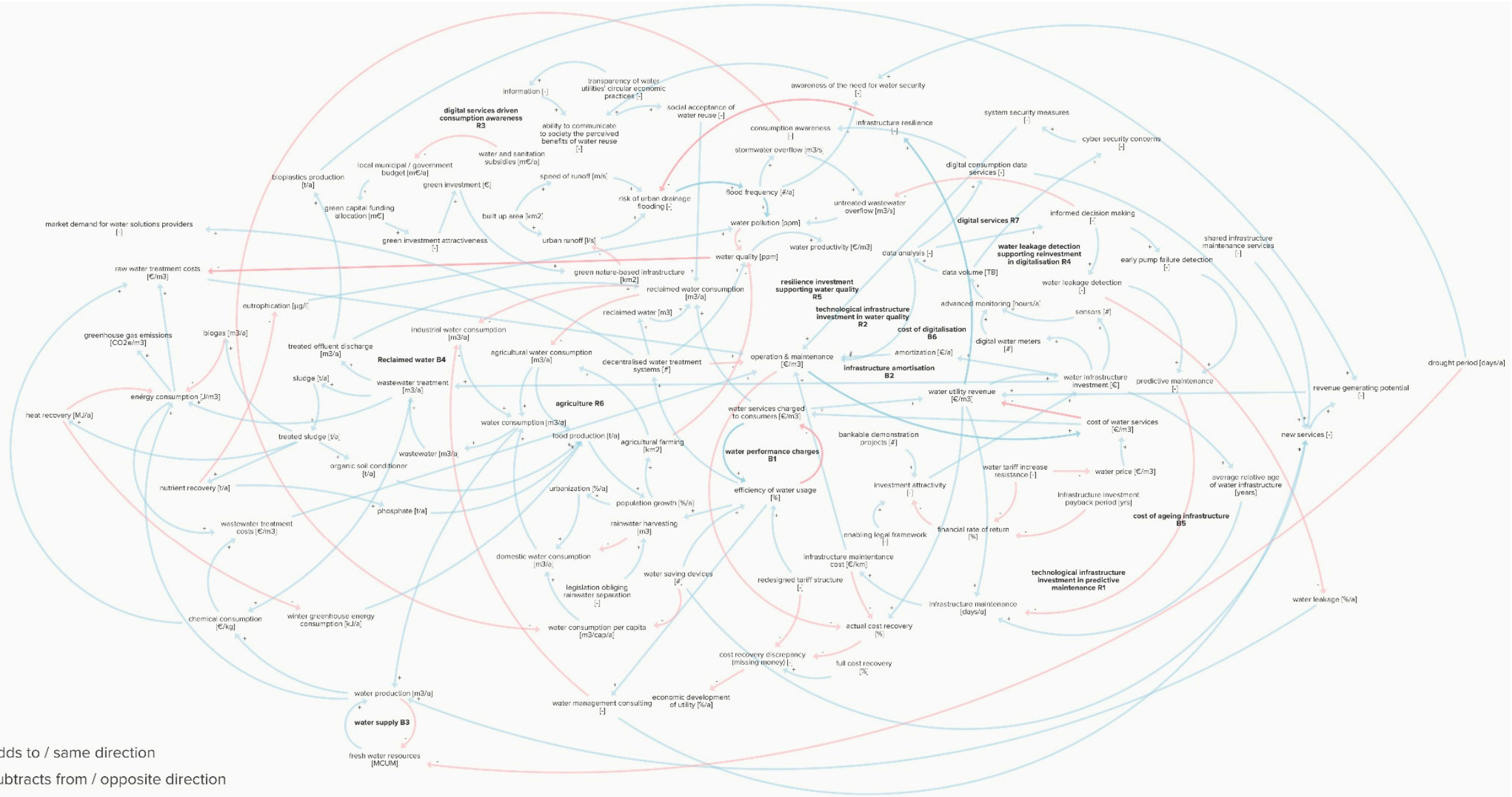

Figure 14. A synthesis CLD describing a circular water economy system. 


\subsection{Alternative Water Billing}

In contrast with the UWS, where the customer affordability loop is a determinant of the water services charged to consumers, under the CWES charges are based on a redesigned tariff structure that rewards water efficiency by assuming a purely volume-based tariff structure with a rising block structure, as shown in Figure 15 (for illustrative purposes only). With each successive band of water consumption crossed, an increasing cost is charged to the consumer. The prices assigned to the price bands are variable in order to reflect seasonal availability.

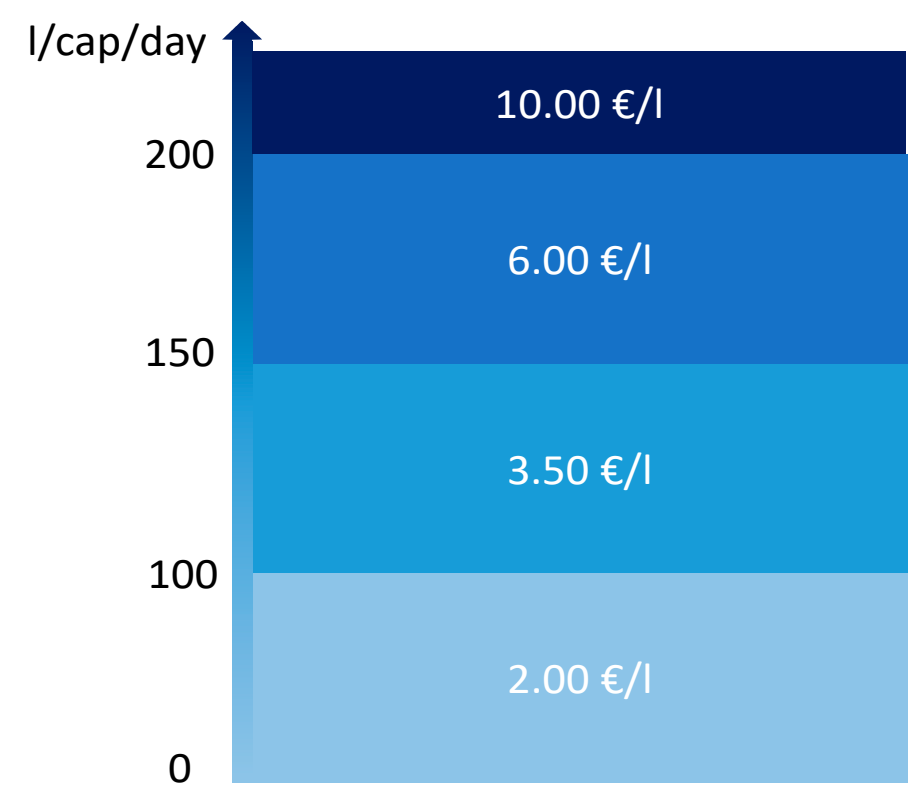

Figure 15. Illustration of the tariff structure redesign.

The introduction of such a tariff system would readjust the revenue earned by WUs because low consumers would potentially pay less and high consumers significantly more. However, the polarity of a causal relation cannot be made explicit between redesigned tariff structure $\rightarrow$ water services charged to consumers as this requires knowledge of quantification. Essentially the tariff structure is designed to encourage efficiency and not to specifically increase water service charges passed onto consumers, hence the connection between redesigned tariff structure and efficiency of water usage in Figure 16. Ultimately, the new tariff structure helps to recover the missing money because the charges are shown to reflect externalities in the direct connection between the cost of water services and water services charged to consumers, a connection not existing in the UWS.

This would eliminate the need for subsidies to recover the missing money freeing up government funds for supporting WUs in other more constructive ways, such as green financing for green infrastructure. Green infrastructure has shown to be a cost-effective way of preventing flooding and with-it water pollution from surface run-off contaminants, which is typically the case in an urban environment. Figure 17 shows how the resulting effect on the WU is that the water quality of water sources is improved and therefore the operational costs for water treatment are reduced and revenue increased over time. Green infrastructure also has been shown to avoid investment in gray infrastructure and flood protection; however, because this is very specific to the context depending on the flood intensity and whether or not the existing infrastructure calls for reinforcements, this is not included. 


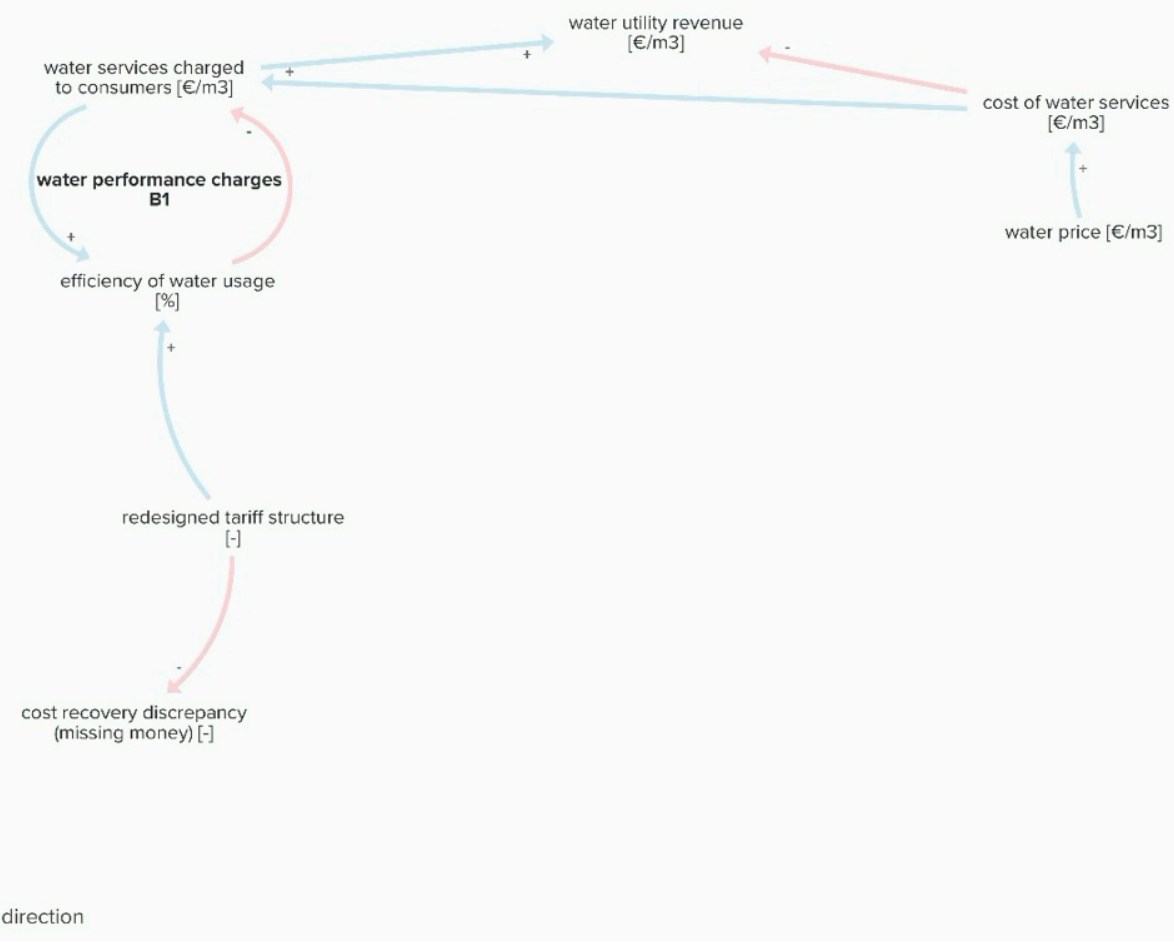

Figure 16. Synthesis of causal relations describing the water performance charges loop.

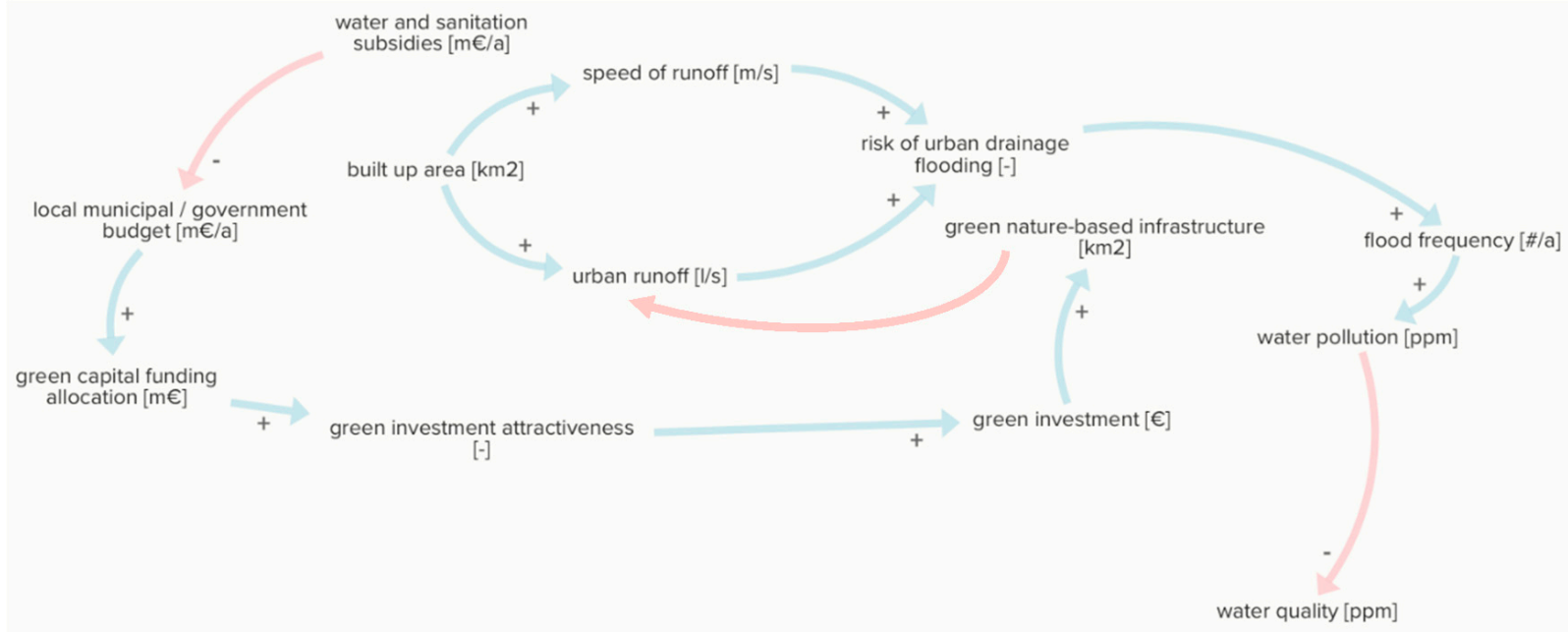

Figure 17. Synthesis of causal relations describing green capital funding from water and sanitation subsidies alternative.

\subsection{The Effects of Water-Performance Based Charges}

Figure 18 maps ways in which encouraging water efficiency can affect different consumer sectors. By encouraging water efficiency, heavy consumers in an industry unable to economically sustain the increase in prices attributed to their excessive usage would be forced to invest in means of reducing consumption. One such option would be to recycle their water with decentralized water treatment systems. A mushrooming market for decentralized systems creates a demand for water solutions providers for maintenance, monitoring water quality and, depending on the industry, recovering resources in the water that can be reused in the business processes. 


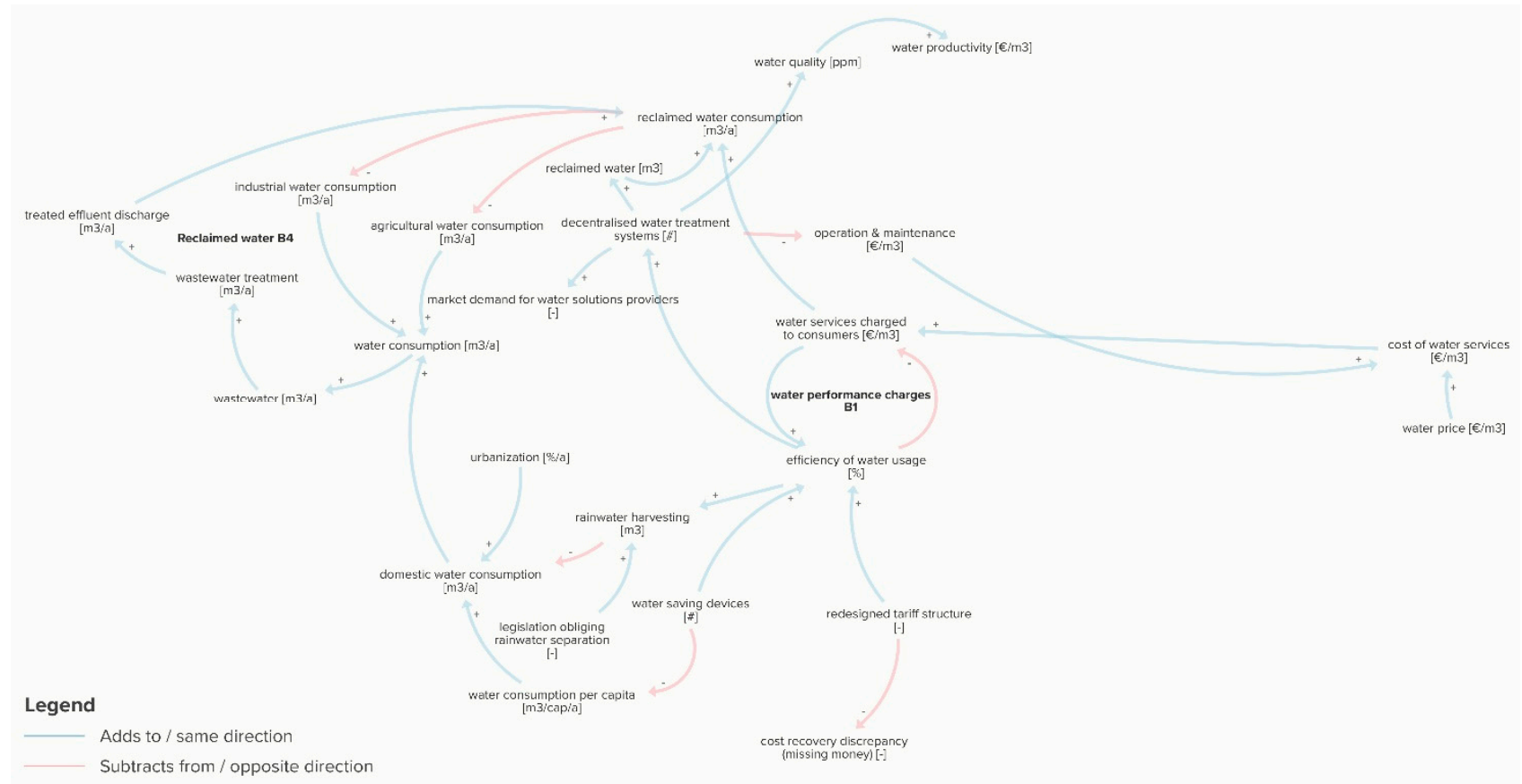

Figure 18. Synthesis of causal relations describing the reclaimed water loop and the effects of charging consumers based on water efficiency.

Not only would the industry have the option of using decentralized systems to curb consumption, but WUs could take the opportunity to consult companies looking to achieve still deeper cuts in their water consumption for financial savings or improving their discharged water quality. Water management consulting together with digital consumption data services, water savings device sales and infrastructure sharing make up the suite of additional services WUs could offer in support of revenue generation at the expense of encouraging water efficiency. Efficiency can also be seen to encourage high consumers within the residential sector, who find that installing equipment for harvesting rainwater and/or water savings devices endorsed and sold by WUs reduces their water bill.

Important to note is that when the water price is low, it kills any prospects of a market for reclaimed water as there is no financial incentive to consume it when consuming freshwater is more cost-effective. This is depicted in the positive relations: water price-> water services charged to consumers $\rightarrow>$ reclaimed water consumption. Centrally and decentrally produced reclaimed water ease pressure on freshwater resources from industry and farmers as well as promote water resource efficiency.

Despite the potential reclaimed water has, push back from society can limit WW reuse and thus requires efforts to guide and mold perceptions. As addressed in an interview, capitalizing on bad weather conditions (floods and droughts) can have the desirable effect of awakening society to the need for robust water security measures, thus providing a platform to openly communicate and inform society on the crucial role water reuse has in supporting water security. This, in turn, can increase society's perceived benefit of water reuse in favor of water reuse, as shown in Figure 19.

With infrastructure investment lagging, resistance to increasing water tariffs and long payback periods that bring about low financial rates of return work to create an unfavorable investment climate. It was suggested that bankable projects should be used to showcase to investors the viability of circular projects, such was the case for Ostara, a nutrient management solutions company based in Vancouver, Canada. Additionally, legislation has been pointed to as a vital means of creating an investor-friendly climate sending signals to investors that their inclusion is needed and highly desirable. Figure 20 depicts the key relations surrounding investment attractivity. 


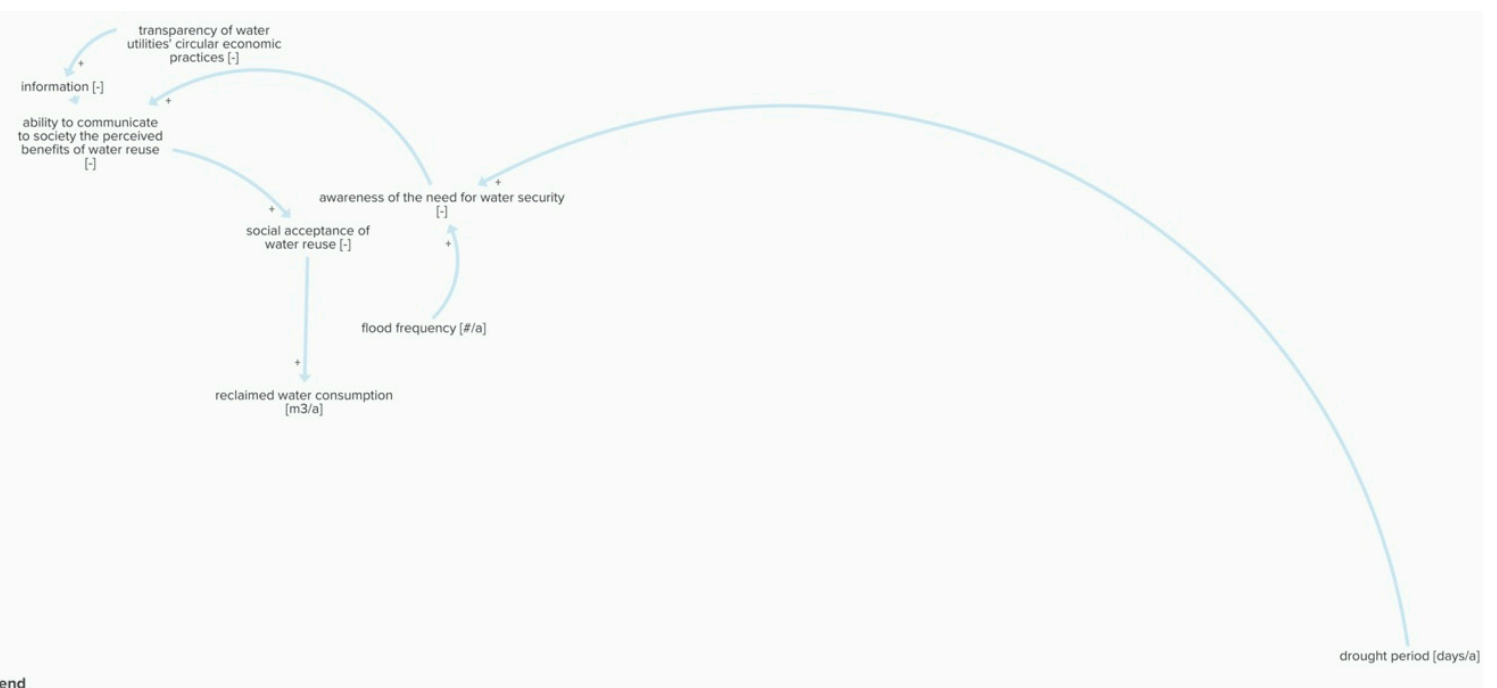

Legend Subtracts from / opposite direction

Figure 19. Synthesis of causal relationships indicating ways of altering societal perception on water reuse.

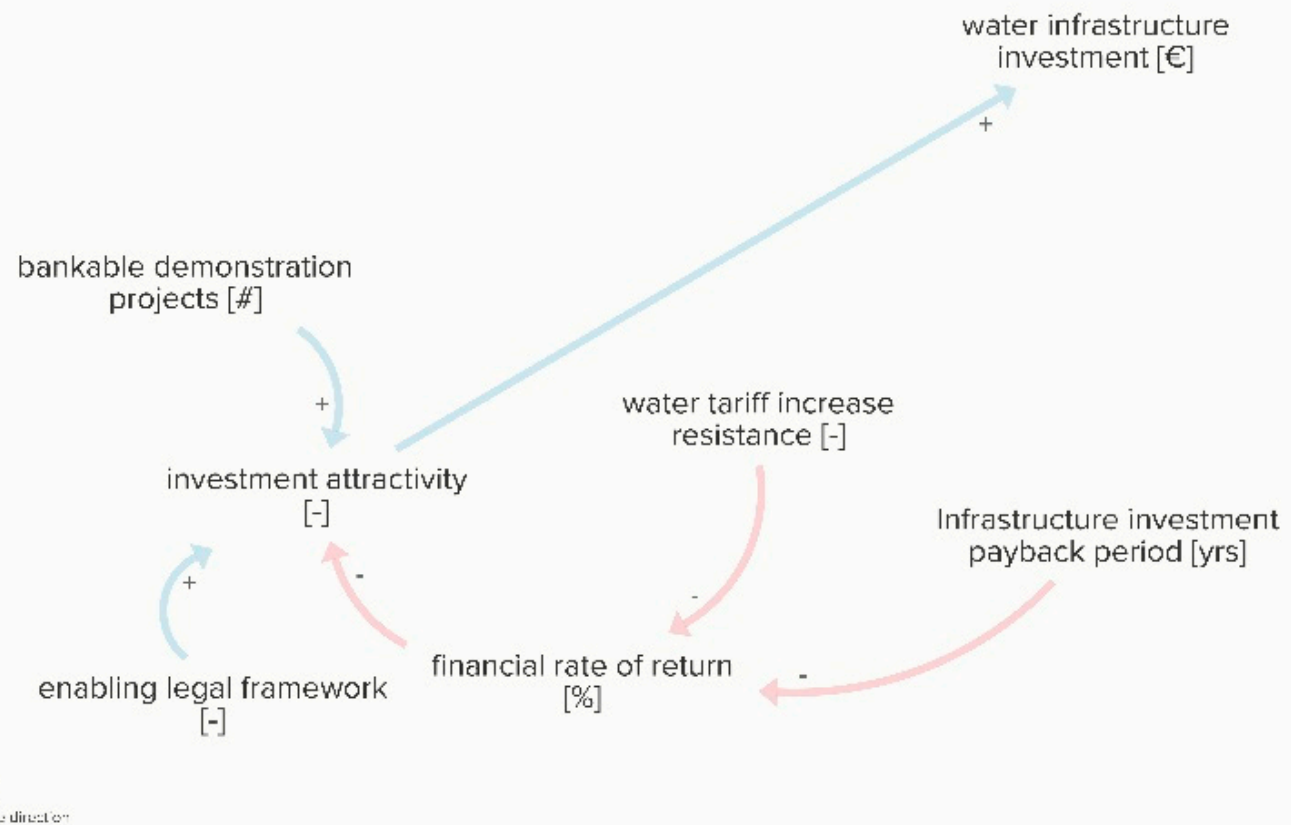

Figure 20. Synthesis of causal relations surrounding investment attractivity.

The circular paths for sludge explored in Figure 21 are not exhaustive as not every possibility can be captured without compromising on complexity and understanding. In reality, not all options are at the disposal of WUs for any number of reasons; hence the circular options are limited to those explicated in the interviews. Sludge is the feedstock for biogas, while heat energy is recovered as a byproduct of the anaerobic digestion process. Both can supplement the plant's energy demand, thereby reducing operational costs and greenhouse gas emissions. Any excess heat recovered can be supplied via district heating to greenhouses, for example, to support food production. The sludge can be treated in order to mine organic soil conditioner and struvite for phosphate fertilizers, both supplying the agricultural market in support of food production. 


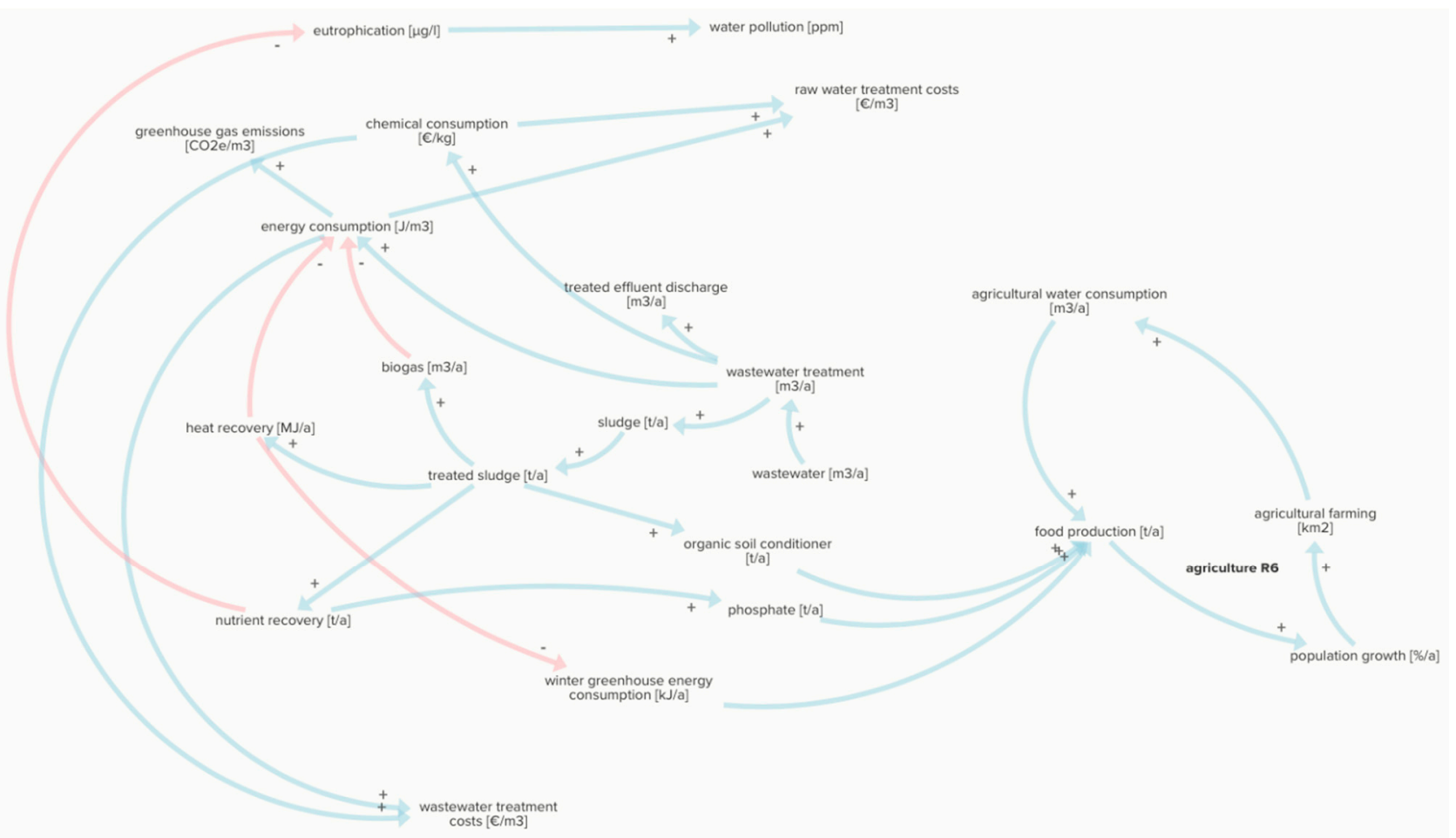

Figure 21. Synthesis of causal relations describing ways of making wastewater circular.

\subsection{Digitalization Loop}

Water infrastructure investment in digitalization improves revenue generation on two fronts: through consumer awareness and predictive maintenance. There is strong support for WUs to share consumption data with residential consumers and possibly with data of their neighbors to cultivate a stronger sense of awareness regarding how much water they consume based on their usage patterns over time and comparison with neighbors. This is thought to give consumers the drive to want to improve or change habits that noticeably spike consumption.

Given that under the CWES, the business model does not depend on EoS but instead on a redesigned tariff structure, the WU supplies less water, and fewer operational costs contribute to the cost of water services.

It is important to note that under the CWES, revenue is stacked through multiple means; therefore, because water sales no longer form the cornerstone of the business model, there are no loops exhibiting EoS with revenue supporting maintenance and infrastructure.

Furthermore, unlike the UWS, the CWES has no direct connection between infrastructure maintenance alleviating water leakages but rather digital infrastructure investments supporting timely water leakage detection and early pump failure detection that reduces the need for infrastructure maintenance. In Figures 22 and 23 are loops consisting of digital infrastructure investments and data supporting informed decision-making in two ways: water leakage detection and early pump failure detection moving in the direction of preventative maintenance; and avoidance of combined sewer overflows (untreated wastewater overflow) and water pollution. Both help to ease operational costs through reduced infrastructure maintenance costs and raw water treatment costs, respectively. 


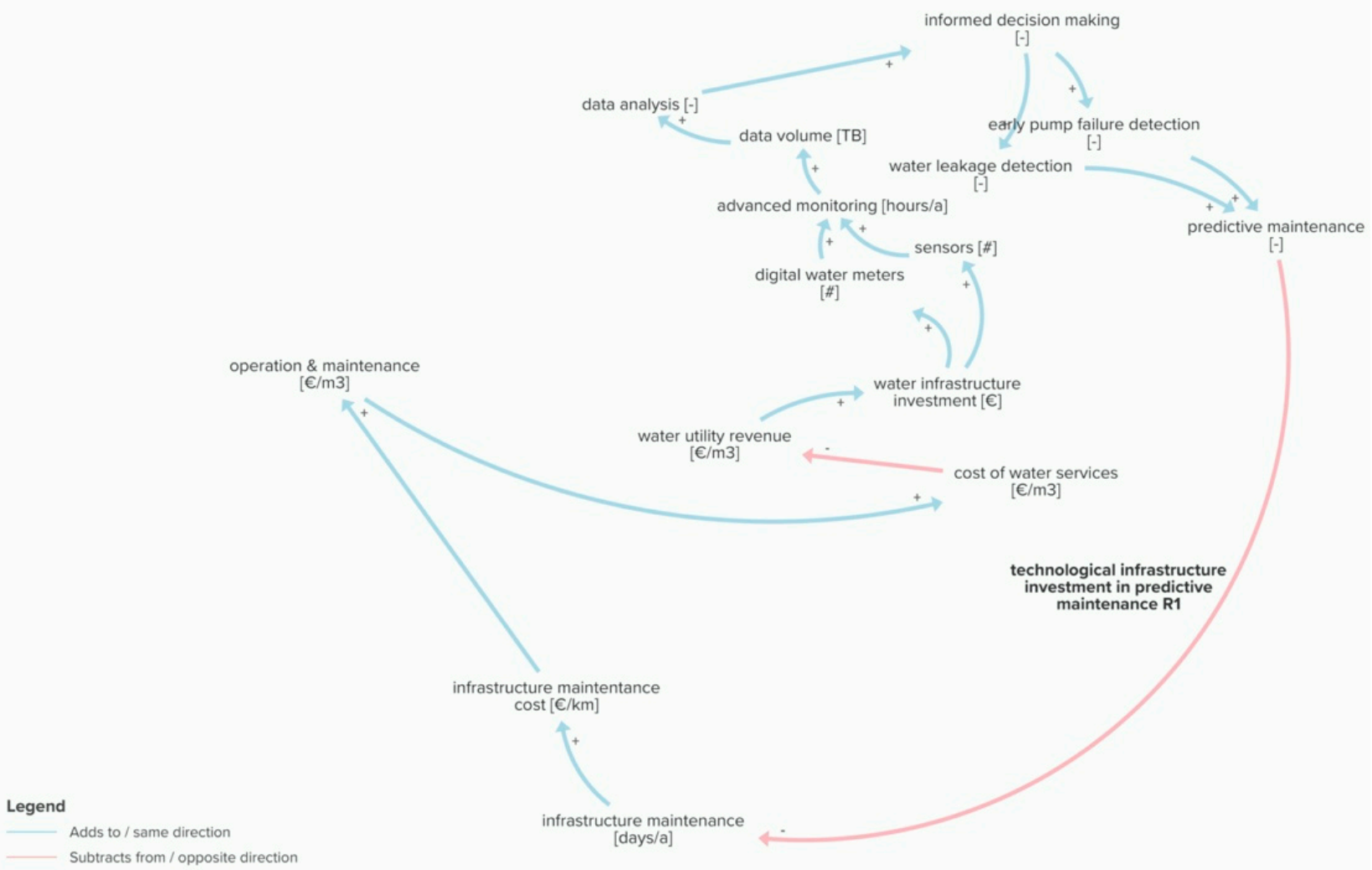

Figure 22. Synthesis of causal relations describing the technological infrastructure investment in predictive maintenance reinforcing loop.

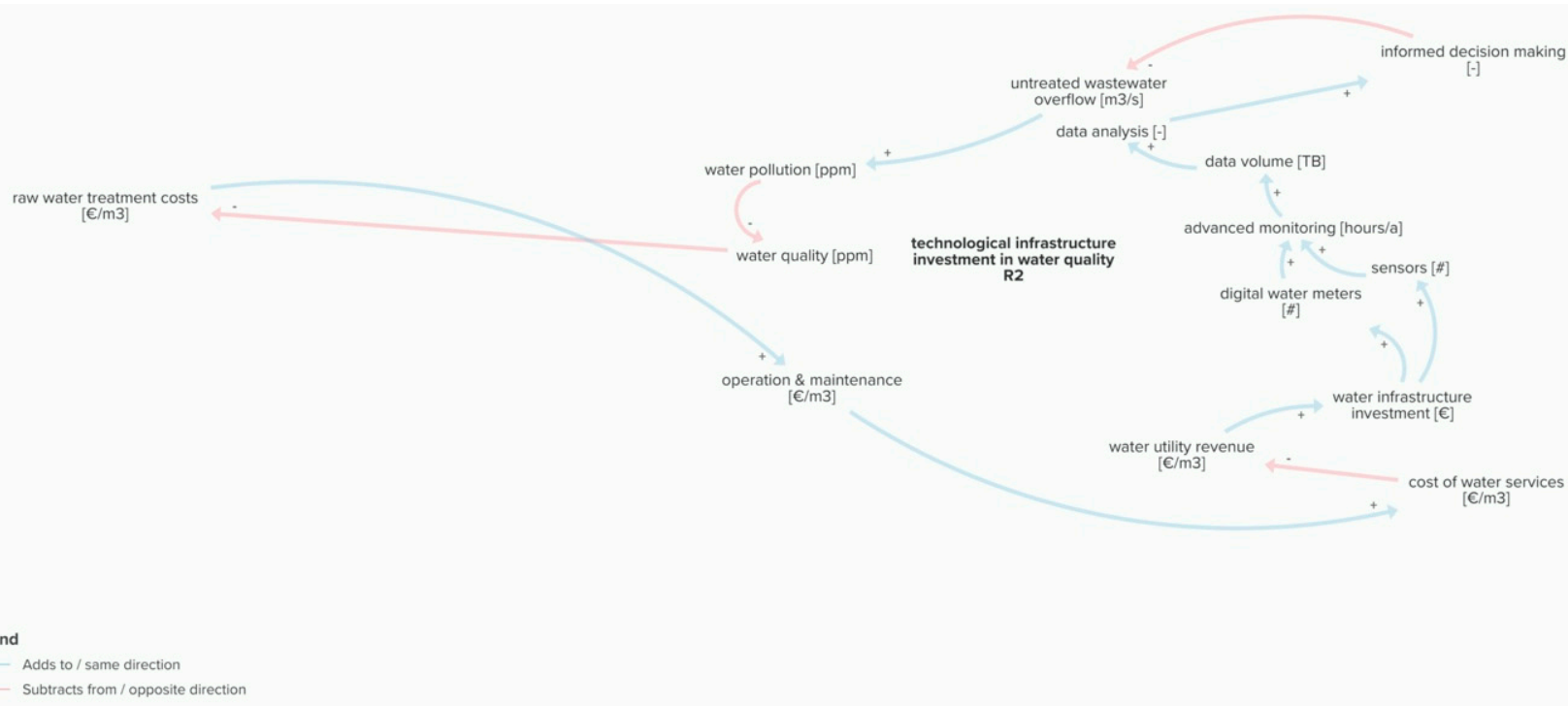

Figure 23. Synthesis of causal relations describing the technological infrastructure investment in water quality reinforcing loop.

Early detection of water leakages creates a reinforcing loop that feeds back into digitalization, as exhibited in Figure 24. Investment in digitalization leads to cost savings from less non-revenue water production and operation and maintenance costs that support reinvestment. 


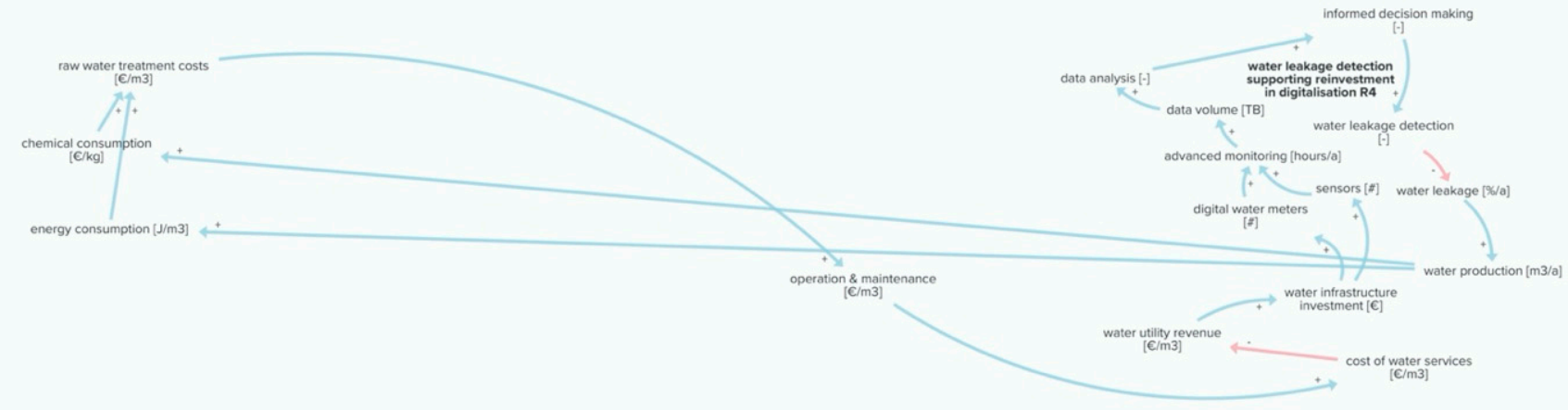

Legend

Adds to / same direction

Subtracts from / opposite direction

Figure 24. Synthesis of causal relations describing the water leakage detection supporting reinvestment in digitalization reinforcing loop.

\subsection{Cost of Digitalization Loop}

Investing in a digitalized infrastructure has so far shown to create reinforcing loops that yield a return on investment by aggregating cost savings through operational efficiencies. However, there are costs regarding cybersecurity, data storage and maintenance associated with digitalization that must be factored into the cost of water services as shown in Figure 25. This gives rise to balancing and reinforcing loops of competing strengths that, without quantification, the dominant behavior cannot be identified. Hence, digitalization can be understood to render eco-efficiencies, but to what degree is highly dependent on the financing conditions (e.g., interest rates), how the technology is exploited regarding what gains it produces, and the maturity and cost of the technology used, etc.

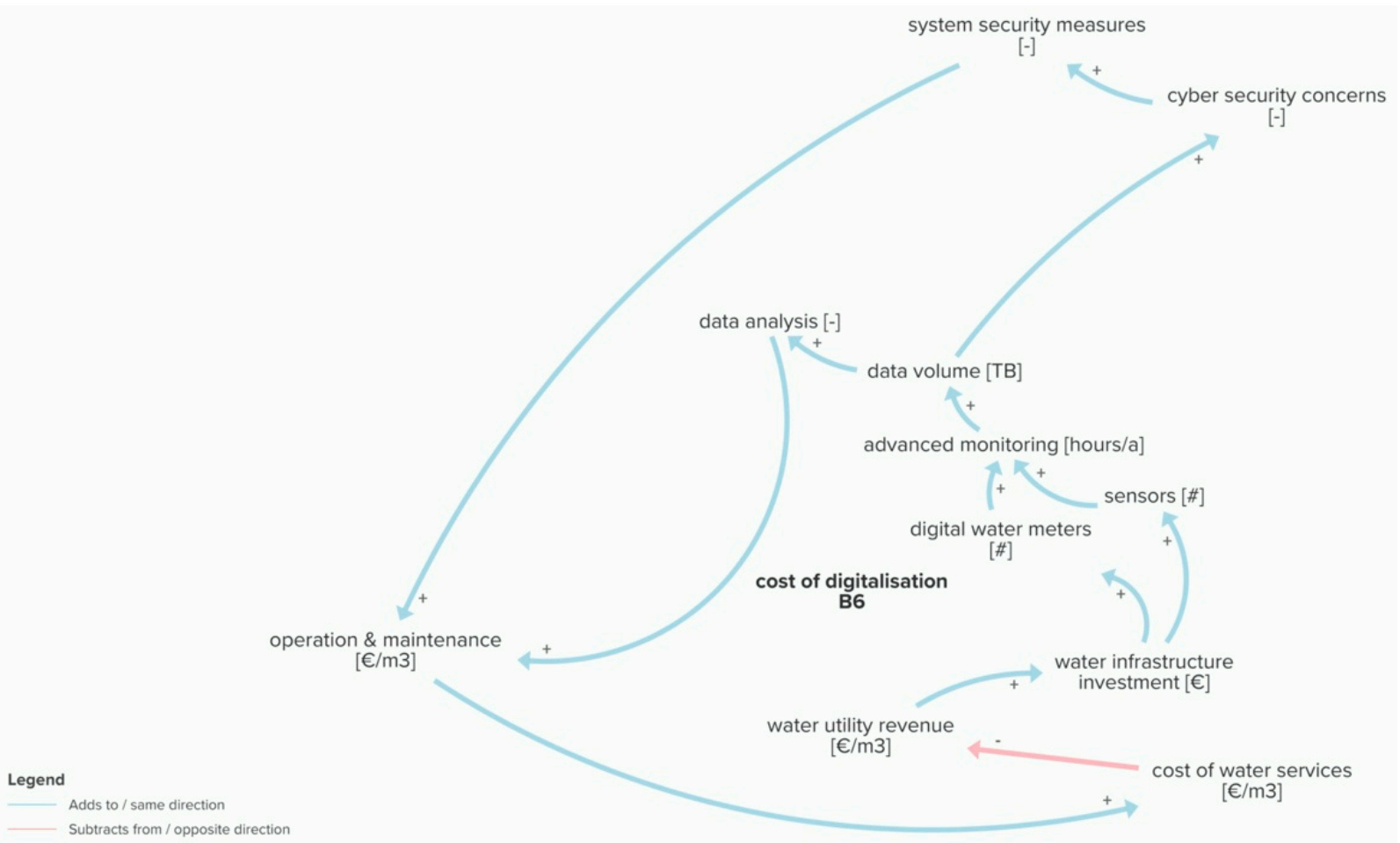

Figure 25. Synthesis of causal relations describing the cost of the digitalization loop. 


\section{Discussion}

The road to a circular water economy can take on many forms. Crucially, it can offer alternatives to freshwater sources, protecting our water sources from rising perils whilst forming new streams of revenue [43]. The water industry is grappling with the practical application of circular economic practices in part because it is still somewhat a theoretical construct, which requires more concrete guidelines and measurability for mobilization. With an already ailing business model, WUs stand to benefit from WWTPs reinventing their role from waste removers to bio-factories, consultants, research partners, energy providers and infrastructure service providers inter alia. For water suppliers, the binary system of dirty water in and clean water out is more nuanced, with multiple incoming water sources of different quality levels matching the customers' prescribed purpose. For this to happen, a paradigm shift is necessary and political will is imperative for $\mathrm{CE}$ to start to take root and have lasting implications. Despite gainful steps having already been made legislatively, for example, with the Water Reuse Regulation as part of the CE Action Plan, significantly more needs to be done, e.g., setting quality standards of recovered resources destined for different sectors [43].

Digital water, water reuse, and resource recovery are the tools foundational to creating sustainable integrated water management that incorporates $\mathrm{CE}$, although each is accompanied by its own set of barriers $[43,44]$. Most noticeable and common to all three is the lack of financial resources available for WUs, along with legislation, which has a pivotal role in supporting a coherent framework and fostering their uptake. Specific to nutrient recovery and water reuse, limited awareness of potential benefits among stakeholders; public perception; health concerns; and marketability challenges are causing sluggish wider uptake in the EU.

Different from the other areas where legislation has been lacking, legislative provision has been made for the pricing of water on the EU-level, calling for member states to recover costs, reflect resource costs and environmental externalities in the water price. However, failure to execute it on the national level appears to be the underlying cause of the undervaluing of water, where unclarity lies with how to value externalities. The EEA [35] drafted a blueprint for pricing systems to reflect local or regional circumstances for WUs to follow, suggesting that:

- A substantial part of the water bill be variable (charged per cubic meter);

- Volumetric or increasing block (banded system) rates be used;

- Rates are high enough to enable water service suppliers to invest in (efficient and environmentally sound) improvements, innovation and expansion;

- Affordability be addressed by separate, social measures, and not by interventions reducing water price incentives (such as reduced VAT rates);

- Regional variations in water-scarcity and other relevant conditions are to be reflected in water prices;

- Different water users are treated on an equal footing;

- Differences in water prices are related to differences in water-use characteristics and not to the sector in question.

The volumetric redesigned rising block tariff suggested (Figure 15) aligns with the EEA's proposal, which relies on studies indicating that volumetric variable pricing mechanisms are most effective at maximizing water-use efficiency in urban areas [45]. With flat rates still widespread in the EU, the adoption of a volumetric tariff structure will bring meaningful change to consumer behavior across all sectors. A model of the rising block tariff without circular practices revealed that although higher more expensive consumption blocks reduce the water price for lower blocks, enhancing economic stability for WUs and affordability for consumers, an adverse effect over time is that demand elasticity causes some consumers to drop to lower blocks leading to revenue shortfall [46]. This makes a case for debt financing; reinforcing the need for alternative revenue streams from $\mathrm{CE}$ and external finance sources. Larger price differentials between consumption blocks were seen to lead to greater revenue reduction [46]. 
A more extreme tariff structure that is not only volume-based but also based on water quality discharged was suggested in order to taper heavy point source pollution and over time improve water quality and costs for WWTPs. It is also the belief of the authors that this would do well to not only disincentivize pollution but also more closely capture associated treatment costs. This, however, requires high-resolution data to provide water quality parameters at the building level as opposed to the district level and will take longer for WUs to attain because of the sophisticated technological efforts required not yet commonly used. Going one step further into the future, the authors propose basing water charges on yielded productivity (i.e., economic output per cubic meter of water), which would undoubtedly bring reform to the pricing system. In Flanders, drinking water costs $\left(€ 2.10 / \mathrm{m}^{3}\right)$ less than WW $\left(€ 2.40 / \mathrm{m}^{3}\right)$. Under this proposed tariff system, the converse would be true, where water consumed would theoretically have the greatest charge attached to it, compared with gray water, which would be the cheapest, as shown in Figure 26. This is because water consumed and not returned to the system will not provide added value downstream. In contrast with WW, graywater is greater in volume relative to blackwater and less polluted making it easier to treat for reuse and gain revenue from; hence it would create a greater economic output. Moreover, it has a higher energy potential given that it has higher excess heat to be recovered closest to the source. Therefore, it has a relatively lower cost to income ratio that justifies its lesser charge. Blackwater, on the other hand, would need to cost more to treat per cubic meter than graywater due to its high pollution concentration. Although it has a high potential for biogas production and nutrient recovery, biogas production requires a reactor to be heated to 37 degrees Celsius, which reduces its energy yield potential; and recovered struvite has an unattractively low market value of $€ 50 /$ ton. Taking this into consideration, the cost to income ratio is distinguishably higher in blackwater than gray water. Granted, this tariff system calls for advanced stages in CE to be reached first with standardized, streamlined processes and well-defined loops in order for WUs to calculate the typical productivity of gray water destined for a particular use, such as cooling blood banks. The productivity-based tariff system charges water according to its utility while crucially incentivizing consumption of reclaimed water provided that reused water would become cheaper than freshwater. Maximizing the utility of water has the potential to create a medium profit potential [47].

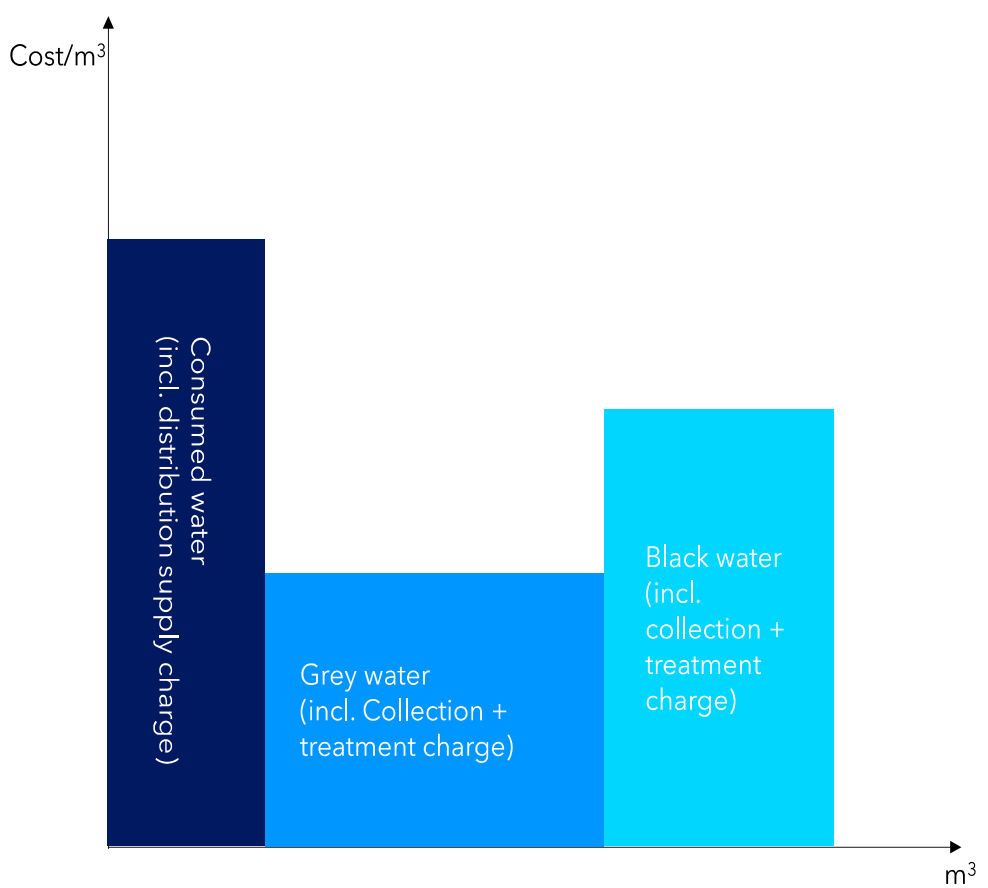

Figure 26. Productivity-based water billing illustrative concept. 
Considering the overall system behavior, the most influential variables introduced to the CWE model can be reduced to those shown in Figure 27. These variables offer either operational cost savings or new income streams, creating a more robust business model with diversified income, efficient resource processes and resource productivity of recovered and reused resources $[44,48]$. Sewage management constitutes a significant portion of WW treatment costs that can be reduced by new WW treatment methods, such as nutrient recovery, because they reduce the sewage quantity as a whole and improve the quality [44]. For a utility whose asset costs can spiral out of control over decades and struggle to generate sustainable revenue, this provides an attractive alternative to business as usual. Water and sewage companies should verify their existing business models in order to carry out activities that increasingly align with the circular model [44].

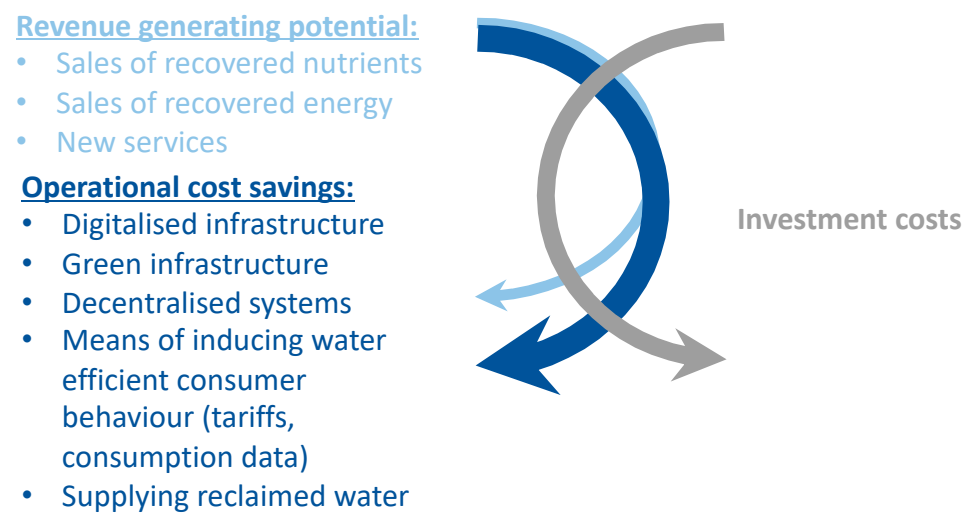

Figure 27. Highly aggregated system effects of the circular water economy model.

On the opposite side are investment costs, a black-box, an unknown deciding factor in the system behavior with respect to its magnitude when stacked against the cash flows attributed to cost savings and new revenue streams over time. The economic viability of a project is context-specific, with the financing source conditions and self-financing ratio being influencing factors. It was proposed that governments divert water subsidies towards financially supporting WUs in their transition, but only when full cost recovery for WUs is ensured through more cost-reflective pricing. Full cost recovery by definition should include water service costs as well as the cost of externalities as integral parts of the water price rather than the latter being accounted for as taxes. This will ensure a direct form of revenue for the total costs incurred by WUs. Governmental support could be in the form of innovation technology subsidies, green bonds or loans with attractive rates [39]. Meanwhile, the European Commission has called upon member states to encourage private sector investment in resource-efficiency [9]. Whether this is sufficient to drum up more investment opportunities and create more public-private partnerships, for financing water infrastructure is unclear especially given that the investment climate still needs to be made attractive for investors. Key requirements for this are the price of water, legislation and return on investment.

WUs are generally not in the position to finance basic technology, such as sensors and smart meters, to begin taking the necessary steps towards digital water; therefore, it is reasonable to conclude that the total cost of ownership for digital water poses a great financial hurdle for WUs [44]. To shed some light on costs, in Spain in order to meet the required quality standards defined in legislation, the upfront investment on water reuse can vary widely between extremes of $5 € / \mathrm{m}^{3}$ produced/day for basic filtration to $736 € / \mathrm{m}^{3}$ produced/day for the advanced chemical treatment suitable for potable reuse. Operational and maintenance costs may vary from $0.04 € / \mathrm{m}^{3}$ to $0.45 € / \mathrm{m}^{3}$ produced/day [49], $1-13 \%$ of the average water price in Europe. There is a sizable gap required for financing at this cost rate, and water reuse remains an unattractive costly option with low returns on investment when the price of water remains low and the abstraction of freshwater 
resources is more cost-effective. Cyprus handled this by subsiding water reuse tariffs by $33-40 \%$ of freshwater rates to gain water reuse acceptance [49]. It is unclear whether this is short-term or long-term; however, this method of incentivizing water reuse does little to address the fundamental issue of the true value of water that has the power to change societies' perceptions on how it is used.

Politicians have a duty to address such loopholes. Environmental legislation can be a key driver to accelerate the recycling and recovery of resources where the additional associated costs are against it [50]. Whenever the costs to the economy for collecting and reprocessing a product, component or material, are lower than the linear alternative (including the avoidance of end-of-life treatment costs), circular systems can be economical [51].

WUs are also not powerless to initiating change in the way they choose to invest. Instead of more of the same capital-intensive investments, they can respond by investing strategically by tending to low-hanging fruits, prioritizing and diversifying their investments that result in operational efficiencies and cost savings. Moreover, paying attention to the growing trends of sustainable investment lenders. In addition, by joining forces with academia in research projects, the results could be used to support an investment proposal and reap the rewards. The mobilization of a blended package of funds sets a solid base for meeting financing needs.

A shift to decentralized systems and green nature-based infrastructure can improve water quality and reduce centralized water treatment costs, thus reduce O\&M maintenance costs. Predictive maintenance, made possible by digitalization, should make up an increasingly bigger portion of the O\&M budget as this requires large resources to set up and maintain; however, in the long run, it should reduce infrastructure maintenance costs. Optimization through leveraging big data, automation, and remote sensing; improved performance and efficiency have medium profit potential [47]. It is the belief of the authors that existing and new WUs should be managed differently. For new utilities, CE should be considered at the onset in the design of plant processes and infrastructurally; with the creation of a smart water grid; where newly built neighborhoods, districts and point source polluters deploy decentralized systems with source separation on the building level for gray and blackwater collection; and hybrid gray, green and blue infrastructure.

With the endless possibilities of digitalization and data management being the springboard for innovative solutions, digital water is best capitalized on when used first to optimize and improve daily operations (e.g., leakage detection) and second, as an add on to broaden areas of activity (e.g., valorize information data services). It can be used to reach greater heights in operational efficiencies providing returns on investment that foster further deployment. The upfront and operational costs are expected to be substantial, but through increased system performance, they can be recouped. Not all technologies will reduce costs, many may improve performance, and some may over time bring change [47]. It is also reasonable to expect that the learning curve will have a decreasing effect on the operational costs over time. Although the concept of how to monetize data are still in some respects vague, monetizing data are set to incentivize uptake.

With the water industry being highly fragmented, digitalization offers opportunities for interoperability and a higher degree of collaboration, which will certainly be needed for setting up cybersecurity defenses. Such is the case in the Nordic Water Association, where their success in finding smart water solutions has come off the back of close collaboration with technology vendors, manufacturers, software companies and academia, inter alia. Dutch water authorities meet together weekly. These WUs have experienced the value in creating links to bridge the gap between knowledge and practice and create valuable exchanges. As more advanced water industries, these should be viewed as models to learn from and adopt. Another lesson to be learned from the Nordics is their willingness to share data, making it open-source for software developers to use, find meaning from and spark innovation to create value out of smart solutions. Therefore, the collaboration also entails WUs being willing to be transparent and open to data sharing. 
A key part of Article 14 in the Water Framework Directive requires all member states to genuinely engage with the people who live, work and play in a catchment area. Therefore, it is critical that local communities are involved in the management and decisionmaking related to protecting and, where necessary, improving their water resources. An expert stated that WUs need to refrain from letting water treatment be a black-box and communicate openly with citizens regarding how and why treatment is done the way it is. In Italy, at the Milano Nosedo WWTP, they have open days to present their activities to the general public and to farmers in order to encourage acceptance [49]. It was a governmentled ad campaign that helped Singapore overcome community concerns over effectively "drinking toilet water" when implementing a direct potable water reuse scheme. Smart water is a holistic approach not achievable single-handedly or in one go. A stepwise roadmap to tackle the different aspects is recommendable. Important to note is that there is no "one-size fits all" approach as the feasibility, impacts and economics can only be assessed on a case-by-case basis [43]. This study offers just one route out of many options that are viable for specific contexts.

Summing up, CE in the water industry is anchored in digitalization, water reuse and resource recovery bringing resource efficiency and productivity to the business processes of WUs in the quest for water security while in turn enabling resource security and energy sufficiency. Many possible paths can lead to the utopic state of closed water, energy and nutrient loops, but this is not without cost and collaboration. WUs need to view their role in society as more than water service providers but also through a multidimensional lens. The potential to cultivate a water-wise and water-conscious community can be made possible through new cost reflective water tariffs bringing awareness to consumers about their consumption; engaging with the public about the value of water reuse, and educating the public about storm drains needing to be kept free from anything other than water. Without strong political will and leadership, $\mathrm{CE}$ will suffer setbacks because regulatory policies have the power to accelerate the transition. Whether or not utilities have the appetite for this paradigm shift and be ahead of the curve in anticipation of the evolving legislative and regulatory environment is yet to be seen.

\section{Conclusions}

This study explored the economic and operational system effects of a CE on WUs. Based on interviews with water industry experts, case studies, conference proceedings and literature, it was found that three core tools that engender circularity are digitalization, water reuse and resource recovery. It was found out that they have the potential to yield lower operational costs through network efficiencies and boost revenue generation through new service offerings and cascading of reused water and secondary resource products.

By qualitatively modeling an economic view of the urban water system, a circular water economy system was subsequently modeled, to which amendments were made to incorporate forms of digital water, water reuse and nutrient recovery. It was determined that the non-cost reflective price of water is crucial to solving the current issues of partial cost recovery that WUs experience, in addition to ushering in the successful implementation of circular practices. A redesigned rising block volumetric tariff structure incorporated into the circular model has the potential to induce water-efficient consumer behavior that lowers operational costs. Digital water is seen to be particularly helpful in transferring water network data into knowledge for informed decision-making that supports predictive maintenance and avoidance of combined sewer overflows. Reclaimed water, as an alternative water supply, eases pressure on freshwater resources resulting in lower operational costs. In contrast, resource recovery has the potential for generating multiple revenue streams when sewage contents are treated and sold to receiving markets. Underpinning all three is the need for investment funding and an enabling cohesive legal framework to smooth out impediments and catalyze circular activities. Aging infrastructure places an increasingly heavy financial burden on WUs and slows down the adoption of new 
technology. Diversified investments in a less-capital intensive hybrid infrastructure of centralized and decentralized systems and more nature-based solutions reduce this burden.

The findings of this study reveal that CE is a means by which WUs can maintain water security through reduced water consumption and protection of water quality. It sheds light on water pricing policy and advocates for the need for full cost-recovery that accounts for environmental externalities and resource costs that send positive signals to investors, maintains a sustainable business for WUs and frees WUs from financial incapacitation that hinders them from self-financing new investments for CE. Looking into the future, it proposes a water tariff structure based on the productivity water yields in a loop, appropriate for more advanced stages of circularity. In an upcoming paper, the authors will present a circular business model for WUs and discuss the intended and unintended consequences of circular water on people, the planet and prosperity.

Author Contributions: T.M.M.: conceptualization, methodology, data collection, formal analysis, writing-original draft and visualization. C.G.: conceptualization, data contribution, supervision, writing - review and editing. All authors have read and agreed to the published version of the manuscript.

Funding: This research received no external funding.

Data Availability Statement: All relevant data are within the manuscript.

Acknowledgments: The authors would like to thank the stakeholders who participated in the interviews for their beneficial input, which made this study possible.

Conflicts of Interest: The authors declare no conflict of interest.

\section{Appendix A}

\begin{tabular}{|c|c|}
\hline Node & Description \\
\hline $\begin{array}{l}\text { ability to communicate to society the perceived benefits of } \\
\text { water reuse (-) }\end{array}$ & $\begin{array}{l}\text { the effectiveness of the level of communication used to convey } \\
\text { to society the benefits of water reuse }\end{array}$ \\
\hline actual cost recovery $(\%)$ & the portion of costs covered by revenues \\
\hline advanced monitoring (-) & digital means of monitoring network state and water \\
\hline agricultural farming $\left(\mathrm{km}^{2}\right)$ & area of land dedicated to agricultural farming practices \\
\hline agricultural water consumption $\left(\mathrm{m}^{3} / \mathrm{a}\right)$ & the volume of water consumed by agricultural farmers per year \\
\hline amortization $(€ / a)$ & $\begin{array}{l}\text { the capital expenses associated with investments over their } \\
\text { useful life }\end{array}$ \\
\hline average relative age of water infrastructure (years) & $\begin{array}{l}\text { the average year's infrastructure is in operation in a } \\
\text { particular year }\end{array}$ \\
\hline awareness of the need for water security (-) & the level of public perception for the need for water security \\
\hline bankable demonstration projects (\#) & number of projects that have demonstrated bankability \\
\hline $\operatorname{biogas}\left(\mathrm{m}^{3} / \mathrm{a}\right)$ & $\begin{array}{l}\text { the volume of biogas produced per year from anaerobic } \\
\text { digestion of sludge }\end{array}$ \\
\hline bioplastics production $(\mathrm{t} / \mathrm{a})$ & $\begin{array}{l}\text { the mass of bioplastics produced from the treatment of } \\
\text { wastewater effluent }\end{array}$ \\
\hline built-up area $\left(\mathrm{km}^{2}\right)$ & area of the built-up environment \\
\hline chemical consumption $(€ / \mathrm{kg})$ & $\begin{array}{l}\text { cost per weight of chemicals used for raw or } \\
\text { wastewater treatment }\end{array}$ \\
\hline consumption awareness (-) & $\begin{array}{l}\text { the level of awareness consumers have of their consumption } \\
\text { levels and over time patterns }\end{array}$ \\
\hline cost of water services $\left(€ / \mathrm{m}^{3}\right)$ & $\begin{array}{l}\text { costs incurred per volume of water for providing water services } \\
\text { to consumers }\end{array}$ \\
\hline cost recovery discrepancy (missing money) (-) & $\begin{array}{l}\text { the difference between full cost recovery and the actual level of } \\
\text { cost recovery of water utilities }\end{array}$ \\
\hline customer affordability (\%) & $\begin{array}{l}\text { affordability of consumers measured as a percentage of national } \\
\text { income average }\end{array}$ \\
\hline
\end{tabular}




\begin{tabular}{|c|c|}
\hline cybersecurity concerns (-) & $\begin{array}{l}\text { data protection concerns when storing, sharing and utilizing } \\
\text { real-time data from critical infrastructure }\end{array}$ \\
\hline data analysis (-) & $\begin{array}{l}\text { converting collected and stored data into information and } \\
\text { knowledge }\end{array}$ \\
\hline data volume $(\mathrm{TB})$ & the volume of stored data collected from the water network \\
\hline decentralized water treatment systems (\#) & the number of deployed decentralized treatment systems \\
\hline digital consumption data services (-) & $\begin{array}{l}\text { the service offered to consumers by water utilities displaying } \\
\text { their current and past monthly consumption levels digitally }\end{array}$ \\
\hline digital water meters (\#) & the number of deployed smart water meters \\
\hline the discrepancy between true and actual water price $\left(€ / \mathrm{m}^{3}\right)$ & $\begin{array}{l}\text { the difference between the true value of water and the water } \\
\text { tariffs passes on to consumers }\end{array}$ \\
\hline domestic water consumption $\left(\mathrm{m}^{3} / \mathrm{a}\right)$ & the annual volume of water consumed in the residential sector \\
\hline drought period (days/a) & drought frequency in the number of days per year \\
\hline early pump failure detection (-) & the prediction of pump failure through digital means \\
\hline the economic development of utility $(\% / a)$ & percentage change per year of net profit \\
\hline the efficiency of water usage $(\%)$ & $\begin{array}{l}\text { the percentage of water saved compared to the previous month } \\
\text { and/or the same month of the previous year }\end{array}$ \\
\hline enabling legal framework (-) & $\begin{array}{l}\text { the existence of established coherent legislation and } \\
\text { accompanying regulation on the EU-level }\end{array}$ \\
\hline energy consumption $\left(\mathrm{J} / \mathrm{m}^{3}\right)$ & $\begin{array}{l}\text { energy consumed per volume of water produced in process } \\
\text { treatments and distribution }\end{array}$ \\
\hline eutrophication $(\mu \mathrm{g} / \mathrm{L})$ & $\begin{array}{l}\text { water pollution often induced by the discharge of nitrate or } \\
\text { phosphate-containing detergents, fertilizers, or sewage into an } \\
\text { aquatic system causing excessive enrichment; resulting in } \\
\text { excessive growth of algae and oxygen depletion in water }\end{array}$ \\
\hline financial rate of return $(\%)$ & $\begin{array}{c}\text { the net gain or loss on the investment made by water utilities as } \\
\text { a percentage of the investment's initial cost }\end{array}$ \\
\hline flood frequency $(\# / a)$ & flood frequency in the number of times per year \\
\hline food production (t/a) & the amount of food produced from crops grown \\
\hline freshwater resources (MCUM) & $\begin{array}{l}\text { the combined volume of freshwater resources in water bodies in } \\
\text { millions of cubic meters }\end{array}$ \\
\hline full cost recovery $(\%)$ & $\begin{array}{l}\text { when the revenue generated covers } 100 \% \text { or more of water } \\
\text { utilities' expenses }\end{array}$ \\
\hline green capital funding allocation $(\mathrm{m} €$ ) & $\begin{array}{l}\text { the portion of government budget allocated to issuing green } \\
\text { bonds to eligible projects }\end{array}$ \\
\hline greenhouse gas emissions $\left(\mathrm{CO}_{2} \mathrm{eq} / \mathrm{m}^{3}\right)$ & C02 eq. per volume of water produced \\
\hline green investment attractiveness (-) & $\begin{array}{l}\text { the degree to which the water industry exhibits investment } \\
\text { potential for green investors }\end{array}$ \\
\hline green nature-based infrastructure $\left(\mathrm{km}^{2}\right)$ & $\begin{array}{l}\text { the area of land dedicated to different types of green } \\
\text { infrastructure }\end{array}$ \\
\hline heat recovery $(\mathrm{MJ} / \mathrm{a})$ & $\begin{array}{l}\text { the amount of thermal energy recovered a year for a secondary } \\
\text { use }\end{array}$ \\
\hline incineration $(\mathrm{t} / \mathrm{a})$ & $\begin{array}{l}\text { the amount of waste from wastewater treatment plant sent to } \\
\text { the incineration for final disposal }\end{array}$ \\
\hline industrial water consumption $\left(\mathrm{m}^{3} / \mathrm{a}\right)$ & annual volume consumed in the industrial sector \\
\hline information (-) & $\begin{array}{l}\text { the amount of information shared with the public for } \\
\text { educational purposes }\end{array}$ \\
\hline informed decision-making (-) & $\begin{array}{l}\text { the number of decisions that can be taken based on analyzed } \\
\text { data that is converted into actionable information that enables } \\
\text { decisive decision-making }\end{array}$ \\
\hline Infrastructure investment payback period (y) & the time taken to recover the cost of investment \\
\hline infrastructure maintenance (days/a) & time dedicated to infrastructure maintenance measured in days \\
\hline
\end{tabular}


infrastructure resilience (-)

infrastructure resilience investment $(€)$

investment attractiveness (-)

landfill (t/a)

legislation obliging rainwater separation (-)

local municipal/government budget (m€/a)

manual overflow monitoring (\#/month)

market demand for water solutions providers (-)

national income average $(€ / a)$

new services (-)

nutrient recovery $(\mathrm{t} / \mathrm{a})$

operation and maintenance $\left(€ / \mathrm{m}^{3}\right)$

organic soil conditioner $(\mathrm{t} / \mathrm{a})$

phosphate $(\mathrm{t} / \mathrm{a})$

population growth $(\% / a)$

predictive maintenance (-)

rainwater harvesting $\left(\mathrm{m}^{3}\right)$

raw water treatment costs $\left(€ / \mathrm{m}^{3}\right)$

reclaimed water $\left(\mathrm{m}^{3}\right)$

redesigned tariff structure (-)

resource conservation (-)

revenue-generating potential (-)

risk of urban drainage flooding (-)

$$
\text { sensors (\#) }
$$

shared infrastructure maintenance services (-)

$$
\text { sludge }(\mathrm{t} / \mathrm{a})
$$

social acceptance of water reuse (-)

speed of runoff $(\mathrm{m} / \mathrm{s})$

stormwater overflow $\left(\mathrm{m}^{3} / \mathrm{s}\right)$

system security measures (-)

taxes $(\%)$ the ability of the water infrastructure to maintain a level of service reliability despite any shocks

the level of investment that goes into fortifying the water infrastructure against external shocks

the degree to which the water industry exhibits investment potential for investors

the annual amount of waste wastewater utilities send to landfills

the enforcement of the collection of rainwater by law from all households

the total annual budget government budget conventional monitoring of system overflows

a market created as a result of water solutions that are required but are not fulfilled by water utilities

The median household income per annum extended service offerings as a result of CE

the amount of phosphate recovered from wastewater per year cost per volume of water produced attributed to operation and maintenance

amount of bio-waste from sludge converted into soil conditioner for agricultural farmers

the amount of phosphorus compounds extracted from sludge

the percentage increase of city dwellers per annum

techniques applied to determine when maintenance should occur; enabled by technology that monitors the state of in-service equipment

the volume of rainwater accumulated from rooftops and stored for reuse onsite for sanitation rather than allowing it to run off

the cost of treating abstracted water per unit volume

the volume of wastewater that is reused for the same or another purpose

reconfiguration of the conventional flat or volume-based tariff structure

the preservation of the quantity and quality of water resources the ability to create value

the likelihood of flooding due to poor/insufficient urban drainage system

the number of sensors deployed in the water network

sharing water infrastructure as a service offering to another unrelated field where maintenance is outsourced to water utilities

the annual amount of residual, semi-solid material that is produced as a byproduct during sewage treatment of municipal wastewater

level of public support for water reuse

The speed of the flow of excess water (i.e., more than the land can absorb) across the surface of the land

the flow of excess water directly attributed to rain from extreme weather

measures in place to reinforce data security, limit the risk of a cyberattack and shield from the impacts of an attack

taxes received by water utilitiesincome taxes that utilities pay 
transparency of water utilities' circular economic practices (-)

treated biosolid waste $(\mathrm{t} / \mathrm{a})$

treated effluent discharge $\left(\mathrm{m}^{3} / \mathrm{a}\right)$

treated sludge $(\mathrm{t} / \mathrm{a})$

the true value of water $\left(€ / \mathrm{m}^{3}\right)$

untreated wastewater overflow $\left(\mathrm{m}^{3} / \mathrm{s}\right)$

urbanization $(\% / \mathrm{a})$

urban runoff $(\mathrm{L} / \mathrm{s})$

wastewater $\left(\mathrm{m}^{3} / \mathrm{a}\right)$

wastewater treatment $\left(\mathrm{m}^{3} / \mathrm{a}\right)$

wastewater treatment costs $\left(€ / \mathrm{m}^{3}\right)$

water and sanitation subsidies $(\mathrm{m} € / \mathrm{a})$

water consumption $\left(\mathrm{m}^{3} / \mathrm{a}\right)$

water consumption per capita $\left(\mathrm{m}^{3} / \mathrm{cap} / \mathrm{a}\right)$

water infrastructure investment $(€)$

water leakage $(\% / a)$

water leakage detection (-)

water management consulting (-)

water pollution (ppm)

water price $\left(€ / \mathrm{m}^{3}\right)$

water production $\left(\mathrm{m}^{3} / \mathrm{a}\right)$

water productivity $\left(€ / \mathrm{m}^{3}\right)$

water quality (ppm)

water-saving devices (\#)

water services charged to consumers $\left(€ / \mathrm{m}^{3}\right)$

water tariff increase resistance (-)

water utility revenue $\left(€ / \mathrm{m}^{3}\right)$

winter greenhouse energy consumption $(\mathrm{kJ} / \mathrm{a})$ how much water utilities are willing to show, open up about and inform the public of their practices regarding CE and the outcomes

the amount of organic solid waste that results from treated sewage per year

the amount of the liquid part of treated sewage discharged per year

the annual amount of sewage sludge from wastewater that is treated per year

the price of water reflective of involved externalities and resources costs

the flow of excess wastewater due to flooding

percentage change in the number of citizens moving to urban areas per year

The flow of excess water (i.e., more than the urban drainage system can absorb) across the urban surface

the volume of wastewater that needs to be treated per year

the volume of wastewater treated per year in a wastewater treatment plant

the cost of collecting, treating and disposing of wastewater

(including any additional process steps for extraction of suspended contents)

the number of government funds targeted at supporting water utilities' operations expenditures as a result of the difference

between the revenue generated and expenses incurred

the total volume of water consumed per year

the volume of water consumed per person per year

the amount of money spent on investing in water infrastructure

percentage per year of water supplied that is lost in the distribution before reaching consumers

the ability to locate water leakages along the water network service offered by water utilities to other sectors looking to implement sustainable water management

number of contaminants present in water resources in parts per million

the price of water in the form of water tariffs, taxes or transfers

the total volume of water abstracted, treated and supplied to consumers per year (including water lost)

measures the amount of economic output produced (euros or PPS purchasing power standard) per unit of water abstracted

$\left(\mathrm{m}^{3}\right)$ and provides some indication of how efficiently water resources are used.

the measure of the condition of water relative to the requirements of any human need or purpose

the number of water-saving devices sold by water utilities to be installed in consumer households

the price of water services passed on to consumers per unit volume of water (different from the cost of water services) the level of opposition to the increase of water tariffs from water stakeholders

net profit per unit volume of water supply and wastewater utilities

the annual energy consumption of winter greenhouses 


\section{Appendix B}

\section{Appendix B.1. Barriers to Circular Economy in Water}

On a systemic level, 4 out of 5 respondents refer to the legislation as a barrier for reasons of being outdated and not encouraging of CE. Nutrient recycling is made difficult in those countries requiring permits and, in some cases, illegal. This legal status of waste hinders reclaimed water or recovered phosphate fertilizers from entering the food industry. Health and safety risks, as well as fluctuating fertilizer quality that naturally cannot always be guaranteed, are other barriers that hamper social and market acceptances, respectively. In San Francisco, California, WW is treated to drinking quality water standards-potable use. However, rather than returning the treated drinkable water directly to the system for consumers, it is injected into the ground to recharge aquifers. The water is then pumped out eight to 16 kilometers away to be used again for drinking water-indirect potable use. It was remarked that this highlights the challenge faced regarding the strong psychological effect in society against direct recycling of water.

On the WU level, expensive technology, such as online meters (e.g., E. coli, N2O probes), which some WUs simply cannot afford, remains a significant hurdle. Moreover, a high-level of IT readiness and capability for handling big data increases overheads for organizations that "are by definition low-income generators". Although all the benefits of smart meters are known, not many of them help the business case. Therein lies the challenge for smart meters despite being on the market for the last 10-15 years.

The Belgian utility cautioned that it is important for WUs to find an equilibrium in prioritizing their investments. Namely between large-scale infrastructure and decentralized systems, whether it be on the city or district level, because this ensures that the massive 50-year investment made in centralized infrastructure does not become redundant as a result of a complete shift to decentralized systems.

The WU solutions expert plainly framed the problem: "we currently do not see a technically listed solution to be adopted. CE is a concept, but we do not see what it translates into for companies to adopt, and model and it be compatible".

\section{Appendix B.2. The Price of Water}

There is a common understanding that the price of water is not reflective of the true cost of externalities, and in the impending era of $\mathrm{CE}$, the cost of closing the loop will need to be socialized. In addition, 4 out of 5 respondents have a shared understanding of the need to redesigned tariff structures, i.e., alternative billing. However, when it comes to whether the price of water should be raised, there is less agreement. It was expressed by two interviewees that as a basic good, it is necessary to keep tariffs low as it is the job of WUs to provide it to all of society and thus maintain affordability. Applying a penalty for excessive use was supported as a solution for the industrial sector as opposed to the residential sector. Another opponent preferred fluctuating water prices for all sectors based on seasonal availability; therefore, in periods of drought, the tariffs would be higher.

Although commonplace in the power sector, currently, time-based tariffs in the water sector are a "thinking experiment", according to the Belgian utility, that would encourage rational use and water reuse on the part of the industry, saving them money on the discharge and fresh drinking water intake. Another suggestion for exploring alternative ways to charge for water is to factor in the associated costs into the tariff cost structure using a rising block banded system that ensures that water remains affordable but at the same time disincentivizes irresponsible usage. This would mean that there is an affordable charge for basic water services, and if end users exceed this basic level of water consumption, the cost increases considerably, and then disproportionately if that band is further exceeded in order to encourage thoughtful water use.

The Belgian utility respondent is a supporter of a self-proclaimed "extreme method" that would be to not only base charges on the quantity consumed on the supply side, but also on the quality discharged on the collection side similar to a polluter pays principle, but for all consumers. This would motivate hospitals and industry to improve the quality 
of water discharged even if it means they need to include an additional process step locally before discharging. Eventually, the desired effect would be that heavy polluters end up paying less as a result of the additional treatment step prior to discharge because it should cost less than the charge for heavily polluted water. Furthermore, the quality of water discharged to WWTPs would improve, making CE easier to implement and the costs of treatment less for WWTPs.

The issue of partial cost recovery from water sales revenue is a real one for a Belgianbased utility and, despite being opposed to a tariff increase, made it clear that water reuse poses a threat of decreasing revenue.

\section{Appendix B.3. Infrastructure}

4 out of 5 respondents view infrastructure is as a financial burden and also a deterrent to circularity because very large investments that depreciate over the next 30 to 50 years are supposed to be funded by water sales revenue. The implications are that large-scale utilities find themselves "stuck" with the technology and infrastructure they have for decades without the opportunity of rapidly adapting the network or directly investing in and implementing new technologies.

Decentralized systems are seen as an alternative to avoid this, although their applicability is country-dependent. For example, in Flanders, Belgium, neighborhoods, cities and villages are densely packed but highly scattered between each other; therefore, there is an existing large distribution network. If decentralized systems are looking to be deployed financially, it makes sense to install them in new builds, cities and districts. Therefore, a complete shift to decentralization will not occur, but rather decentralized systems will complement centralized treatment to form a hybrid network. Although decentralized systems are not expected to be very lucrative for WUs, they do promise a less capital-intensive outlay of investment; make it easier to shift more rapidly to new technologies because the scale of investment is smaller; and create a demand for water solutions companies to build, operate and maintain decentralized systems. The Flanders WU is carrying out a pilot on decentralized systems and expects a return on investment between $8 \%$ and $12 \%$ with a payback time of 10 to 12 years, stating that they will not get rich, but it is essential for them to demonstrate feasibility.

A case in the Netherlands exhibits a different situation. A WWTP is not yet looking to make the shift to decentralized treatment, but rather strategically deploying decentralized systems at specific point pollution sources, such as hospitals, where a decentralized water solutions company, Pharmafilter ${ }^{\circledR}$, is the owner and monitor of such systems. Here the WW is being treated before being discharged to the WWTP, and the (medicinal) waste is being recovered for reuse by Pharmafilter ${ }^{\circledR}$.

An EU Horizon 2020 project, HYDROUSA (Figure 12), is focused on local decentralized circular solutions in the Greek Islands by developing local supply chains that recover water, energy and materials that are to be valorized at the local level for the benefit of the local community. This came about because under the EU Directive 91/271/EEC; there is no requirement to develop a sewerage network for agglomerations with a population of 2000 or less. The Directive mentions that the WW in such communities should receive "adequate" treatment. However, the level of treatment and the type of technologies to be used is not specified. HYDROUSA is, therefore, taking the initiative focusing on providing low-cost, nature-based solutions, such as management of rainwater and stormwater for water-scarce decentralized areas and constructed wetlands, which require less operational costs than conventional activated sludge processes for the treatment of WW.

\section{Appendix B.4. Circular Practices}

Water reuse for irrigation is common for the interviewees directly involved in water treatment. One such case is reclaimed water, originally from desalination on island nations in the Americas, predominantly used for irrigation or is WW treated for potable use. The sewage is given to farmers, albeit for free due to legal complications, hindering nutrient 
recovery prospects. For this water-as-a-service company, efforts are geared towards biogas production on the treatment side and salt recovery on the supply side; however, the latter is exhibiting a suboptimal business case with salt being a cheap commodity and the surface area required for evaporation being substantial. In HYDROUSA, they are tasked with demonstrating bankability of all the circular economic projects they are implementing; and one such project involves nature-based desalination with the help of mangrove tree roots and the recovery of salt to be sold to the local community. It is yet to be seen whether this nature-based form of salt recovery is indeed financially viable.

Others are already involved in producing biogas and biomethane from anaerobic digestion of dewatered sludge. Unless a sizeable amount of organic matter is available, meager energy yields are sufficient for only heating the reactor for the digestion process. In the Dutch case, the biomethane cheapens WW treatment by a few cents per cubic meter, where it is injected into the gas grid and is found to be a worthwhile business case. The Flanders utility is looking to improve energy yields by integrating the food waste network with the sewage network to increase the organic content for biogas production. However, prior to that, the legal obstacle hindering the network merger must be overcome.

The Dutch WW company and the HYDROUSA project are more advanced in their circular practices. Both producing biogas for transportation. The WW company sends their sludge to a third-party company with the aim of producing phosphate fertilizer, bioplastics and treating the sludge for final disposal. Further aspirations for circularity include treating and reusing the WW effluent for recreational water bodies designated for swimming instead of discharging into the sea, and in so doing, effectively storing water for drier periods.

\section{Appendix B.5. Digitalization}

HYDROUSA is deploying many low-cost sensors to evaluate the water quality by measuring $\mathrm{pH}$, temperature and conductivity to determine the salt content of water in case any seawater has seeped into the groundwater. Additionally, they are using energy meters to determine the energy efficiency of the systems. The utility in Flanders is in the "development phase" when it comes to smart meters. At the time of writing, they were installed and prepared to be under investigation in a building complex with new families planned to move in in February 2020. Here, online data would be shared with the families, informing them of the presence of leaks and providing daily consumption data for comparison with other households in order to create awareness about their water consumption. In the Netherlands, smart water meters have been rolled out; consumers are updated regularly on their usage patterns; however, due to privacy issues, consumption data of other consumers cannot be shared. If end-users are exceeding their usual consumption levels, the utility passes on tips for conserving water. In Flanders, online flow meters are being used to monitor the network efficiency and to detect leaks using district metered areas (DMAs). With DMAs, an area is located where the incoming and outgoing flow is known, and over time if there is a significant difference between in- and outflow, this indicates leakage in that metered area. Automated online data analysis using statistics can define where the leakage is and for how long it has been there.

\section{Appendix C.}

\section{Appendix C.1. Transcript of Belgian University Professor and Water Utility Personnel}

TM: What do you see as the barriers to circular economy systemically?

P.BD: Definitely two barriers that are connected with each other, one being legislative boundaries because we are facing them in Flounders and Belgium as well. For example, if you look at the use of recovered nutrients for wastewater treatment and food production, so for agriculture, then you might have a problem because you are selling a product and that is destined for food production and but is a waste. So, there is specific legislation for it, hence you need specific permits for it, so it's not that easy. 
TM: Is there an issue of quality when we now speak of waste that is going to be a product or something that is to be sold off. Is there consistent quality whether it is fertilizer or biogas?

P.BD: So, the first point was legislative and the next is acceptance by the public and acceptance by the market. For example, for fertilizers of course the quality is not the same, it is actually worse than chemically produced chemicals because in a large chemical plant you can exactly control the process defined quality. This is not the case in a wastewater treatment plant today. So, are there problems? - Well I would say there are challenges, there are risks in terms of hygiene and risk of pathogens that have to be taken into account. And specifically, for fertilizers we see that that the current state of the art which is struvite precipitation. That struvite is not really wanted by the fertilizer market. So, you can use it in agriculture, but fertilizer companies are not willing to use that product for further processes because of the quality. Additionally, a general term of acceptance. If you look at water reuse, you also have to convince the public that it is safe. So, in the mindsets of people it is not very easy to explain that when they flush the toilet in a couple of hours, they receive the water back in the drinking water tap. Technologically speaking it is perfectly feasible, it is perfectly safe, but the wider public needs to overcome some boundaries.

T.M: And how does one overcome those boundaries with public acceptance?

P.BD: Information. I think it's crucial to inform people, therefor don't do the treatment in a blackbox. Communicate openly with citizens how and why you treat the water. Why you implement reuse. In Flounders we are facing in the last 3 years very dry summers. We are in a water scarce area, so you have to inform the public, so they see what is going on, they see that it doesn't rain for a couple weeks. We have to inform them about what is the impact of ground water research and why we need to think about wastewater reuse directly at the plants, why it is important and safe to do it and how can we guarantee that it is safe-open communication.

T.M: What are the barriers specifically for water utilities?

P.BD: That is twofold. There is a challenge, water utilities have to find an equilibrium because they invest in very large infrastructure for large scale production plants and the transportation of drinking water through large-scale networks (the centralized approach) which is definitely needed. So, there is a big investment that you make for 30-50 years. In light of that, decentralized treatment at the household or city district level is a bit conflicting because if everybody starts to use water at the decentralized level, it thus makes the centralized network and production not necessary anymore. So, finding an equilibrium in making the right choices in investments, but on the other hand it also opens up opportunities for water utilities: You can follow the technology, make it a new market, business model, in terms of quality you can join forces with technology providers to guarantee the water quality, leverage the experience in the laboratory of drinking water utilities and also to convince the general public, so that the general public has confidence in the water utilities so that they know what they do and that they know what drinking water is. So, they cooperate with other technology providers in order to can guarantee the safety of the water.

T.M: With regards to how consumers are charged for water services, what is your view on this? In in terms of price, do you feel the price is fair? Do you feel the prices needs to change? Do you feel the price reflects the value of water?

P.BD: That's not an easy question. Does it reflect the value of water? -No. That I can also very straight forward and clearly say about (drinking and tap water). If you compare the price to bottled water and if you see what is asked on the market for bottled water and you compare the price of one litre of tap water (which at least in Flounders is better controlled and examined parameters of bottled water) that is provided to homes in a good quality, at pressure (people forget this), so in terms of the service provided by utilities and also in terms of sustainability, it's much more sustainable to use tap water instead of bottled water because bottled water also includes transportation and recycling of the bottles, if there is any recycling, so compared to bottled water, tap water is still cheap. And 
people often forget to think about why it is important to rationally use tap water when it is offered at such a low price. But I am fully convinced that providing safe drinking water is one of the public tasks of the water utility. So, it has to be done at an affordable price for the complete society.

T.M: So, does this mean that you think the price of water does not necessarily have to change or increase?

P.B.D: No, not necessarily. I am convinced that we have to provide excellent drinking water quality to all of society, also to the poor or people facing financial problems, they have to gain access to safe drinking water. That is my belief and that is a United Nations' goal. So, we don't want to end up in a situation where it is all privatized. We see this already on the market that companies sell what they call an extra treatment to put on your tap then you have premium quality water. What does premium quality do? The tap is also drinkable. We don't want the rich to only have good water quality, we have to provide it to complete society then we have to control the price. That is being done at the moment in Belgium and Flounders. So, the price is limited in order to keep it affordable.

T.M.: Does the price of water have an effect on consumption? Do you think that if it was more expensive people would be more conservative with their use or is the price too low that it does not provide much of an incentive?

P.BD: Of course, using the price you can steer industries and customers to rationalise their use. An interesting idea about that is to make fluctuating water prices based on the availability. Meaning in dry periods we increase the price or give a certain amount of water that is enough to provide consumers for potable use and bathing. Then once a certain volume is used we increase the price just to prevent people from excessive use such as watering the garden or washing the car.

T.M: Do you use time-based tariffs now?

P.BD: Today the price of water is always the same. At the moment time-based tariffs are a thinking experiment: that the price of water could be steered as a function of the availability. Same thing for industry, the price could be increased during drier periods. They would be the first to invest in water reuse because it saves them money on the discharge, and meanwhile they save money on fresh drinking water intake. The more they recycle the better for them. So, it is just to encourage rational water use. This we can see with electricity and oil. The energy price is susceptible to fluctuations because of availability. For example, if there is a war somewhere then availability is threatened and the price goes up.

T.M: Today for the most part, water is treated to the same high drinking quality standards and if water utilities were to treat water and provide different levels of quality to customers. What kind of effect do you think this would have on the water utilities' business model in terms of needing to invest in the infrastructure to do this and how does it affect you're the revenue-generating ability?

P.BD: In the short-term it is definitely possible to provide lower quality water to industry. This is something I have seen in the Netherlands with a large company (Evedes) that has a big division for industrial water, they actually treat the water to a certain quality that is not drinking quality water, then they have a large transportation network to provide that B-quality to industry, further on they treat the B-quality water to A quality to make drinking quality water. So, it's definitely possible. It opens up opportunities and business models providing a lower quality water to industry. Another possibility going on in Flounders and our utility, is that we provide information, and equipment for rainwater reuse. It is obligatory now to separate rainwater from the other wastewater in Flounders. Separating is not enough, a buffer tank, pump and filter system need to be installed to flush toilets with filtered rainwater. Also washing machines, dishwashers or showers can use reused rainwater. Again, informing the public, i.e., giving advice, selling the filter and pumping systems are an opportunity for water utilities. Going a step further and installing a complete alternative network in the street connected to every house will cost too much money for utilities and society. That is one step too far. 
T.M: What do you mean by an "alternative network for the rainwater"?

P.D.B: For any lower grade water type of water that is not drinking water the inlet of the house has two incoming connections; one non-drinking water and one drinking. I think this is one step too far.

T.M: Does this go along the lines of source separation? Is source separation financially feasible for water utilities?

P.D.B: This refers to wastewater at the outlet. So, rainwater is the first source to be separated that has a clear market and is already obligatory and then separating also has a market for utilities separating blackwater from grey water. But of course, it has to be treated. The centralised large-scale wastewater treatments of Flounders are the responsibility of Aquafin, that is one major utility funded by the governments to treat and operate all the large-scale wastewater treatment plants. But if you separately collect it and treat it decentrally on the household or district level, then that is not the responsibility of that one major utility, Aquafin, but there are possibilities for other companies to operate the decentralised treatments and other companies includes private partners and also water utilities so again this is an opportunity to build and operate a decentralised water treatment plant.

T.M: Are decentralised systems financially feasible?

P.D.B: The models and simulations show you will never get very rich from it or earn a lot of money, but it is definitely our aim to show that decentralised wastewater treatment including resource recovery are economically feasible. So, we really want a positive balance at the end. We want a sound business model and we expect a return of investment between $8 \%$ and $12 \%$. So that means a payback time of 10 to 12 years. If you compare that to payback times in industry that is way too long. However, we want to demonstrate that it is feasible, and of course it is still a demonstration project so the more lessons we learn can be applied in the next demonstration. But for this first example we want it to be beneficial.

T.M: To explore alternative ways of charging for water; for example, as a function of the productivity (or economic output) it yields; where water consumed directly is most costly, grey and black water returned to the system would be less costly given that they would yield more productivity later in the cycle). I would need to compare which water has a relative higher revenue to cost ratio between grey and black water. Is there an obvious difference here between the two water types?

P.D.B: In practice in Flounders we charge per cubic meter for the wastewater discharged and the water consumed. You pay roughly $2.10 € / \mathrm{m} 3$ for drinking water and $2.40 € / \mathrm{m} 3$ for wastewater collection and treatment. That money goes to Aquafin. So, wastewater costs more than drinking water. This shows that drinking water is too cheap. I am not stating what should be billed to the customer, but in reality, blackwater costs much more money per cubic meter to treat than greywater if the revenues are taken into account for. This is because the greatest revenue is found in the greywater and the water itself can be reused. So, it is the largest volume and is less polluted. You can easily reuse that water and sell that water for example to an industry. So that brings in revenue. Plus, greywater has the highest excess heat, so the highest energy potential. When you take a shower, the water is at 35 degrees and it leaves your sink at 25 degrees. If the shower water is collected very close to the home, this can avoid energy costs by recovering heat by heat exchange creating a lot of revenues. That is not the case for blackwater, in fact when you treat it anaerobically you produce a bit of biogas, but you also have to heat that reactor to 37 degrees so basically the biogas you produce is sufficient to heat your own reactor. The situation today, is that blackwater has the highest potential for nutrient recovery. As already mentioned in the beginning, the state-of-the-art today is to recover nitrogen and phosphorus in the form of struvite but it has no real market value-about $€ 50 /$ tonne. Not enough to payback the installation. The challenge for research would be to recover more products with a higher added value then the return for blackwater treatment might be higher. Today the cost of black water per cubic meter is much higher than drinking water and greywater 
T.M: How can utilities continue to generate water if water efficiency is being encouraged?

P.BD: Customers can be provided with extra quality control of rainwater or reused water. There are many private companies on the market that sell devices to produce drinking water from rainwater. As there is no real quality control, this is a kind of service. Service providing is another business opportunity for water utilities because they already have a drinking water laboratory; they can extend the laboratory to services for quality control of reused water. This helps to increase the trust of the quality of reuse. Additionally, water utilities can provide service and technology to industrial companies to install water reuse equipment. Definitely in the food industry there is always a close relation to public acceptance. If a food producing company switches from drinking water to recycled wastewater to treat their food products which are sold to the market, their customers have to be convinced that their end product is still safe and still has the same quality although they use wastewater instead of drinking water. For these companies it is an advantage to say that they work together with a water utility for more acceptance.

T.M: Is there also an opportunity to share knowledge with industry on how best to manage their water?

P.DB: Definitely, we do it already for legionella control. A bacterial disease spread through water that is dangerous when the water droplets containing it are inhaled causing a respiratory infection. Drinking water utilities have a lot of experience in it, enabling them to provide a lot of assistance; for example, disinfection and information helping facilities to keep legionella out.

T.M: Regarding the typical cost structure of a water utility, where does most of the money earned go? I ask this to understand what happens if the business model were to become circular, and a large portion of the revenue now comes from services and less operational costs are incurred due to greater energy efficiency; where does the increase in revenue go?

P.DB: Definitely for our situation, it would go to the drinking water price because it does not cover our costs completely. In the past the business model was based on the revenue from the drinking water you sell. So, the more water that is reused, the less water is sold. And then you end up with a business model that collapses because you still have to invest and operate your large-scale network that is already there; and the longer that it is there the more costly it is to maintain. So, if you sell less water, then you have less revenues to maintain a network that requires more maintenance and replacements. Hence why we have a situation where there is not an equilibrium because the drinking water prices are limited by the government and cannot be increased; you have more costs; and you sell less. Because of this you need to look for new opportunities and new sources of revenues that support the drinking water department, which then opens the market for new services; like rainwater treatment; grey and blackwater treatment; resource recovery; and water reuse for industry.

T.M: While on the aspect of investment and water not covering investment costs, what options are there for investment acquisition for water utilities?

P.BD: They are funded basically from water sales revenue, so not much support comes directly from government for drinking water. It is really difficult for a water utility because they have very large investments that depreciate for the next 30 or 50 years. Meaning you are stuck with that technology and infrastructure for the next 30 years. So large-scale utilities don't have the opportunity to rapidly change the network or directly invest and implement new technologies. So, large-scale infrastructure is a bit of a burden. Working on the decentralised level gives much more opportunity to shift more rapidly to the new technologies to implement new technology because the scale of investment is not that big. You can easily adapt to the newest developments and technology.

T.M: "Shifting to decentralize infrastructure" does this actually mean really moving away from centralized infrastructure or is it more of incorporating more decentralized infrastructure while still using centralized infrastructure? 
P.BD: Well that depends a bit on the situation per country. In Flounders where the housing, city and villages are densely packed but scattered between each other, you need a large transportation network to provide drinking water everywhere. If it is already there, you cannot make the complete shift to decentralised treatment. It is a good system for new developments, for new cities, districts where you have to install new piping anyway, but there will always be a combination with a centralised network. In places like Africa it is different, there is often no centralised infrastructure present yet. We can say we simply skip centralised and move to installing a decentralised system in every village. Again, because you are not stuck with large-scale investments for the next 30, 50, 100 years that is not there anyway. Probably it is more economically feasible to install decentralised treatments in every city instead of building a central treatment acting on the cities.

T.M: How does Farys manage water leakages? Is there new technology they are using?

P.BD: We are always investigating new technologies to detect leakages and to repair them. For detection we are using district metered areas (DMA). A concept on the district or village level where you use online flow meters and basically find an area where you exactly know how much water is going in and out. Based on the online data, the difference between outgoing and ingoing can be measured and also the difference in the consumption of households. Overtime if there is a significant difference between in and out, this indicates a leakage somewhere in that area. With automated online data analysis using statistics you can even define where the leakage is and how long it has been leaking for. Using flow meters as much as possible also to look at the efficiency of our network. Of course, we always lose some water, called non-revenue water, that is not only due to leakages but also because the fire brigade uses water that is not metered. For repair of the small pipes, they are simply replaced, however for the large piping we are constantly looking to new technologies of how to repair them. One technology is called a "Sock". We pull a plastic layer through a large pipe and force it in the inner wall.

T.M: What does the contractual relationship look like for water utility recovering energy, nutrients and minerals? Would that be outsourced to a third party? Or would that be done in-house?

P.BD: That can be done both ways, a third party can be hired or the operation can be done ourselves. So, we treat the water ourselves and are responsible for the water reuse, and for example we give the struvite fertiliser and the energy we give to a third party-an ESCO (energy service company).

T.M: Do you get the energy back to use for your own proposes at a cost?

P.BD: Yes, at a cost.

T.M: Who do you think water utilities need to collaborate with most intensely and why? P.BD: All stakeholders need to be collaborated with:

- The city government-it all starts with them to develop a new district. They have to include rational water use and sustainable water treatments as one of the criteria to the granted project.

- Project developers-to understand the need for water treatment and to implement it

- Technology providers - the technology has to be ready

- Operators-e.g., Farys to operate the treatment and also the energy service company

- Customers-for example in Ghent they are connected to the district heating system that better we use the district heating system the more revenue we make. Grey and blackwater needs to be separated. With blackwater we can treat kitchen waste so the better they separate their kitchen waste and avoid placing plastics in the waster the better the plant operates and the more revenue we can make.

T.M: Are you looking to integrate food waste with biosolids from sludge?

P.BD: Yes, we are.

T.M: Are you using smart water meters and what has your experience been with them?

P.BD: In a couple weeks we will be installing them. We are exploring smart water meters at the customer connection and household since last year. We are testing several. The Ghent case will be the first of example of actually installing it. We will install digital water 
meters in households and we will share the online date with the customers to inform them if there is a leak and provide daily consumption data for them compare their consumption with other households to create a kind of awareness about water consumption. They are installed but the residents of the new houses are not there yet. They will arrive in February next year. So, they are under investigation; in the development phase.

\section{Appendix C.2. Transcript of Dutch Utility Personnel}

T.M: What are the barriers to circular economy for water utilities?

M.J: What do you mean when you say water utilities? Because in the Netherlands wastewater treatment is a different organisation than drinking water companies.

T.M: I understand that you work at Delfland, a water authority?

M.J: It's a regional governmental water authority for the water systems and the wastewater treatment.

T.M: So, when I say water utility I mean from your perspective as wastewater treatment plant.

M.J: The barriers in the Netherlands are that legislation is behind to really provide circular economy; for example, to recover resources out of the wastewater is difficult because you are not allowed to do it.

T.M: Is the reason for this because waste is legally considered as waste and therefore you need to change the legal status of waste to be allowed to recover resources?

M.J: Yes, exactly.

Also, safety. In cities of the future, recovered water from wastewater treatment can be used for food production or maybe drinking water consumption, the safety may be a barrier. There are a lot of emerging substances as I think not all substances in water are always treated, the water is still polluted. And high costs and high risks make the transition to this circular economy difficult.

T.M: Does the Dutch government subsidise water?

M.J: As a governmental organisation, our revenue comes from citizens paying taxes for water treatment, safety and transport annually. Drinking water companies charge for water on a monthly basis as they are non-governmental, somewhat private, but are awarded projects from the government.

For wastewater treatment, no [this is not subsidised]. Sometimes a project in circular economy, for example here at my water authority, the government has done that for one project for an extra treatment step to reuse the water for swimming water purposes, but that is a special case.

T.M: If in the future wastewater companies want to fund more circular economic projects how do you think these would then be funded?

M.J: This depends. Here we have a water bank that gives loans to water authorities at a cheap rate.

T.M: What do you think about the price charged for water?

M.J: The prices we pay are widely accepted. It is really low. However, my water authority is higher, which may be problematic for some.

T.M: Is there a reason why you are charged more?

M.J: Due to the dense population of our region. We have made the largest wastewater treatment plant in Europe which was really expensive.

T.M: Who should pay for closing the loop?

M.J: In the end I think everyone needs to pay as this should be in the interest of everybody. We need circular economy because of climate change and resources. The citizens need to pay for this to secure enough water in the future.

T.M: In the Netherlands would this result in an increased tax?

M.J: Yes.

T.M: In some U.S. states power utilities charge different households according to their income distribution i.e., shifting costs on to households that can afford it. In your opinion, 
could transferring this to the water sector be a reasonable way to increase the cost recovery of water utilities?

M.J: I don't know a lot about power, but I think there are similarities with water, it is the same quality. If you look to wastewater, the quality we get is really important in the way of treatment. So, if you only look to the quantity or the costs, I think that is not really good because for circular economy it is important that we get a good input in our treatment plant.

For example, only wastewater from households. And maybe people who use medicines, they need to pay more. This is a little bit of an extreme view, but it's the same as those who discharge a lot of salt.

T.M: So, you mean charging based on the quality of the water discharged?

M.J: Yes. Also maybe using a label system similar to the energy label. This would motivate people to discharge good quality wastewater to facilitate circular economy.

For households it [the label system] would mostly be for awareness, but it would be really for industry because they are the biggest polluters, which I think is major risk for circular economy.

T.M: So, industry should be charged accordingly: if they pollute more they should pay more and by so doing encourage them to discharge better quality water or do something with the water before discharging it to improve the quality?

M.J: Yes, charging differently than how it is currently. So, this way heavy polluters pays more and others less. People become more motivated to do something. But in the end, they will pay less [because treatment will cost less]. Eventually everyone will pay less but the quality will be better and implementing circular economy becomes easier.

T.M: Are the annual taxes for water treatment you earn enough to cover the costs of operations and investments?

M.J: I am not sure because about the finances in my organisation, but I think that the we pay the majority of investment from taxes. I pay $€ 90$ per year for the treatment tax, this is not only for maintenance and operation but also my organisation is already thinking about how in 20 years we need another treatment plant or treatment step; so, they are already thinking about this process plan and factoring it into this $€ 90$. Sometimes there can be some unknown challenges, and that's when we ask for a loan from this water bank.

T.M: Do you think the price of water can affect people's behaviour and how they use water? Or is the price so low that doesn't really matter to them?

M.J: Now, it does not really matter.

T.M: To explore alternative ways of charging for water, for example based on the productivity it yields (whereby water consumed directly is most costly, grey and black water returned to the system would be less costly as it will yield more productivity later). The relative higher revenue to cost ratio between grey and black water would need to be compared. Is there an obvious difference here between the two water types with regard to revenue to cost ratio?

M.J: I think blackwater is more expensive due to the energy cost per treatment. Also, there is an energy cost to create biogas.

T.M: Given that infrastructure can last for 50 years, how then does water infrastructure need to be designed in order to facilitate circularity?

M.J: The design has to be such that is easy to make changes. For example, now wastewater and rainwater are discharged into the same pipe, but we want to separate rainwater from wastewater, but this can only be done when it is financially feasible. This means we have to wait for 50 years before upgrading the infrastructure.

T.M: Are there any current circular economic practices being carried out now at your plant?

M.J: Green gas production it is higher than natural gas [quality]. It is used as fuel for cars by putting back into the power network.

T.M: Are you aware of what they do with the effluent water separated from the sludge? 
M.J: At the moment, we treat the water and discharge it into the sea. The sludge goes to another company and there they try to make phosphate out of it and are doing research on how to make bioplastics out of it.

T.M: What does the contractual relationship like with this company?

M.J: We make the biogas first and we pay the company to treat what is left, our waste, to make phosphate. We are the first to do this.

T.M: Is the biogas given for free?

M.J: We have a contract with them, but as a governmental organisation, it is difficult to ask for money.

T.M: Is Delfland involved in any kind of decentralised water treatment?

M.J: We try to make centralised systems, but we have decentralised systems for example near a hospital. After the hospital there is a decentralised system that reuses everything and they discharge cleaner wastewater so not a lot of medicines are entering the environment.

T.M: So, do they discharge water that they reuse again themselves? Or do they clean up their own water before giving it to you?

M.J: They clean up the water before passing it on to us at the moment. It's not only wastewater but they also reuse their waste. It's a company called Pharmafilter ${ }^{\circledR}$.

T.M: Do you have any responsibility of monitoring this system?

M.J: No, Pharmafilter ${ }^{\circledR}$ does this.

T.M: Do you know of any forms of digitalization that is being used?

M.J: Together with the municipalities we have a digital program to measure and monitor the quantity of the water.

T.M: Are smart water meters being used in the Netherlands?

M.J: Yes, every household has their own smart water meter. So, I can look on my phone how much water I have used today.

T.M: Can they see their consumption patterns over the past months?

M.J: With power I can see my consumption anytime, but with water they inform us about it in half a year or in three months. If you use a lot then they tell you use too much you can try to do $\mathrm{x}, \mathrm{y}$ and $\mathrm{z}$ less.

T.M: Can you see other people's consumption data?

M.J: No, this is legally not allowed here due to privacy issues.

T.M: Is there a concern from water utilities that if consumers are becoming more water efficient that sales revenue will decrease? If so, how do you plan to deal with this?

M.J: I don't think so. I think the drinking water companies want that consumers become more efficient because they really need enough water to supply. Because they are non-governmental but still kind of, they are not for-profit companies their primary goal is not to earn money. I know that in England it is more, but here it is not.

T.M: If you are implementing more circular projects, does the business model need to change to become more circular?

M.J: Earnings from the biogas we produce makes the treatment of water cheaper. It really has the quality of natural gas, so its higher than biogas. The taxes are not really adjusted as a result, but it would be a few cents off the taxes paid. It is a good business case.

T.M: Who would you say are the most important partners utilities need to collaborate with most intensely for driving a circular water economy? And why?

M.J: Here in the Netherlands we have a network with municipalities and drinking water companies, where we see each other every week. But I think it would be good to meet with industry and agriculture more as they use a lot of water and discharge different water qualities.

T.M: Are microplastics an issue at all when treating water?

M.J: Microplastics are really difficult to measure, so we don't know which is really scary. And we don't know the exact impact on the environment despite research being done. But we are researching this topic. 
T.M: Are there any future plans for being more circular with regards to reusing the water you treat and not discharging it into the sea?

M.J: Now our effluent will be discharged for swimming water, so when it is really dry, we have more water available. We are thinking more about how to make farmers and industry become more circular themselves. And in our region we have a lot of greenhouses, so they need to become circular themselves.

\section{Appendix C.3. Transcript of HYDROUSA Project}

T.M: What is your view on water services charged to consumers? Is the value of water reflected in the consumer price for water services? If not, should the true value be reflected in any case? And if it should, how should water be charged in such a way that it more accurately reflects its value?

S.M: Water resources from lakes and rivers are free, but providing that water to society comes at a cost. The associated costs must be designed into the cost structure of the tariffs using a banded system ensuring that water is affordable for all, but at the same time disincentivizing irresponsible usage. This means that there is an affordable charge for basic water services; and then when end users exceed this basic level of water consumption the cost increases considerably; and when that band is exceeded the cost increases disproportionately in such a way as to encourage thoughtful water use.

T.M: In some U.S. states power utilities charge different households according to their income distribution i.e., shifting costs on to households that can afford it. In your opinion, could transferring this to the water sector be a viable way to increase the cost recovery of water utilities?

S.M: This is an unfair billing method that I do not think should be used, as charging for water based on income does not help to curb the consumption patterns of those who can afford it. All levels of society should be encouraged to use water responsibly. We should charge people based on water consumption and not on how much money they earn.

T.M: In the end, will the price of water account for the closed loops realised through circular economic practices such as resource recovery and technology deployment? If not, then who pays for closing the water loop?

S.M: This is effectively a socialised cost paid by the water utilities before being passed on to consumers. But today the price of water does not reflect the externalities associated with its extraction.

T.M: For a water utility to shift towards circularity requires diversification of investment and a reorientation of finances. So rather than investing more in infrastructure and water supply projects only, finances need to go towards other additional measures such as digitalizing the infrastructure, building and maintaining nature-based infrastructure, etc. How then is this financed by water utilities? Is it intended that the investment costs are to be covered by revenue generated from water services without the need for additional outside funding? Or is it reasonable for a portion or all to be financed externally? Is pre-financing an option?

S.M: Loans, subsidies on innovative technology investments offered by some regional authorities (e.g., Nordkanal membrane bioreactor to treat municipal wastewater was subsidized by the German Regional Authority) and self-financing from generated revenue are possible sources.

Demonstrating the successful bankability of projects such as Ostara nutrient recovery in Canada has the potential draw investor interest.

T.M: To access funds from institutions such as the EIB (EU Climate Bank) the projects must be bankable. Are the solutions undertaken in Hydrousa proving to be "bankable"?

S.M: Part of ours task in HYDROUSA project will be to demonstrate the bankability of the solutions we are developing. These solutions are low-cost, nature-based solutions such as constructed wetlands which require less operational costs than conventional activated sludge processes for the treatment of wastewater; we also employ low -cost nature-based solutions for the management of rainwater and stormwater. 
T.M: Hydrousa is focused on decentralised water systems. What is driving the need for decentralised systems and what benefits do they render?

S.M: Under the EU Directive 91/271/EEC, there is no requirement to develop a sewerage network for agglomerations with population less than 2000. The Directive mentions that the wastewater in such communities should receive adequate treatment. However, the level of treatment and the type of technologies to be used are not mentioned. HYDROUSA is focusing on providing solutions for these water scarce decentralized areas to adequately treat wastewater so that it can be reused for domestic and agricultural purposes and to recover energy and valuable resources (compost, nutrients).

In HYDROUSA we are developing local supply chains so that the recovered water, energy and materials and valorized at a local level and for the benefit of the local community. Whereas with centralized systems for example in Athens, Greece, the location where reclaimed water is produced is not the place where it is needed for use. So, in addition to finding a market that wants the products we also need to transport it there which increases the cost.

T.M: Are smart water meters being used in the Hydrousa project? If so, what has been your experience so far with them?

S.M: Digitalisation is an important aspect of circularity which is required to evaluate the water-energy-food nexus and the efficiency of the implemented circular solutions. However, some online meters (e.g., E Coli, $\mathrm{N} 2 \mathrm{O}$ probes) can be very expensive and may not be affordable for water utilities.

In HYDROUSA we are also making use of low-cost sensors to evaluate the water quality. These sensors measure $\mathrm{pH}$; conductivity to determine the salt content of water in case any seawater has seeped into the groundwater; temperature; etc. Additionally, we use energy meters to determine the energy efficiency of the systems.

T.M: Can you describe how the treatment of sludge for the recovery of, for example, energy, nutrients and minerals would be handled and what the contractual relationship would therefore look like with utilities? Would the relationship be set up as one of the following?

a. as an in-house revenue generating business activity

b. $\quad$ sludge sold to a third party (e.g., Billund BioRefinery in Denmark)

c. handling of sludge, treatment and recovery outsource to a third party that retains the sales revenue but also sells back/gives back some biogas produced for the wastewater treatment plant's energy needs

d. other

S.M: Any of these are possible. In many cases sewage sludge is seen as a burden by water utilities so if they can get someone else to handle it, they would be happy with that.

We need to clarify here that the basic sludge processing units are integrated in the wastewater treatment plants and are utilized by the plant operators. These processes include thickening, anaerobic digestion, dewatering and potentially other processes such as drying. However, once sludge is out of the WWTP it can be handed by a third party. Also, the materials recovered from sewage sludge (nutrients, compost, energy) can be valorized by third parties.

T.M: Who would you say are the most important partners utilities need to collaborate with most intensely? And why?

S.M: Within a circular economy where materials are recycled, it is important for the water utilities to establish good relationships with the the end users of the recovered products, or with the intermediates who are handling these issues. Water utilities need to know their needs particularly in terms of the quality of products to be provided. End users of products can be farmers, cement industries, chemical industries, construction industries etc.

T.M: From the expertise you have gained from Hydrousa and Smart plant what are the critical success factors for a fully circular water economy?

S.M: 1. Bankability, 2. Knowing the needs of the end consumers of the products recovered to ensure a market pull; 3 . legislation that enables circular practices. 
T.M: In Hydrousa how was engagement with the local community handled?

S.M: Multiple forms of engagement are done with the local community in the form of co-creation workshops where we asked them to provide feedback, based on which we develop our design; hackathon; summer camps; local seminars; demonstration events etc.

\section{Appendix C.4. Transcript of CEO of Water Utility Solutions Company}

T.M: What causes water utilities to require your services, or what pains are you relieving of theirs?

D.B: Most water utilities their main activity is water distribution. So, they have distribution piping, it goes down the streets. They have pipe connect to homes and businesses to the main distribution system. And when you look at their core activity, it's the distribution of water and then it's billing individual homeowners and businesses and collecting those bills.

The source of the water, usually if it's just surface water, it doesn't really require sophisticated purification before the water is put into the distribution system. But if they are in an arid climate, or they have to deal with polluted water sources the treatment gets more sophisticated and most utilities don't have that processing expertise. And that's where we come in.

So, when we supply water to the US Virgin Islands Water and Power Authority (WAPA). We take ocean water and purify it to drinking water standards. And then we fill the WAPA storage tanks so that they can take the water and put into their distribution system. We're basically a bulk water provider. We typically have one customer for a plant and so in the case of the US Virgin Islands we've got two main facilities one on St. Croix and one on St. Thomas; and we provide all the water that WAPA then takes and puts into their distribution networks. The main reason we're there is that WAPA doesn't have the expertise and skill set to reliably operate a seawater desalination plant.

T.M: Water utilities and industry make up your customer base, is there a difference in the service you offer

D.B: The same thing applies, so if you look at our plant in Peru our customer is the Misky Mile Mine, it's a phosphate mine, and here you've got a mining company whose expertise is basically digging holes in grounds; they're expertise is removing minerals from the earth. They need water in their manufacturing process. The mine is located in an arid environment. So, the only source of water to supply the mine is the ocean, but that water has to be desalinated before it can be used in the mining process and the mine themselves don't have the expertise. That's where we come in; we provide all of the water to the mine that they use in their mining process. Same thing is true in refineries and power plants; basically, the core activity of these companies is something other than water purification. So, they outsource their water to somebody like us who are considered the water treatment experts.

T.M: If I understand correctly, with water utilities, you are doing the specified task of treating the water. In your build-own-operate transfer [BOOT] arrangements are you ever stepping in as a water utility to take over other tasks or is it limited to the purification of the treatment of the water, are you having first-hand contact with consumers?

D.B: Right. But we do have a very small distribution activity in the Turks and Caicos, we have 200 homes we supply water to where we own the pipes in the road. But $98 \%$ of our business is being a bulk water provider and our job is limited solely to the purification of a water supply so that the water can become useful.

T.M: How do you price water, given that water is a commodity and is priced very low? How greatly does the price of water affect the services that you offer?

D.B: Effectively for us water is free, we put a pipe in the ocean, we don't have to pay anybody for that water, but our costs are our operating costs of our plant. There are two factors: how much capital does the plant require to be built? And what are the operating expenses of the plant as we purify the water? We have costs, but ironically the water itself 
doesn't cost us anything. The product water costs us, but it's all based on the operating expenses and the capital required.

T.M: By outsourcing you for water purification purposes, is there a price adjustment that is passed on to consumers as a result for your services?

D.B: We sell our water to WAPA; WAPA factors our costs into their rate base; they have to go to a regulator who sets the rate which they can charge the consumers in the US Virgin Islands. What we charge is relatively insignificant compared to the cost of operating and maintaining the distribution network. So as a an idea, if they were charging $\$ 2.50$ per cubic meter to their customers and their cost is $\$ 2$ per cubic meter the cost of operating the distribution system is probably $\$ 1.50$, so 75 to $80 \%$ of a utilities operating expenses are related to distributing the water not to purchasing the water that they then distribute

T.M: Are you also involved in the collection and treatment of wastewater?

D.B: Yes, we do that too. We collect sewage, extract water from the sewage, and purify that water so it can be reused. Right now, the reuse is typically used for irrigation, but in some places in the world direct potable reuse is practiced, $25 \%$ of Singapore's drinking water supply comes directly from their sewage plants.

T.M: Are you able with your technology to produce water for potable reuse?

D.B: Yes, we do it.

C.G: Is the sewage you have also seen as a nutrient resource?

D.B: We do get sludge from our sewage that farmers like. So, it is reused, but there are certain rules that you have to follow, but it is an interesting source of nutrients.

C.G: Do you sell the sludge or just give it away to the farmers?

D.B: Just give it away.

C.G: Are you not allowed to sell it?

D.B: That's correct, there are real complications with selling it, it is just easier to give it away.

C.G: Do you also burn it [sludge] or take phosphorus nitrogen or take anything additional?

D.B: No, it's too complicated

C.G: What do you do the sludge you don't give to the farmers?

D.B: Landfill

T.M: What proportion of water is discharged into the ocean?

D.B: Going back to desalination, you're taking ocean water and you're splitting it into two streams; one of which has almost no salt in it. So, ocean water is typically about 36,000 parts per million [ppm] of total dissolved solids. Drinking water standards are typically 500 parts per million total dissolved solids. So, we take 35,000 ppm and the product we produce has 300 parts per million. Which means the brine which is about $50 \%$ of that water supply has about 65,000 parts per million in it. We then take that brine and we put it back in the ocean.

Now, there have been a lot of studies that have shown that if your brine diffuser is properly designed you can have basically no environmental impact in the distribution of that brine back into the ocean because the flow rate of a desalination plant, even the big ones, is quite insignificant compared to the volume of water that's in the ocean. When the brine gets into the ocean, the salt diffuses and typically you see that within 10 feet of the diffuser you cannot measure the difference in the salt content of the ocean water, you have to be at significantly less than 10 feet to see a difference in the salinity.

Now, there have also been a lot of studies that have shown in fact that the movement of water attracts fish because they can stay in one place and the water going by them has nutrients. The fish are typically attracted to these diffusers and are not harmed. So we put the brine back in the ocean.

The product water that we provide eventually ends up back in the ocean, because if you look at the water cycle, water is not destroyed, water goes through a cycle; it's in the ocean that reaches the atmosphere; comes down as rain; people consume it; they flush your toilet; it goes back into a waste plant; that waste plant discharges it back into the ocean and 
its one big cycle. The number of water molecules in the world is the same now as it was a million years ago.

T.M: Is the brine ever at a higher temperature when it is discharged?

D.B: All desalination technologies used heat to evaporate the water and then they would condense it because the water steam that evaporated doesn't have minerals in it. And when the condense it you get pure water and so that was the technology that they started with a hundred years ago. Membrane technology doesn't change the temperature of the water and it's much more energy-efficient, it uses about a third of the energy that a thermal process uses.

T.M: What market share do you currently hold worldwide?

D.B: Worldwide desalination produces about $1 \%$ of the worlds water. In some countries like Saudi Arabia desalination produces 50\% of their water. So, it depends on the environment, if you have a water-stressed environment where there is not a lot of natural surface water or rain water; you are more likely to turn to desalination. It is still more expensive than just collecting rainwater. If you can collect rainwater, you're going to do that first. And then you will look to alternatives. Alternatives can include drilling a hole in the ground and looking for well water. There are places where there are big aquifers in the state of Texas. Most of Texas water comes from groundwater supplies. But when you get into places where there's no groundwater, and there's no surface water then you have to turn to desalination. Desalination water is two to the three times as expensive as surface water.

T.M: How do you think then what utilities can be able to still generate money given the strive to be more water efficient and water conscious?

D.B: Water efficiency and conservation are something that should be the first things you focus on in terms of trying to get more out of a water source. But in general, that's not going to get you there. That's not going to get you to a point that is a total solution.

There are two things that are going on for water utilities: one is that the population is growing, and more people means more water. But the second thing is that the per capita water consumption is growing as well. If you look at it worldwide, from 1950 to the year 2002 population more than doubled, that ended with an increase that was $140 \%$. During that same period from 1950 to 2000, water consumption per capita went up over 350\%. So, when the population is growing $150 \%$ water consumption is growing $350 \%$ because per capita consumption more than doubled. And why did per capita consumption more than double? One reason is that the standard of living improved; more people had access to showers and laundry. But also, the standard of living is continuing to go up. So, the car you drive used 250,000 gallons of water to be produced. If you're wearing a cotton shirt, it needed 1000 gallons of water to be produced. Your cell phone used 500 gallons of water. And so, as the standard of living increases and we have more stuff we use more water. So, the water utilities are always in this catch-up mode.

T.M: So, the effect of water efficiency would not be something significant enough to promote any kind of change to the water utilities?

D.B: It wouldn't be significant enough to be the only solution for the water utility. It has to look at increasing water efficiency, but they also have to look at expanding their water sources.

T.M: For sure, water efficiency is not the only thing, it is one option among others such as reuse.

D.B: Water reuse is huge deal. It is going to happen in my lifetime. The cost of extracting water from a sewage plant is half of the cost of desalting water and I can make that sewage water as pure as the ocean water, most water, Evian bottled water. I can make it to any standard, even ultra-pure water used in the manufacture of electronic chips. So, from a scientific perspective there is no reason I cannot make the water drinkable. It's a psychological issue. The Singaporeans have done a great job of marketing NEWater ${ }^{\circledR}$ with ads for decades because they don't think twice about it. That's one of the things that is going to really have a dramatic impact on our drinking water supply. 
C.G: So, at the moment the reason is only a psychological one?

D.B: Right, exactly.

C.G: So even if you were to treat it to the highest standard it would still be cheaper to use sewage water than ocean water?

D.B: Yes.

T.M: You said currently reuse is normally for agriculture, is that correct?

D.B: Agriculture or industry.

T.M: Is a set quality standard not required for reuse for particular end consumers?

D.B: Yes. In California they treat their sewage to drinking water standard but then they injected it into the ground where basically they are recharging their aquifer. And then they can pump the water out of the aquifer in a different location 5 or 10 miles away and now it's drinking water. Because somehow the ground did something to it. I mean in reality they don't need to pump it into the ground because its drinking water quality as it comes out of the sewage plant, but that's a way of dealing with this psychological thing of not wanting direct reuse. So that is something that is called indirect reuse. They are doing it in California and in other places, it's becoming more common. It's kind of like an interim step before they get to reuse because it doesn't make any sense if you pump the water into the ground here and you pump out of the ground over there that somehow its now drinkable.

T.M: Do you know cases where different qualities of water are supplied to households, for example, recycled water for the flushing of toilets and drinking water quality for drinking water?

D.B: Yes. A lot of modern construction have purple pipes which are grey water pipes. So, there are two water sources, one for drinking and the other for the rest. Grey water is a term that refers to purified water that has come out of a sewage plant. In New York City, there are apartment buildings classified as being environmentally clean although I can't remember the correct term - they have purple pipes. Their sewage goes into collection tank in the basement, the water gets purified, put into the purple pipes and reuse it for flushing toilets, irrigation and other non-potable uses.

T.M: Is it not expensive to retrofit buildings with these decentralised systems and dual networks?

D.B: It's a lot easier for new builds but I have seen some that have retrofitted also which is a much more expensive task. You see this plumbing in a lot of new buildings because the incremental cost of doing it when the building is new insignificant.

C.G: Is a second pipe required in the ground?

D.B: Yes. You need the pipes to collect all the wastewater from the showers, dishwashers, washing machines and the toilets. It goes into a storage tank, gets purified and then you need a separate distribution system for that grey water.

T.M: You mentioned growth in urbanisation and population: do you think there is any way that society's consumption patterns can be altered by utilities?

D.B: The biggest thing I think the utilities can do if they want to encourage conservation, is charge more. Make it more expensive.

Most countries subsidise the cost of water for the population. A lot of places they don't even charge them for the water. And if you look at most countries, the water utility is a government entity and their operating costs are subsidised by the government, so the population is paying a very inexpensive price for the water. We are facing a situation whereby a lot people believe wrongfully, I think, that water should be free. That ignores the fact that making the water consumable so that it is safe to consume and getting it to homes costs money. That water is not free. The problem with the tariffs is that is does not reflect the true cost, I am paying a third or quarter of what it truly costs to purify the water and get the water to me, so it's subsidised, which encourages people to be wasteful.

Charge more, the population won't be happy, it's something that is politically difficult to do, I think. 
T.M: Is Seven Seas Water in a position to meet the changing needs of water utilities with respect to circularity where wastewater treatment plants take on the new role of becoming production plants that recover energy and extract nutrients and minerals from water? If so, how?

D.B: We are looking into a few things. Producing biogas at our sewage plants. On the water treatment side, the one alternative that has been floated around for a long time but we just haven't figured out how to make it work is harvesting sea salt from the brine leftover after desalination. It is challenging to make it work economically as salt is such a cheap commodity and the surface area required for evaporation is huge.

C.G: About the salt what do you do currently with the salt?

D.B: The salt is discharged in the ocean as brine.

T.M: You mentioned working with power plants, correct?

D.B: Yes. We are working on a couple of projects to see how much revenue stream we can generate from producing biogas.

T.M: What water quality needs to be provided to thermal power plants?

D.B: Generally, a power plant requires far purer water than what you drink. Drinking water has 300 million ppm of total dissolved solids, a power plant typically requires 1 ppm of total dissolved solids or maybe less. The water that generates the steam has to be very pure, otherwise minerals deposit on the turbine blades and cause corrosion; so the steam they require has to be very pure.

\section{Appendix C.5. Transcript of Private Software Corporation Utilities Specialist}

T.M: Does circular economy form a part of your solution strategies and is it identified as new opportunities for water utilities?

M.C: Yes and yes, in different dimensions. By using intelligence with companies around the world, we try to understand what they are looking for, what are the challenges and based on that we try to bring them solutions. This [circular economy], is one of the subjects but not just in water. Circular economy deals with the entire value chain and thus goes beyond water utilities such as manufacturers, power generation companies that require steam a certain kind of water, or agricultural consumption that need another kind of water. So, this is holistic, and this logic needs to be included into our systems to model, otherwise we will be out of the market.

T.M: What do you see as the main barriers to circular economy on the systemic level?

M.C: The absence of a global solution that creates the necessary effect needed for other countries to act. A good example of this is all the discussions going on around the CO2 subject with the Kyoto agreement This shows how solutions can be provided and accepted on the global level. Such solutions included a business case which could help to manage an economy on that path as a concept. Also, it was an incentive for companies like ours for new technology and innovation approach.

The second lesson is that there is a big gap in the lack of commitment due to tactics from countries and lobbies. They block such things for tactical interests; such as the US' retreat from this [CO2 subject] which is disincentivizing. So, it needs to be global and has to deal with this trend from big countries.

T.M: What do you see as the main barriers to circular economy for water utilities specifically?

M.C: Assuming that it is a global issue, the driver is scarcity of resources and we currently do not see a technically listed solution to be adopted. Circular economy is a concept, but we do not see what it translates into for companies to adopt that target and model and it be compatible. There are experiments, proof of concepts and activities going on in this direction because there is sensibility and consciousness but not yet a global agreement on several things to be done, a timeframe with revenue and penalty content enabling any organisation on the value chain to attach and declare their own road path.

This could be linked with the fact that water is a business in some countries and in others it has of course a financial channel which is fair. So, in order to break that business 
dynamic there should be a global question on the business model that lies behind the water value chain. There is privatisation, in some areas, pure privatisation like the UK which is in deep crisis because of that. Another toxic privatisation is the concession model, where some municipalities hand over the water management to a multinational company so they maximise the benefit out of it by giving a contract for 20 years. Over this time there is no real investment, it is just tactics because they try to get all maximum amount of benefits. The financial instrument that is used for developing water infrastructure, can be such that, in cities like Washington, they rely on and sometimes the agenda is not clear as to whether they try to help or try to politically influence.

T.M: What is your view on how consumers are charged for water services?

M.C: From the company perspective, there is not an opinion from SAP because we just provide the software for the needs of companies.

But my personal opinion is that it is a life thing. Putting a price on water consumption to a citizen is unfair as it is a basic service. I do not see the value or the benefit from that. As a definition, this is global service. In fact, if you look into the tax structure of a country it should be allocated as part of taxes to guarantee the basic services. Not to pay the payroll of the civil servants; it is about giving back the society some shared services. When a country has high taxes but also bills the water consumption, for me they are cheating society. If an interesting price is placed on water that then triggers greed and then lobbyists try to influence this and make a business out of it.

T.M: Do you think placing a price on water for companies can affect their consumption?

M.C: It is a basic need. It's a monopoly. People and companies need to consume water. Of course, there are countries that want to put a price for rationing consumption for example agriculture. That is an educational need not a tax.

T.M: So, water prices should not be seen as a leverage to alter consumption or be used as a way to send signals to the market for investment within the industry?

M.C: You have water and you make an investment for the water to be made fit for drinking purpose. Then there is another part which is what do you do with the outcome of that water? Human consumption being one and another being water that factories produce which requires reinvestment for recycling. Depending on the amount of consumption, a penalty for excessive use must be applied, which is ethical. There is a dimension of water use for a business purpose not for human consumption. Then that makes sense as it is complementary.

But when we talk about water price, we are always talking about the residential sector, which is the least relevant consumer. This should be applied to companies, factories, thermal power produces that need to produce steam. Then it is much more logical to share additional costs of water for those elements that are beyond the basic purpose of water, which is to help humans to exist.

T.M: Are infrastructural investment costs a huge barrier to utilities?

M.C: Infrastructure is the real money in water-in the form of CAPEX. You can discuss with the government or regulators for compensations for that. There is no real control on how those companies invest in infrastructure and who delivers it. In Spain, the largest or second largest water concession management water company that has more than 500 mini -water companies from 100 municipalities in Spain is a construction company. So, they award the wrong company to do the works on refurbishment. As a result, they can manage the bills and invoices then they receive compensation. This is what I mean as greed and making a business out of it

T.M: Can water utilities legally lobby for legislation and political incentives?

M.C: It depends on the political organisation of a territory. If a water company relies on a municipality, they belong to them in most countries. If in those countries there are structures where they cluster municipalities for example Belgium with the Flanders region and France, then automatically the water companies naturally can discuss with each other and find clustering solutions. With the converse, that is not the case. 
Water companies, as they are a public entity, have a tradition of helping develop research projects in the universities that are tied to municipalities. For those places where concessions exist there is zero research regardless of the size of the universities.

T.M: How do you think an open sludge market, similar to what they have in the UK, would affect continental European water utilities?

M.C: I am not sure. I do not have enough information to see that this would expand to other countries.

T.M: What are the digital trends that you see being adopted by water utilities currently?

M.C: The readiness level of adopting IT technologies depends on the maturity of IT adoption in the local context. So, it is not the same to talk about systems and solutions in western Europe and in South Africa.

But with concessions, they just want to collect money, they want low total cost ownership of applications, they want efficiency but are not forward looking, no quality and no customer engagement. So, whether there is a concession in place or not or affects the willingness to adopt new technology.

Small municipalities try to look at in-house applications which is very challenging given that they require resources to maintain them and thus cannot grow and bring in new technologies.

T.M: How prevalent are digital water meters and do they have the ability to create awareness among consumers of their consumption?

M.C: They have been available on the market for the last 10-15 years. Water utilities have been struggling firstly with the business case and the internal readiness for the handling of big data. When these are dealt with, then they can use this for awareness and to detect leakages.

The business case is a huge barrier that is not yet accomplished in many countries. For example, now there are countries thinking on an aggregated level to level out the costs, because they see the benefits, but the costs are too high. These companies [water utilities] are by definition are low income organisations.

Secondly, when investing in smart meters, an infrastructure needs to be set up to collect all this data which needs to be analysed and connectivity to building systems is required to build the consumption. This means a lot of IT readiness which increases the size of the bill. It is not only the cost of the meters, but the back office too. Hence the reason why the deployment of smart meters is very challenging. All the benefits are known [such as creating awareness] but not many of them help the business case.

T.M: Are infrastructure investments for circular economy justifiable given the potential revenue stream they could generate?

M.C: The learnings from electricity and gas companies but especially electricity distribution companies are parallel to water companies with respect to the business model when it comes to infrastructure investment. For example, smart grids: when a privatised electricity distribution company wants to invest in the grid, they inform the regulator of their plans for investment they want to make for a smart grid which they need to be compensated for as this is capital investment that they need funding for. The regulator agrees to providing a portion of the investment needed or they can do co-funding (increasing the rate to get this funding). This is how this part of an electricity distribution companies has become the most profitable; more than energy retail; and more than energy production because of this compensating of CAPEX. This is the same for water with an additional element; most have an engineering and construction department, so they can even play with the rates.

T.M: If a water utility is to promote water efficiency, how does it continue to generate revenue?

M.C: As mentioned before, CAPEX gives more revenue than consumption, so consumption is not the only source of revenue they have. They also have construction compensation, water treatment and by-products they produce, etc. My principle is that I think it is a wrong approach to rely on the price of water while it is already paid for by taxes. 
So, focusing on the price is effectively doubling the price: once through taxes and again through the water bill. I think a focus should be on those elements of the value chain that create benefits out of water, then it becomes about the outcome of that water for example. But for citizens there should not be a price.

T.M: Who would you say are the most important partners utilities need to collaborate with most intensely? And why?

M.C: On a global level, this depends on the scope of the water company because they have different territories. For example, Barcelona city has no agriculture, but just consumption and factories. But other territories may face land usage, so there is not really a pattern, there should be different scenarios. I think that the winning formula for a water company wanting to develop this strategy is that it should be linked with local universities or research institutes because they know better and can provide assistance. Water companies have limited resources and they are focused on providing a service. I have seen this in several countries but unfortunately not in Spain because it is privatised by terrible concessions. This is a terrible loss of knowledge and opportunities.

\section{Appendix D.}

Appendix D.1. Digitalization

Case 1: Smart Cities-Greenergy in Fredrikstad, Norway

Innovative solutions for water, sanitation, stormwater and energy

Modern cities must optimize wellbeing, and that includes minimizing environmental impact. GREENENERGY will reduce water consumption by using water-saving fixtures as vacuum toilets, facilitate the recycling of nutrients to urban and peri-urban agriculture and thus, almost eliminate pollution of surface water.

Biogas production from toilet waste (blackwater) and organic household waste (OHW) is a key treatment technology. $\mathrm{CO}_{2}$, heat and power from biogas combustion are utilized together with the nutrient-rich retentive in a super-insulated greenhouse for local resource reuse and year around plant production.

Advanced wastewater management in Norway and China

In the Fredrikstad Showcase, the wastewater is source-separated into two fractionstoilet waste (blackwater) and graywater. A vacuum system is used for the collection of blackwater and ground organic household waste, followed by a biogas reactor (heat from the reactor will be used for heating a greenhouse during the winter season and effluent from the reactor will be converted to solid and liquid fertilizer). The graywater will be treated locally to good bathing water quality when it comes to indicator organisms.

Greenergy will:

- $\quad$ Reduce the water footprint up to $90 \%$;

- Introduce safe recycling of nutrients for urban food production;

- Provide a user-friendly control and communication platform.

Case 2: An efficient water utility using digital wastewater developed in Provas Network, Haderslev, Denmark

Appendix D.1.1. Accumulating Real Time Data from the Sewerage System

In May 2017, a collaboration between Provas (The Utility of Haderslev, Denmark) and the pump manufacturer Grundfos started. The purpose is to handle challenges related to infiltration water (groundwater entering sanitary sewers through defective pipe joints and broken pipes), overflows, the need for smarter alarms, and asset management and energy consumption in the wastewater system.

Casper Koch Nordow, operations manager at Provas, "If we are to serve our customers as well as we do now, in the future, then we must work more efficiently. We have many data, but we have not had it analyzed properly. The Grundfos system will do this for us via automated processes." 
The new system generates an up-to-date job list daily for a water utility operational manager in wastewater, turning service from a reactive approach to a proactive service strategy. The system will analyze the data to indicate what the technical problems are-for instance, if power consumption and pressure increase at the same time, it could mean constipation within the system and a risk of overflow.

\section{Appendix D.1.2. Improve Utility Management}

Grundfos iSolutions Cloud for Wastewater Networks (GiCWWN) turns sewer network data into actionable information for network operators, providing real-time visibility of hydraulic and mechanical conditions. At its foundation is an algorithmic flow estimation. The system can estimate flow without relying on flow meters.

\section{Appendix D.1.3. Smart Information and Instant Action}

GiCWWN data in a sewage network is translated into actionable insight for planners or operational managers to use as working instructions to save time in troubleshooting, in doing their own analysis or reducing the hours of alarms. The translation is done by algorithms based on Grundfos knowledge of hydraulic pumps and applications, which are the core of the system. Currently, water utilities pay consulting/service companies much money for audits to calculate infiltration and actual flow in pumping stations. GiCWWN provides this information on a continuous, real-time basis at lower costs.

Access to real-time utilization data based on pumping station capacity enables energy optimization. Accurate, proactive overflow alarms help reduce the number of site visits to check alarms and reduce the number of overflow events. Experience shows that predictive maintenance reduces the number of alarm visits by eight per year per pumping station (both in and out of working hours).

Case 3: Stationary Overflow Monitoring System (SOMS) saves operations and ensures the water environment in Skanderborg, Denmark

\section{Appendix D.1.4. Smarter Ways to Control Overflows}

Untreated wastewater discharged to recipients is likely to cause an imbalance in the ecosystem. This happens when the system overflows due to bursts or blockages, plant spills, stormwater overflow or the like. Especially with the increase in extreme rain, overflows are expected to become a recurring event, which is why there is a critical need for smart solutions for utilities.

Manual monitoring of overflows has disproven itself as being a cost-effective method; SOMS has shown to be an important tool. By increasing the effort to reduce wastewater overflow, the volume of untreated wastewater discharged to receiving waters can be reduced. In turn, this leads to an improved environment, including a healthier bacterial balance and a better quality of public recreational water.

The stationary overflow monitoring system will provide data to support decisionmaking focused on conducting a prioritized effort to reduce overflow. From a financial perspective, the solution facilitates more efficient and cost-effective asset management as well as enabling value-added investments. In terms of maintenance operations, it allows for the utility company to move from scheduled maintenance to predictive and preventative maintenance.

Appendix D.1.5. Smart Data Logging Improves Monitoring and Reporting of Data

The data logger D Log has built-in algorithms, which by a simple contactless level measurement on the grid, can calculate flow quantity, time recording, number of overflows, etc., all together in the same report. This solution costs about one-quarter of traditional flow measurement methods minimized, making the payback time very short; moreover, the large resources that Skanderborg Utility uses on manual inspection and flushing of grids after rain events are minimized.

Case 4: Lungegaarden Data Lake in Bergen, Norway 
Appendix D.1.6. Need for Smarter Data Use to Secure Water Quality in Norwegian Fjords

Bergen municipality has huge amounts of data stored in different IT-systems. The original data systems are normally isolated, and the exchange and use of data between the different systems and sectors are very limited. There is a need for storing this highresolution real-time data from the SCADA system and making these data available for both internal and even external use in some cases. The question for Bergen is how to share and utilize these data in a smart and secure way in order to provide good services to the customers and to safeguard good water quality in the fjord.

\section{Appendix D.1.7. A System to Store Real-Time Data}

Bergen municipality has established a data lake for storing real-time data for different municipal sectors, including the water sector. The data lake is named Lungegaarden. Every minute of data from 13,000 measuring points from the water and wastewater system in Bergen is collected and stored in the data lake. Each sensor or monitoring point contributes more than 500,000 data values each year. Within the framework of the data lake, the municipality develops their own apps and tools for visualizing and analyzing the data, but also external software companies are building their own cloud-based solutions on top of Lungegaarden data lake.

\section{Appendix D.1.8. Smart Data Storage Provides New Opportunities for Their Utilization}

The innovative part of the solution is the storing of the data in a cloud-based data lake, which opens up a window of opportunities for utilizing the data, e.g., related to identifying water leakages or early detection of pump failures. When storing, sharing and utilizing real-time data from critical infrastructure like wastewater systems, cybersecurity issues are a major concern. Linking real-time data from SCADA to water infrastructure assets and making the data available for the operators in the field will lead to better decisions and improved communications between operators and planners.

Case 5: Future City Flow (FCF), Sweden

Appendix D.1.9. Need to Upgrade Wastewater Systems to Improve the Environment

Aging water infrastructure, climate change with larger volumes and more intense rainfall and urbanization lead to increased stress on our wastewater systems. This leads to increased amounts of water in the sewer network causing combined sewer overflows (CSO's), flooding and increasing overflows of untreated wastewater to the environment. The effects that urban water has on receiving waters and their long-term biological and chemical status have presented wastewater utilities with the need to make significant investments to mitigate these problems.

Appendix D.1.10. Cloud-based Application for Economic Planning and Management

Future City Flow (FCF) is a cloud Azure-based application with modules for benchmarking evaluation of historical trends and actual state, automatic real-time monitoring data analyses with KPIs for trend analyses and follow-up. The built-in simulation capabilities within FCF allow continuous long-term simulations covering years within minutes. This is the backbone of the serious gaming environment that opens a new world for nonexpert modelers. The real-time control solution uses rainfall forecasting combined with a model-based approach to predict the nearby future rain and, using model-predicted controls, select and implement the most optimized operation at each time.

Appendix D.1.11. Improving Decision-Making and Prioritization among Different Options

Future City Flow provides the utility with a model-based driven application that optimizes the operation of the wastewater system in real time as well as supports identifying the most cost-efficient priorities of long-term investments to reduce the negative effects of infiltration inflow (water entering sanitary sewers from inappropriate connections, such as 
roof drains, cellar drains, and yard drains, etc.). We want to ensure that all urban water is handled sustainably by utilizing green infrastructure, optimizing the use of our existing infrastructure instead of creating floods or discharge untreated wastewater.

- $\quad$ Reduced discharge of untreated wastewater: Increased water quality in our waters, in which people can enjoy a swim, and our natural habitat will thrive;

- Reduced flooding: People do not need to worry when rain is expected, and insurance companies are reducing their reimbursements;

- Reduced wastewater treatment costs: Reduced use of chemicals and lower operating costs;

- Cost-efficient long-term planning of infiltration and inflow management reduces the investments and makes more efficient use of existing infrastructure.

\section{References}

1. Byers, E.A.; Coxon, G.; Freer, J.; Hall, J.W. Drought and climate change impacts on cooling water shortages and electricity prices in Great Britain. Nat. Commun. 2020, 11, 1-12. [CrossRef] [PubMed]

2. Shastri, H.; Paul, S.; Ghosh, S.; Karmakar, S. Impacts of urbanization on Indian summer monsoon rainfall extremes Hiteshri. J. Geophys. Res. Atmos. 2015, 120, 495-516. [CrossRef]

3. Vörösmarty, C.J; Sahagian, D. Anthropogenic disturbance of the terrestrial water cycle. Bioscience 2000, 50, 753-765. [CrossRef]

4. Marsh \& McLennan Companies and Zurich Insurance Group. The Global Risks Report 2019; World Economic Forum: Geneva, Switzerland, 2019; Available online: http:/ / wef.ch/risks2019 (accessed on 13 March 2019).

5. European Environment Agency. Close Up—Water in the City; European Environment Agency: København, Denmark, 2019; Available online: https:/ /www.eea.europa.eu/signals/signals-2018-content-list/articles/close-up-2014-water-in (accessed on 25 December 2019).

6. European Environment Agency. Use of Freshwater Resources in Europe; European Environment Agency: København, Denmark, 2019; Available online: https:/ / www.eea.europa.eu/data-and-maps/indicators/use-of-freshwater-resources-3/assessment-4 (accessed on 23 December 2019).

7. Pearce, D.; Turner, K.; Pearce, D.W.; Turner, R.K. Economics of Natural Resources and the Environment. Am. J. Agric. Econ. 1991, 73, 227-228. [CrossRef]

8. Stahel, W.R. The Product-Life Factor. In An Inquiry into the Nature of Sustainable Societies: The Role of the Private Sector (Series: 1982 Mitchell Prize Papers); NARC: Patan, Nepal, 1982; pp. 72-105. [CrossRef]

9. European Commission. Communication from the Commission-Towards a circular economy: A zero waste programme for Europe. Eur. Comm. 2014, 398, 1-14.

10. Tahir, S.; Steichen, T. Water and Circular Economy: White Paper. 2018. Available online: https://us.anteagroup.com/sites/ default/files/Water_and_circular_economy_Co.Project_White_paper.pdf (accessed on 4 March 2019).

11. Koszewska, M. Circular Economy-Challenges for the Textile and Clothing Industry. Autex Res. J. 2018, 18, 337-347. [CrossRef]

12. Dobrucka, R. Bioplastic packaging materials in circular economy. Logforum 2019, 15, 129-137. [CrossRef]

13. De Angelis, R.; Howard, M.; Miemczyk, J. Supply chain management and the circular economy: Towards the circular supply chain. Prod. Plan. Control 2018, 29, 425-437. [CrossRef]

14. Pagliaro, M.; Meneguzzo, F. Lithium battery reusing and recycling: A circular economy insight. Heliyon 2019, 5, e01866. [CrossRef] [PubMed]

15. Veolia. Water at the Heart of the Circular Economy. 2014. Available online: https://www.veolia.com/sites/g/files/dvc2 491/files/document/2014/12/economy-circular-water.pdf?fbclid=IwAR18db6PZiMw1GkfrlM7s3m7HpVPzk7JjC150A5 KVvlxOWAqdMXYeX2BFfA (accessed on 11 February 2021).

16. Meyer, B. Macroeconomic Modelling of Sustainable Development and the Links between the Economy and the Environment. 2012. Available online: http:/ /www.gws-os.com/discussionpapers/gws-researchreport12-1.pdf (accessed on 11 February 2021).

17. Stanchev, P.; Vasilaki, V.; Dosta, J.; Katsou, E. Measuring the Circular Economy of Water Sector in the Three-Fold Linkage of Water, Energy and Materials. 2017. Available online: https:/ / pdfs.semanticscholar.org/5824/dac5157d557328540dd109cc9bf3b39263fb. pdf (accessed on 28 September 2020).

18. D’Odorico, P.; Davis, K.; Rosa, L.; Carr, J.; Chiarelli, D.; Dell'Angelo, J.; Gephart, J.; MacDonald, G.K.; Seekell, D.A.; Suweis, S.; et al. The Global Food-Energy-Water Nexus Paolo. 2018. Rev. Geophys. 2018, 56, 456-531. [CrossRef]

19. Del Borghi, L.; Moreschi, L.; Gallo, M. Circular economy approach to reduce water-energy-food nexus. Curr. Opin. Environ. Sci. Heal. 2020, 13, 23-28. [CrossRef]

20. Smol, M.; Adam, C.; Preisner, M. Circular economy model framework in the European water and wastewater sector. J. Mater. Cycles Waste Manag. 2020, 22, 682-697. [CrossRef]

21. Smith, H.M.; Brouwer, P.J.; Frijins, J. Public responses to water reuse-Understanding the evidence. J. Environ. Manag. 2018, 207, 43-50. [CrossRef] [PubMed] 
22. Kakwani, N.S.; Kalbar, P.P. Review of Circular Economy in urban water sector: Challenges and opportunities in India. J. Environ. Manag. 2020, 271, 111010. [CrossRef] [PubMed]

23. Makropoulos, C.K.; Butler, D. Distributed water infrastructure for sustainable communities. Water Resour. Manag. 2010, 24, 2795-2816. [CrossRef]

24. Roest, K.; Smeets, P.; van den Brand, T.; Zwertvaegher, A.; Cortial, H.; van Odijk, S.; Klaversma, E. Applicability of decentralized versus centralized drinking water production and wastewater treatment in an office park as example of a sustainble circular economy in Amsterdam, The Netherlands. Procedia Environ. Sci. Eng. Manag. 2016, 3, 139-148.

25. Espíndola, J.A.G.; Cordova, F.; Flores, C.C. The importance of urban rainwater harvesting in circular economy: The case of Guadalajara city. Manag. Res. Rev. 2018, 41, 533-553. [CrossRef]

26. Stutchey, M. Rethinking the Water Cycle. 2015. Available online: https://www.mckinsey.com/business-functions/sustainability/ our-insights/rethinking-the-water-cycle (accessed on 21 August 2019).

27. United States Environmental Protection Agency. Green Infrastructure. 2019. Available online: https://www.epa.gov/greeninfrastructure (accessed on 4 January 2020).

28. Mauter, M.S.; Fiske, P. Desalination for a Circular Water Economy. Energy Environ. Sci. 2020, 13, 3180-3184. [CrossRef]

29. European Commission Directorate-General for Communications Networks Content and Technology Smart Cities and Sustainability Unit. Emerging Topics and Technology Roadmap for Information and Communication Technologies for Water Management. 2016. Available online: https:/ /www.ict4water.eu/wp-content/uploads/2015/10/ICT4WaterRoadmap2016_final.pdf (accessed on 7 January 2020).

30. Anzaldi Varas, G.A.A. Digital Single Market for Water Services Action Plan; European Union: Brussels, Belgium, 2018. [CrossRef]

31. Daigger, G.T.; Voutchkov, N.; Sarni, W.; Lall, U. The Future of Water: A collection of essays on 'disruptive' technologies that may transform the water sector in the next 10 years. Nature 2019, 504, 657. [CrossRef]

32. Maxwell, S. Water Is Still Cheap: Dmeonstrating the True Value of Water. Am. Water Works Assoc. 2012, 104, 31-37. Available online: https:/ / www.jstor.org/stable/10.2307/jamewatworass.104.5.31 (accessed on 2 January 2020). [CrossRef]

33. The European Federation of National Associations of Water Services (EurEau). The Governance of Water Services in Europe. 2015. Available online: http:/ / www.eureau.org/resources/publications/150-report-on-the-governance-of-water-services-ineurope/ file (accessed on 21 August 2019).

34. European Parliament and European Council. Water Framework Directive 2000/60/EC: Establishing a Framework for Community Action in the Field of Water Policy; European Parliament and European Council: Brussels, Belgium, 2000.

35. European Environment Agency. Assessment of Cost Recovery through Water Pricing; EEA Technical Report; Environmental Economics; Amsterdam Global Change Institute: Amsterdam, The Netherlands, 2013. [CrossRef]

36. European Commission. Communication from the Commission to the European Parliament, the Council, the European Economic and Social Committee and the Committee of the Regions; Roadmap to a Resource Efficient Europe; European Environment Agency: København, Denmark, 2012.

37. Maaß, O.; Grundmann, P. Added-value from linking the value chains of wastewater treatment, crop production and bioenergy production: A case study on reusing wastewater and sludge in crop production in Braunschweig (Germany). Resour. Conserv. Recycl. 2016, 107, 195-211. [CrossRef]

38. Dobbs, R.; Pohl, H.; Lin, D.-Y.; Mischke, J.; Garemo, N.; Hexter, J.; Matzinger, S.; Palter, R.; Nanavatty, R. Infrastructure Productivity: How to Save \$1 Trillion a Year. 2013. Available online: http:/ / scholar.google.com/sch (accessed on 23 December 2019).

39. Abu-Ghunmi, D.; Abu-Ghunmi, L.; Kayal, B.; Bino, A. Circular economy and the opportunity cost of not 'closing the loop' of water industry: The case of Jordan. J. Clean. Prod. 2016, 131, 228-236. [CrossRef]

40. Binder, T.; Vox, A.; Belyazid, S.; Haraldsson, H.; Svensson, M. Developing System Dynamics Models from Causal Loop Diagrams. In Proceedings of the 22nd International Conference of the System Dynamic Society, Oxford, UK, 25-29 July 2004 ; pp. 1-21. Available online: https:/ / pdfs.semanticscholar.org (accessed on 30 December 2017).

41. Meadows, D.H. Thinking in Systems: A Primer; Earthscan: London, UK, 2008.

42. Purwanto, A.; Sušnik, J.; Suryadi, F.X.; De Fraiture, C. Using group model building to develop a causal loop mapping of the water-energy-food security nexus in Karawang Regency, Indonesia. J. Clean. Prod. 2019, 240, 118170. [CrossRef]

43. Voulvoulis, N. Water reuse from a circular economy perspective and potential risks from an unregulated approach. Curr. Opin. Environ. Sci. Health 2018, 2, 32-45. [CrossRef]

44. Lipińska, D. The Water-Wastewater-Sludge Sector and the Circular Economy. Comp. Econ. Res. 2018, 21, 121-137. [CrossRef]

45. Werner, B.; Collins, R. Towards Efficient Use of Water Resources in Europe; EEA: Copenhagen, Denmark, 2012. [CrossRef]

46. Babamiri, A.S.; Pishvaee, M.S.; Mirzamohammadi, S. The analysis of financially sustainable management strategies of urban water distribution network under increasing block tariff structure: A system dynamics approach. Sustain. Cities Soc. 2020, 60, 102193. [CrossRef]

47. McKinsey \& Company. The Circular Economy: Moving from Theory to Practice; McKinsey \& Company: New York, NY, USA, 2016.

48. Mhatre, P.; Panchal, R.; Singh, A.; Bibyan, S. A systematic literature review on the circular economy initiatives in the European Union. Sustain. Prod. Consum. 2021, 26, 187-202. [CrossRef]

49. Amec Foster Wheeler; IEEP; ACTeon; IMDEA; NTUA. EU-Level Instruments on Water Reuse: Final Report to Support the Commission's Impact Assessment; European Union: Luxemburgo, 2016. [CrossRef] 
50. Shaddel, S.; Bakhtiary-Davijany, H.; Kabbe, C.; Dadgar, F.; Østerhus, S.W. Sustainable sewage sludge management: From current practices to emerging nutrient recovery technologies. Sustainability 2019, 11, 3435. [CrossRef]

51. Ellen MacArthur Foundation. Towards the Circular Economy: Opportunities for the Consumer Goods Sector; Ellen MacArthur Foundation: Cowes, UK, 2013. [CrossRef] 